\title{
Tissue and Intra-Brain Distribution of Perfluoroalkyl Carboxylates and Sulfonates, and Select Precursors, in East Greenland \\ Polar Bears (Ursus maritimus)
}

\author{
by \\ Alana K. Greaves \\ A thesis submitted to the \\ Faculty of Graduate and Postdoctoral Affairs \\ in partial fulfillment of the requirements \\ for the degree of \\ Master in Chemistry with Specialization in \\ Chemical and Environmental Toxicology \\ Carleton University \\ Ottawa, Ontario
}

(C) 2012

Alana K. Greaves 
Library and Archives

Canada

Published Heritage

Branch

395 Wellington Street

Ottawa ON K1A ON4

Canada
Bibliothèque et

Archives Canada

Direction du

Patrimoine de l'édition

395 , rue Wellington

Ottawa ON K1A ON4

Canada
Your file Votre référence

ISBN: 978-0-494-91546-2

Our file Notre référence

ISBN: $978-0-494-91546-2$
NOTICE:

The author has granted a nonexclusive license allowing Library and Archives Canada to reproduce, publish, archive, preserve, conserve, communicate to the public by telecommunication or on the Internet, loan, distrbute and sell theses worldwide, for commercial or noncommercial purposes, in microform, paper, electronic and/or any other formats.

The author retains copyright ownership and moral rights in this thesis. Neither the thesis nor substantial extracts from it may be printed or otherwise reproduced without the author's permission.
AVIS:

L'auteur a accordé une licence non exclusive permettant à la Bibliothèque et Archives Canada de reproduire, publier, archiver, sauvegarder, conserver, transmettre au public par télécommunication ou par l'Internet, prêter, distribuer et vendre des thèses partout dans le monde, à des fins commerciales ou autres, sur support microforme, papier, électronique et/ou autres formats.

L'auteur conserve la propriété du droit d'auteur et des droits moraux qui protege cette thèse. $\mathrm{Ni}$ la thèse ni des extraits substantiels de celle-ci ne doivent être imprimés ou autrement reproduits sans son autorisation.
In compliance with the Canadian Privacy Act some supporting forms may have been removed from this thesis.

While these forms may be included in the document page count, their removal does not represent any loss of content from the thesis.
Conformément à la loi canadienne sur la protection de la vie privée, quelques formulaires secondaires ont été enlevés de cette thèse.

Bien que ces formulaires aient inclus dans la pagination, il n'y aura aucun contenu manquant. 


\section{ABSTRACT}

The distribution of perfluoroalkyl acids (PFAAs) and select precursors were examined in East Greenland polar bear brain tissue (8 different regions), as well as liver, blood, adipose, and muscle. The liver contained by far the highest PFAA concentrations, followed by blood $>$ brain $>$ adipose $\approx$ muscle. A clear trend was seen for the distribution of perfluoroalkyl carboxylates (PFCAs), such that the liver and blood contained proportionally more shorter-chain PFCAs, whereas the brain and adipose contained proportionally more longer-chain PFCAs. The distribution of PFCAs among brain regions was correlated with the extractable lipid content, such that brain regions with higher lipid content contained statistically higher levels of PFCAs. Intra-brain variations could be seen on a wet-weight basis, although all variations became statistically insignificant ( $\mathrm{p} \leq 0.05$ ) on a lipid-weight basis. This lipid dependence had not previously been seen in other tissues, indicating perhaps an interaction between PFCAs and proteins found at the blood-brain barrier. Overall, it appears that PFAAs have tissue-specific pharmacokinetics. As a result, any PFAA-induced toxicity effects may also be tissuespecific. 


\section{LIST OF WORKS ASSOCIATED WITH THESIS}

\section{Refereed Journal Publications}

A.K. Greaves, R.J. Letcher, C. Sonne, R. Dietz. 2012. Brain Region Distribution and Patterns of Bioaccumulative Perfluoroalkyl Carboxylates and Sulfonates in East Greenland Polar Bears (Ursus maritimus). Environ. Toxicol. Chem. Submitted (Chapter 3).

A.K. Greaves, R.J. Letcher, C. Sonne, R. Dietz, E. Born. 2012. Tissue Distribution and Tissue Burden Estimates of Perfluoroalkyl Acids in East Greenland Polar Bears. In preparation (Chapter 4).

A.K. Greaves, R.J. Letcher, C. Sonne, R. Dietz. 2012. Linear and Branched Perfluorooctane Sulfonate Isomer Patterns in Multiple Tissues of East Greenland Polar Bears. In preparation.

\section{Conference Abstracts}

A.K. Greaves, R.J. Letcher, C. Sonne, R. Dietz. 2011. Brain Region Distribution and Patterns of Bioaccumulative Perfluoroalkyl Acids (PFAAs) in Highly Exposed East Greenland Polar Bears. Ottawa-Carleton Chemistry Institute, OCCI Day, May. University of Ottawa, Ottawa, Ontario, Canada. (Poster)

A.K. Greaves, R.J. Letcher, C. Sonne, R. Dietz, E. Born. 2011. Brain Region and Tissue Distribution of Bioaccumulative Perfluoroalkyl Acids (PFAAs) in Highly Exposed East Greenland Polar Bears. Society of Environmental Toxicology and Chemistry (SETAC)North America, November 13-18. Boston, Massachusetts, USA. (Poster)

A.K. Greaves, R.J. Letcher, C. Sonne, R. Dietz, E. Born. 2012. Perfluoroalkyl Acid Tissue Distribution and Perfluorooctane Sulfonate Isomer Patterns in East Greenland Polar Bears (Ursus maritimus). International Polar Year (IPY), April 22-27. Montreal, Quebec, Canada. (Oral)

A.K. Greaves, R.J. Letcher, C. Sonne, R. Dietz, E. Born. 2012. Tissue and Intra-Brain Distribution of Perfluoroalkyl Carboxylates and Sulfonates, and Select Precursors, in East Greenland Polar Bears (Ursus maritimus). National Wildlife Research Centre Seminar Series, May $9^{\text {th }}$. Ottawa, Ontario, Canada. (Oral) 


\section{ACKNOWLEDGEMENTS}

First and foremost, I would like to thank my thesis supervisor, Dr. Robert J. Letcher, for his constant support and encouragement throughout this project. I could not have asked for a better supervisor. His enthusiasm for his work is infectious and truly made this experience enjoyable. I cannot thank him enough for not only providing me with the framework necessary to complete this project, but also for allowing me to set my own goals and deadlines. His help was absolutely invaluable during this process, and I truly appreciate all of his time and effort he has given me.

I would like to thank everyone who participated in the sampling and processing of samples for this study. In particular, I would like to thank Erik Born from the Greenland Institute of Natural Resources, who coordinated the polar bear sampling, as well as Jonas Brønlund, Maja Kirkegaard, Sigga Joensen, and Lene Brun from the National Environmental Research Institute at Aarhus University for their assistance. Pall Leifsson and Niladri Basu participated in part of the brain dissection and provided invaluable support. I would also like to thank Christian Sonne and Rune Dietz at the National Environmental Research Institute at Aarhus University for not only processing and shipping the polar bear samples, but also for their guidance, discussions, and suggestions for all of the conference abstracts and journal articles associated with this thesis. I also thank Shaogang Chu from the National Wildife Research Centre at Carleton University for initially analyzing the brain samples for PFCs, and providing invaluable assistance with the SOPs relating to this thesis. 
My time with the Organic Contaminants Research Laboratory has been truly memorable because of the wonderful people I worked with every day. Thank you to all past and present members, including Shaogang, Eric, Lewis, Da, David, Hattan, Wouter, and Luke for their support (and providing such a light-hearted environment)!

I would also like to thank my parents, Tammy and Rob for their guidance, reassurance, and encouragement, as well as Brian, Kaylie, David G., and Lauren, for their positive attitudes and support. Last but not least, thank you David, for your invaluable help and motivation, without which I would not be where I am today.

Funding for this project was provided by a NSERC Discovery Grant, the Chemicals Management Plan (Environment Canada), the Molson Foundation, and the Northern Contaminants Program (INAC) (to Robert Letcher). Supplemental costs for polar bear sampling were funded via the IPY Program "Bear Health", provided by KVUG, DANCEA and the Prince Albert Foundation. 


\section{TABLE OF CONTENTS}

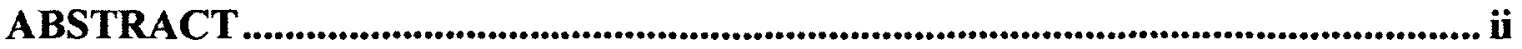

LIST OF WORKS ASSOCIATED WITH THESIS................................................... iii

ACKNOWLEDGEMENTS ................................................................................................ iv

LIST OF TABLES ............................................................................................ ix

LIST OF FIGURES ................................................................................................ xi

LIST OF ABBREVIATIONS ............................................................................ xiii

LIST OF APPENDICES ...................................................................................... $\mathrm{xv}$

\section{Chapter 1}

General Introduction ..........................................................................

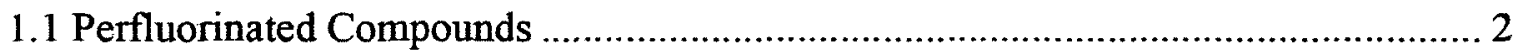

1.1.1 Structure and Properties of PFCs..................................................... 2

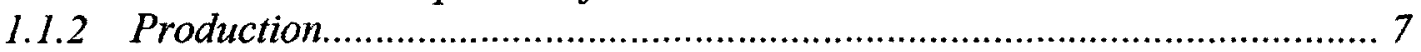

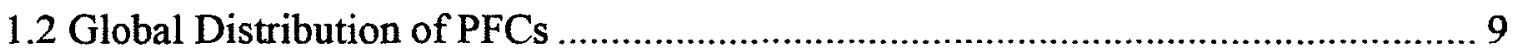

1.2.1 Distribution of Persistent PFCs in the Environment ................................ 9

1.2.2 Distribution of PFCs in Biota ............................................................ 11

1.2.2.1 Wildlife Tissue Distributions.................................................... 14

1.2.2.2 Lipid-Driven vs. Protein-Driven PFC Accumulation in Biota ..... 18

1.2.2.3 Isomer Patterns............................................................... 18

1.3 Toxicity of PFCs

1.4 East Greenland Polar Bears .......................................................................... 22

1.4.1 Physiology of the Brain ..................................................................... 22

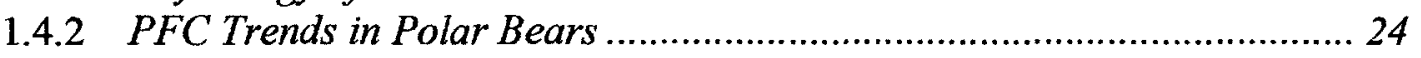

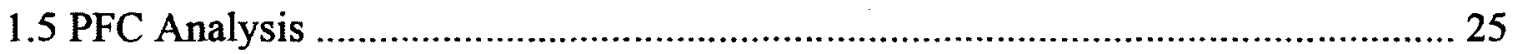

1.5.1 Liquid Chromatography-Mass Spectrometry ........................................ 25

1.5.1.1 Electrospray Ionization...........................................................26

1.5.1.2 Atmospheric Pressure Photoionization......................................... 26

1.5.1.3 Triple-Quadrupole Mass Spectrometry …………....................... 27

1.5.1.4 Quadrupole Time of Flight Mass Spectrometry............................ 28

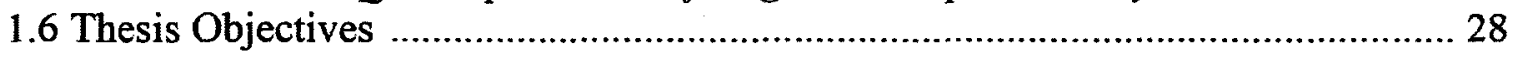

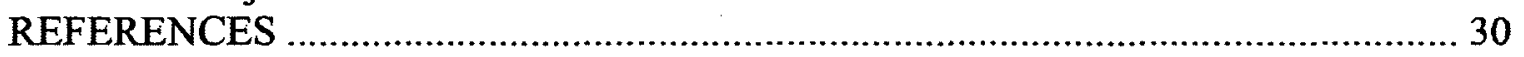

\section{Chapter 2}

Materials and Methods...................................................................41

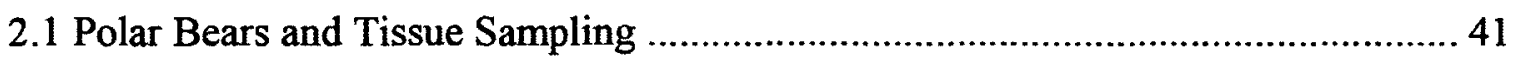

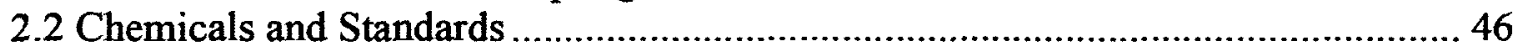

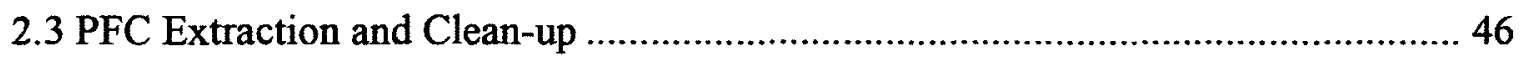

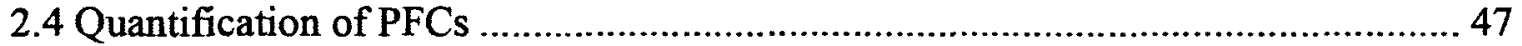

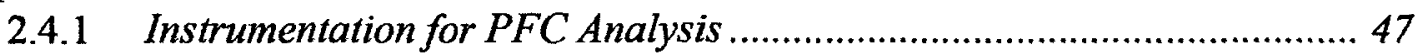

2.4.2 Monitored Ion Transitions .......................................................................... 49

2.4.3 Internal Standards and Percent Recoveries .......................................... 52

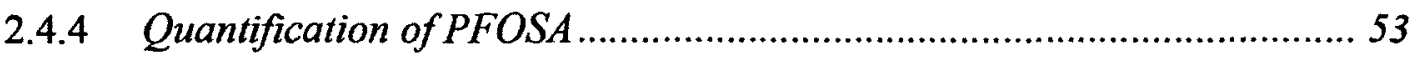

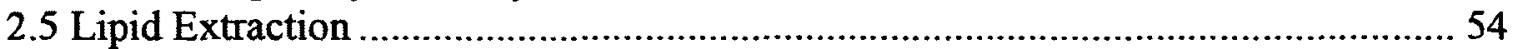




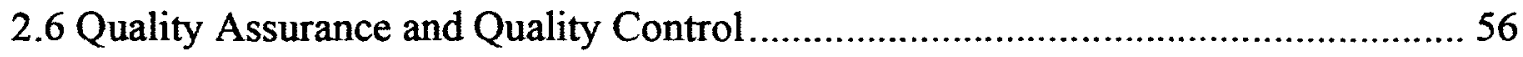

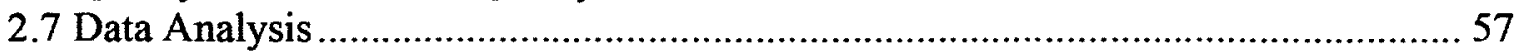

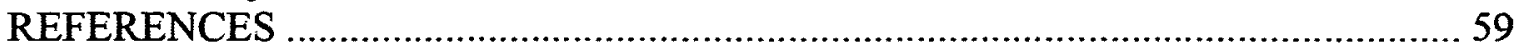

\section{Chapter 3}

Brain Region Distribution and Patterns of Bioaccumulative Perfluoroalkyl Carboxylates and Sulfonates in East Greenland

Polar Bears ...............................................................................................62

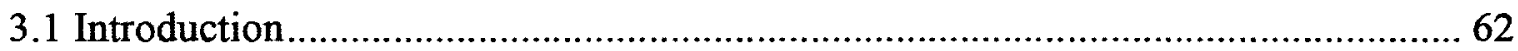

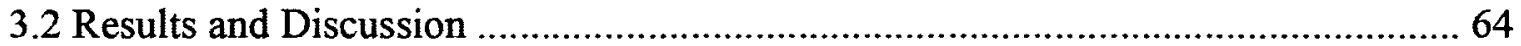

3.2.1 Relationships between PFAA Concentrations and Extractable

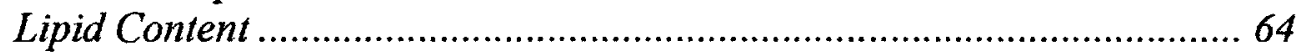

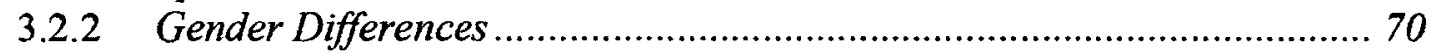

3.2.3 Age Correlations ............................................................................... 71

3.2.4 Relationship between PFOS and PFOSA Concentrations...................... 73

3.2.5 PFCA and PFSA Patterns and Concentrations among Brain Regions ... 76

3.2.6 Estimate of Measured PFC Burden in the Entire Brain .......................... 80

3.2.7 Comparison of PFCAs and PFSAs in the Brains of Other Studied

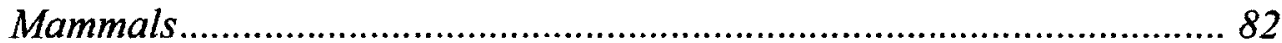

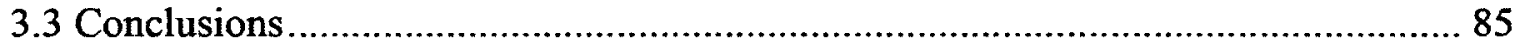

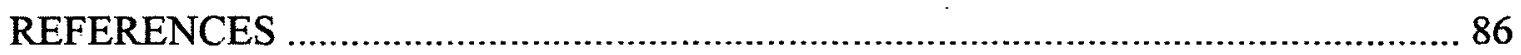

\section{Chapter 4}

Tissue Distribution and Tissue Burden Estimates of Perfluoroalkyl Acids in East Greenland Polar Bears...................................................90

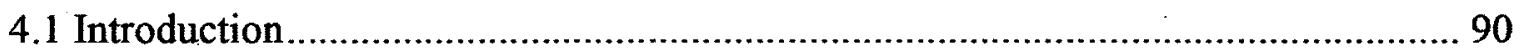

4.2 Results and Discussion ................................................................................. 92

4.2.1 Relationships between PFAA Concentrations and Extractable Lipid Content ........................................................................................ 95

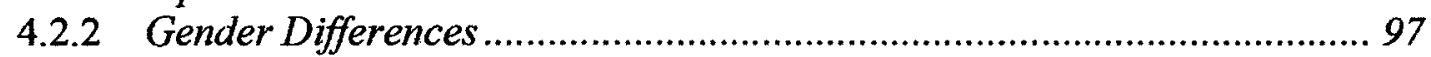

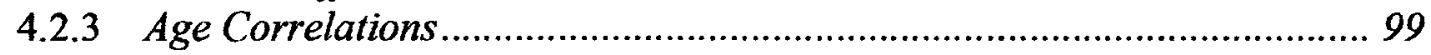

4.2.4 Distribution of PFCAs ................................................................. 102

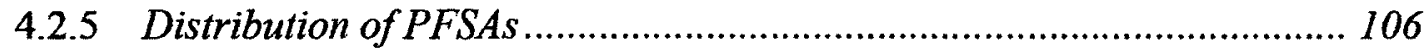

4.2.6 Distribution of Precursor Compounds................................................ 108

4.2.7 Relationship between PFOS and PFOSA Concentrations..................... 109

4.2.8 Correlations between Tissues ............................................................. 111

4.2.9 Estimated PFC Tissue Burdens ................................................ 114

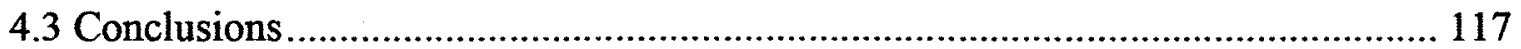

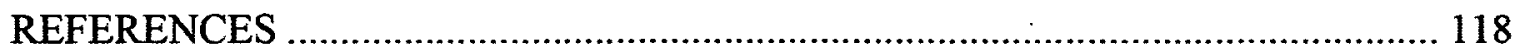

\section{Chapter 5}

Conclusions and Future Directions................................................123 


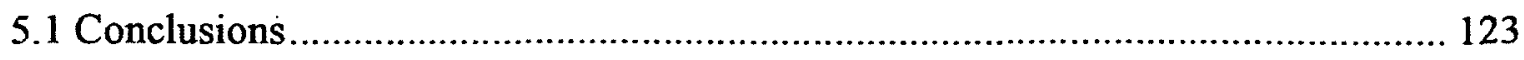

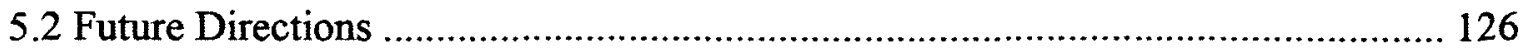




\section{LIST OF TABLES}

Table 1.1 Summary of previous mammalian and avian tissue distribution studies. Concentrations provided are in $\mathrm{ng} / \mathrm{g}$ ww ( $\pm \mathrm{SE}$, when available). For a complete list of compound abbreviations, please refer to Table 2.3.

Table 2.1 Complete sampling list of all polar bear tissues collected from Scoresby Sound, Greenland, from January to March 2006.

Table 2.2 List of monitored ion transitions and retention times for all compounds analyzed by HPLC-APPI(-)-MS/MS.

Table 2.3 List of monitored ion transitions and retention times for all compounds analyzed by HPLC-ESI(-)-MS/MS.

Table 2.4 Percent Recoveries $(\% \pm \mathrm{SE})$ for all internal standards of detected compounds.

Table 3.1 Arithmetic mean lipid contents and concentrations (ng/g wet weight \pm SE), including concentration ranges, of all detected perfluorinated compounds in brain regions of 19 East Greenland polar bears collected in 2006.

Table 3.2 Range of concentrations ( $\mathrm{ng} / \mathrm{g} \mathrm{ww}$ ) for all non-detected perfluorinated compounds. Compounds were considered not detected if less than $50 \%$ of samples were above the limit of detection (LOD). 66

Table 3.3 Correlations of lipid content (\%) and perfluoroalkyl acid concentrations (ng/g wet wt) for all brain samples tested $(n=115)$. $r$ - and $p$-values of all statistically significant correlations are shown. $\mathrm{p} \leq 0.05$ was considered to be statistically significant, and $\mathrm{r}>0.50$ was considered a strong correlation.

Table 3.4 Pearsons' product-moment correlation analyses between perfluorooctane sulfonate (PFOS) and perfluorooctane sulfonamide (PFOSA) (ng/g ww) for all brain regions and their respective PFOS:PFOSA ratios. $r-$ and $p$-values of all statistically significant correlations are shown.

Table 3.5 Arithmetic mean lipid contents and lipid-corrected concentrations (ng/g lipid \pm SE), including concentration ranges, of all detected perfluorinated compounds in all brain regions.

Table 3.6 Estimated PFC burden for the entire polar bear brain. Estimations are based on the polar bear brain masses recorded (Table 2.1), and using brain anatomy data as described by Kamiya and Pirlot (1988). 
Table 4.1 Arithmetic mean concentrations (ng/g wet weight, ww) and ranges for all detected compounds. All compounds reported were found above the method limit of quantification (MLOQ) in at least $50 \%$ of the samples for a given tissue. For compounds which were not detected (n.d.) in $\geq 50 \%$ of the samples, their ranges are given in Table

Table 4.2 Concentration ranges for all non-detected compounds. Compounds were considered not detected if more than $50 \%$ of samples for a given tissue were below the method limit of quantification (MLOQ). 94

Table 4.3 All Pearson's coefficients (r-values) and significance levels (p-values) for all significant correlations found between extractable lipid content and PFCA and PFSA concentrations. Correlations were considered strong when $r \geq 0.50$, and significant when $\mathrm{p} \leq 0.05$. 97

Table 4.4 Gender differences for applicable PFCA, PFSA and PFOSA accumulation in East Greenland polar bears. 98

Table 4.5 Arithmetic mean ratio ( \pm SE) between PFOS and PFOSA concentrations in East Greenland polar bears.

Table 4.6 PFC concentration correlations among tissues. All values shown are the Pearson correlation coefficients ( $\mathrm{r}$-values) for all statistically significant correlations ( $\mathrm{p} \leq$ 0.05 ). The symbol - denotes a non-statistically significant correlation. 113

Table 4.7 Total tissue burden ( $\mu \mathrm{g} \pm \mathrm{SE}$ ) estimates of perfluorinated compounds in the liver, blood, adipose, and brain of East Greenland polar bears. Average tissue masses were estimated based on Equations 1 - 4 (see Appendix 3 for a complete table of estimated masses). 116 


\section{LIST OF FIGURES}

Figure 1.1 Generic structures for poly/perfluorinated compounds.

Figure 1.2 Biotic and abiotic degradation pathways of PFAA precursor compounds. A) Degradation pathways for fluorotelomer alcohols (FTOHs) and unsaturated carboxylic acids (FTUCAs). B) Degradation pathway for perfluorooctane sulfonamides (PFOSA). . 5

Figure 2.1 Polar bear sampling site for this study: Scoresby Sound, Eastern Greenland. Figure modified from Piquet et al., 2010. 42

Figure 3.1 Lipid-PFAA correlations. (A) Correlation between extractable lipid content $(\%)$ and concentration (ng/g wet wt) of the sum of all perfluoroalkyl carboxylates $(\Sigma$ PFCAs) across the whole brain $(\mathrm{n}=115, \mathrm{r}=0.47)$. (B) Correlation between lipid content (\%) and concentration (ng/g wet wt) of perfluorotetradecanoic acid (PFTeA) for the frontal cortex, $(\mathrm{n}=16, \mathrm{r}=0.60)$; cerebellum $(\mathrm{n}=15, \mathrm{r}=0.61)$; pons/medulla $(\mathrm{n}=14, \mathrm{r}=$ $0.65)$ and temporal cortex, $(n=15, r=0.60)$. 68

Figure 3.2 (A) Perfluorooctane sulfonate (PFOS) and (B) perfluorotridecanoic acid (PFTriA) concentrations ( $\log _{10}$-transformed, lipid corrected) versus age (years) across all brain samples from East Greenland polar bears sampled in 2006. 72

Figure 3.3 Pearsons' product-moment correlation analysis between perfluorooctane sulfonate (PFOS) and perfluorooctane sulfonamide (PFOSA) across the entire brain. $r=$ 0.70 . Concentrations were $\log _{10}$-transformed, and not lipid corrected. The PFOS:PFOSA ratio across all brain samples was $25 \pm 1: 1$ 74

Figure 3.4 Concentrations of perfluoroalkyl carboxylates (PFCAs) throughout the eight brain regions of East Greenland polar bears, with (A) wet weight concentrations and (B) lipid-weight concentrations. Error bars represent standard error. Before lipid-correction, statistically significant differences can be seen between compartments, especially for perfluoroundecanoic acid (PFUA) and perfluorotridecanoic acid (PFTriA). These differences become statistically insignificant once corrected for lipid content in the tissues indicating PFCA brain distribution occurs in a lipid-related fashion. For a full list of abbreviations, please see Table 2.3 . 79

Figure 3.5 Recently reported mean brain PFOS concentrations among mammalian and avian species ( $\mathrm{ng} / \mathrm{g} \mathrm{ww}$ ). 83

Figure 4.1 Correlations between extractable lipid content and PFAA concentrations in both the brain (top), and liver (bottom). 96

Figure 4.2 Correlations between age and (A) $\Sigma$-PFCA concentrations (ng/g wet weight), and (B) $\Sigma$-PFSA concentrations (ng/g wet weight) in East Greenland polar bears. 101 
Figure 4.3 Arithmetic mean concentrations (ng/g ww) of $\Sigma$-PFCAs and $\Sigma$-PFSAs in the liver, blood, brain, muscle, and adipose tissue from 20 East Greenland polar bears. The vast majority of the $\Sigma$-PFSA concentrations are due to PFOS, accounting for between $87 \%$ (blood) and $99 \%$ (liver) of $\Sigma$-PFSA concentrations. 102

Figure 4.4 Percent compositions of $\Sigma$-PFCA concentrations from 20 East Greenland polar bears. 103

Figure 4.5 PFCA-normalized $\log K_{\text {ow }}$ values for all tissues analyzed. All $\log K_{\text {ow }}$ values were calculated from the percentage $\Sigma$-PFCA composition in each tissue, and individual $\log K_{\text {ow }}$ values obtained by Jing et al., (2009). An example normalized $\log K_{\text {ow }}$ calculation can be seen in Appendix 2 105 


\section{LIST OF ABBREVIATIONS}

6:2 FTOH
6:2 FTUCA
8:2 FTOH
8:2 FTUCA
10:2 FTOH
10:2 FTUCA
ANOVA
APCI
APPI
BBB
CHL
CYP2C\#
DCCO
DDT
ECF
ESI
FABP
FATP
FOSA
FTOH
FTUCA
HPLC-MS/MS
HPLC-Q-TOF
HSD
IS
$K_{\text {OA }}$
$K_{\text {OW }}$
$K_{\text {WA }}$
LC-MS
LOAEL
LOD
lw
MLOQ
MRM
N-Me-PFOSA
n-PFOA
n-PFOS
NIST
NOAA
NOAEL
NWRC
OCRL

$1 \mathrm{H}, 1 \mathrm{H}, 2 \mathrm{H}, 2 \mathrm{H}-$ perfluorooctanol

2H-Perfluoro-2-octenoic acid $1 \mathrm{H}, 1 \mathrm{H}, 2 \mathrm{H}, 2 \mathrm{H}$-perfluorodecanol

2H-Perfluoro-2-decenoic acid $1 \mathrm{H}, 1 \mathrm{H}, 2 \mathrm{H}, 2 \mathrm{H}$-perfluorododecanol 2H-Perfluoro-2-dodecenoic acid Analysis of variance Atmospheric pressure chemical ionization Atmospheric pressure photoionization Blood-brain barrier Chlordane Members of the cytochrome P450 family Double-crested cormorants Dichlorodiphenyltrichloroethane Electrochemical fluorination Electrospray ionization

Fatty acid binding proteins

Fatty acid transport proteins

Perfluorosulfonamide

Fluorotelomer alcohol

Fluorotelomer unsaturated carboxylic acid

High performance liquid chromatography-tandem mass spectrometry

High performance liquid chromatography-quadrupole time of flight mass spectrometry

Honestly significant difference

Internal standard

Octanol-air partition coefficient

Octanol-water partition coefficient

Water-air partition coefficient

Liquid chromatography-mass spectrometry

Lowest observable adverse effect level

Limit of detection

Lipid weight

Method limit of quantification

Multiple reaction monitoring

N-methyl-perfluorooctane sulfonamide

Linear perfluorooctanoic acid

Linear perfluorooctane sulfonate

National Institute of Standards and Technology

National Oceanic and Atmospheric Administration

Non-observable adverse effect level

National Wildlife Research Centre

Organic Contaminants Research Laboratory 
OMOE

p-value

P1MHpS

P2MHpS

P3MHpS

P35DMHxS

P4MHpS

P44DMHxS

P45DMHxS

P5MHpS

P55DMHxS

P6MHpS

PAP

PBDE

PCB

PFAA

PFBS

PFC

PFCA

PFDA

PFDoA

PFDS

PFECHS

PFHpA

PFHXA

PFHXS

PFNA

PFOA

PFOS

PFOSA

PFPA

PFPA

PFSA

PFTeA

PFTriA

PFUA

POP

POSF

$\mathrm{QA} / \mathrm{QC}$

r-value

RSD

$\mathrm{S} / \mathrm{N}$

SE

SRM

VLDL

ww
Ontario Ministry of Environment

Statistical significance level

Perfluoro-1-methyl-heptanesulfonate

Perfluoro-2-methyl-heptanesulfonate

Perfluoro-3-methyl-heptanesulfonate

Perfluoro-3,5-dimethyl-hexanesulfonate

Perfluoro-4-methyl-heptanesulfonate

Perfluoro-4,4-dimethyl-hexanesulfonate

Perfluoro-4,5-dimethyl-hexanesulfonate

Perfluoro-5-methyl-heptanesulfonate

Perfluoro-5,5-dimethyl-hexanesulfonate

Perfluoro-6-methyl-heptanesulfonate

Perfluorinated phosphate

Polybrominated diphenyl ether

Polychlorinated biphenyl

Perfluoroalkyl acid

Perfluorobutane sulfonate

Per/polyfluorinated compound

Perfluoroalkyl carboxylate

Perfluorodecanoic acid

Perfluorododecanoic acid

Perfluorodecane sulfonate

Perfluorinated ethylcyclohexane sulfonate

Perfluoroheptanoic acid

Perfluorohexanoic acid

Perfluorohexane sulfonate

Perfluorononanoic acid

Perfluorooctanoic acid

Perfluorooctane sulfonate

Perfluorooctane sulfonamide

Perfluoropentadecanoic acid

Perfluorinated phosphonic acid

Perfluoroalkyl sulfonate

Perfluorotetradecanoic acid

Perfluorotridecanoic acid

Perfluoroundecanoic acid

Persistent organic pollutant

Perfluorooctanesulfonyl fluoride

Quality assurance/quality control

Pearsons' product-moment correlation coefficient

Relative standard deviation

Signal to noise ratio

Standard error

Standard reference material

Very low density lipoprotein

Wet weight 


\section{LIST OF APPENDICES}

Appendix 1 Chromatograms of all monitored ion transitions for both HPLC-APPIMS/MS (above), and HPLC-ESI-MS/MS (below, continued onto following page)..... 129

Appendix 2 Example calculation for the determination of a PFCA-normalized $\log K_{\mathrm{OW}}$ value for the liver. Each PFCA-normalized $\log K_{\text {Ow }}$ value was plotted as a function of tissue in Figure 4.6. All percentage composition concentrations are identical as those described in Figure 4.5

Appendix 3 Tissue mass estimates based on the brain mass that was recorded at time of dissection, and based on Equations 1 to 4 (Section 4.2.10). The brain mass for Bears 8, 9, 17 , and 19 were not recorded, and as a result, their tissue masses were not estimated. Errors are standard error (SE).

Appendix 4 PFOS isomer compositions of all tissues analyzed. Isomer compositions are provided on a percentage of $\Sigma$-PFOS basis $(\% \pm \mathrm{SE}$ ). All isomers were considered not detected (n.d.) if less than $50 \%$ of samples were below the method limit of quantification (MLOQ). 


\section{CHAPTER 1 \\ General Introduction}

Environmental contamination and pollution has been one of the many results of human growth, development and industrialization over the last few centuries. As a result of our increasing production and demand on the planet's resources, humans have synthesized non-naturally occurring chemicals to meet the needs of industry. Although highly useful, these anthropogenic compounds can pose environmental and toxicological risks to both humans and wildlife. Polychlorinated biphenyls (PCBs), dichlorodiphenyltrichloroethane (DDT), and polybrominated diphenyl ethers (PBDEs) are all anthropogenic compounds that have gained notoriety in recent decades for their environmental persistence and toxicological effects (Letcher et al., 2009, 2010).

Another class of anthropogenic compounds that has received a great deal of attention in the last few decades is per/polyfluorinated compounds (PFCs). Used in industrial applications since the $1950 \mathrm{~s}$, many longer chained $\left(>C_{6}\right)$ PFCs are found to be accumulating in the environment, and in wildlife (Bossi et al., 2005a; Holmstrom et al., 2005; Olsen et al., 2005; Houde et al., 2006a, 2011; Smithwick et al., 2006; Dietz et al., 2008; Powley et al., 2008; Hart et al., 2009). The full distribution of these compounds in the body is still not well understood, as is their degradation potential,. Many studies have examined the bioaccumulation and toxicity potential of PFCs, in particular the dominant PFC found in the environment, perfluorooctane sulfonate (PFOS) (Berthiaume and Wallace, 2002; Hu et al., 2002; Seacat et al., 2002, 2003; Austin et al., 2003; Hoff et al., 2004; Beach et al., 2006; Loveless et al., 2006; Conder et al., 2008; Johansson et al., 
2008; Slotkin et al., 2008). As a result of these studies, in 2009, PFOS was added to Annex B of the Stockholm Convention, a list of candidate persistent organic pollutants (POPs) (Butt et al., 2010).

\subsection{Perfluorinated Compounds}

Per/polyfluorinated compounds were first developed by the $3 \mathrm{M} \mathrm{Co}$. in the 1950 s (Sherman and Smith, 1971). Originally used as a stain repellent for textiles, PFCs are now used in a wide variety of products such as water and oil repellent protective coatings on carpets, leather, textiles, paper, food packaging, and cardboard; lubricants; pharmaceuticals; insecticides; and surfactants in cleaning products and fire-fighting foams (Smithwick et al., 2005a; Houde et al., 2006a, 2011; Volkel et al., 2008; Martin et al., 2010).

\subsubsection{Structure and Properties of PFCs}

PFCs encompass both per- and polyfluorinated compounds. Both groups are fluorocarbons of varying chain length (usually 4 to 15 carbons long) with either neutral or acidic functional groups at one extremity. Perfluorinated compounds refer to PFCs where the hydrocarbon backbone is fully fluorinated. In contrast, polyfluorinated compounds refer to PFCs where the hydrocarbon backbone is not fully fluorinated. PFCs are classified based on their functional group, and generally fall into one of two very broad categories: environmentally terminal perfluoroalkyl acids (PFAAs), or precursor compounds. PFAAs are fully saturated chains and contain, among others, perfluoroalkyl carboxylates (PFCAs) and perfluoroalkyl sulfonates (PFSAs). PFCAs and PFSAs are 
extremely stable, and to date have shown no evidence of natural degradation, either by biotic or abiotic pathways (Remde and Debus, 1996; Rayne and Forest, 2009a; Martin et al., 2010). There are many PFCs that are precursors to known and environmentally bioaccumulative PFAAs, including fluorotelomer alcohols (FTOHs), fluorotelomer unsaturated acids (FTUCAs), perfluorosulfonamides (FOSAs), and perfluorooctanesulfonyl fluoride (POSF). Precursor compounds are less stable than PFAAs, and are thus named due to their ability to degrade to give PFAAs. For example, fluorotelomer alcohols have been shown to degrade to PFCAs, and both PFOSA and POSF have been shown to degrade to the eight-carbon PFSA, perfluorooctane sulfonate (PFOS) (Dinglasan et al., 2004; Ellis et al., 2004; Martin et al., 2010). General chemical structures for all above-mentioned PFCs can be found in Figure 1.1. Known biotic and abiotic precursor degradation pathways are illustrated in Figure 1.2. 
Perfluoroalkyl carboxylate (PFCA)

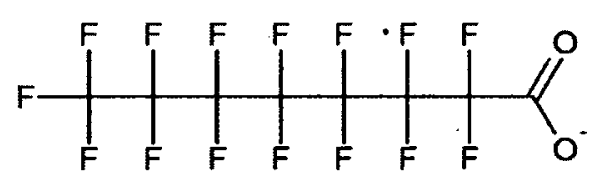

ex: PFOA (perfluorooctanoate)

Perfluoroalkyl sulfonate (PFSA)

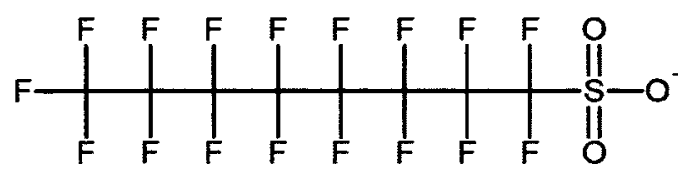

ex: PFOS (perfluorooctane sulfonate)

Perfluorosulfonamide

(FOSA)

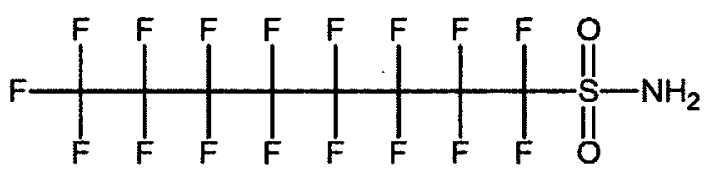

ex: PFOSA (perfluorooctane sulfonamide)

Fluorotelomer Unsaturated Carboxylic Acid (FTUCA)

Fluorotelomer Alcohol (FTOH)

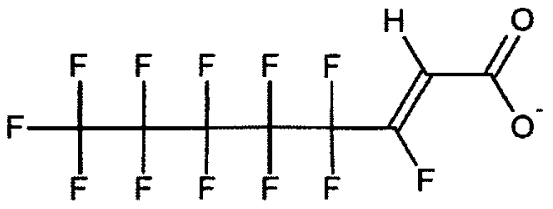

ex: 6:2 FTUCA (2H-perfluoro-2-octenoate)

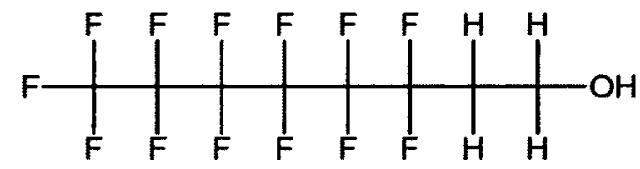

ex: 6:2 FTOH $(1 \mathrm{H}, 1 \mathrm{H}, 2 \mathrm{H}, 2 \mathrm{H}$-perfluorooctanol)

Perfluorooctanesulfonyl fluoride (POSF)

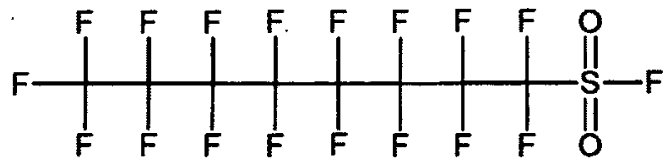

ex: POSF (perfluorooctanesulfonyl fluoride)

Figure 1.1 Generic structures for poly/perfluorinated compounds. 
A

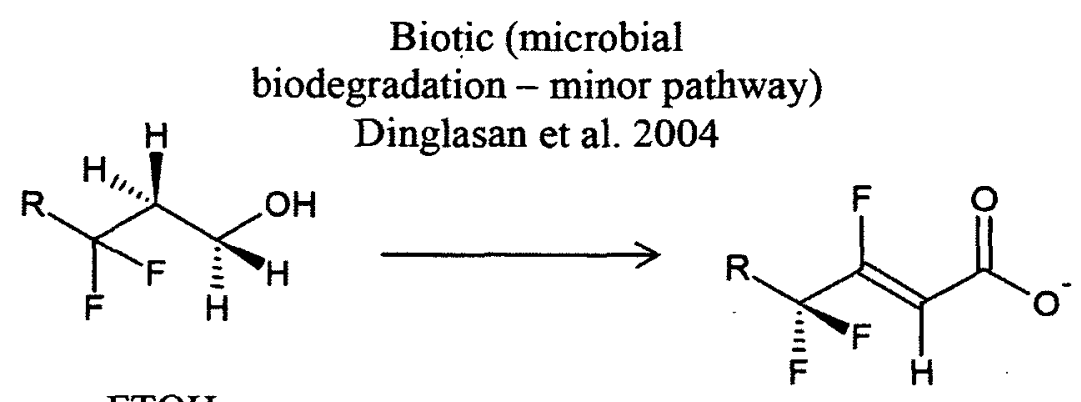

FTOH

FTUCA

Abiotic (atmospheric
oxidation) Ellis et al. 2004

Biotic (microbial biodegradation) Dinglasan et al. 2004

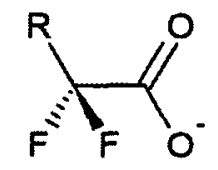

PFCA

B

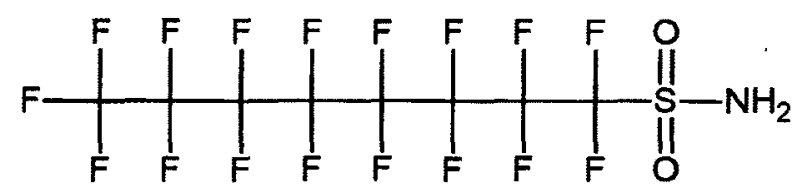

PFOSA

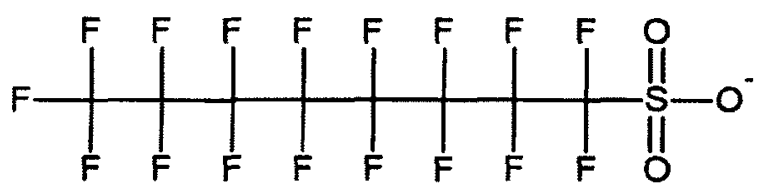

PFOS

Figure 1.2 Biotic and abiotic degradation pathways of PFAA precursor compounds. A) Degradation pathways for fluorotelomer alcohols (FTOHs) and unsaturated carboxylic acids (FTUCAs). B) Degradation pathway for perfluorooctane sulfonamide (PFOSA). 
The fluorine-carbon bond is one of the strongest single bonds in organic chemistry. The large number of fluorine-carbon bonds present in PFCs makes these compounds extremely resistant to both thermal and chemical degradation. The fluorinerich region of PFCs also imparts oil-repellency, making these compounds ideal for treating surfaces which are desired to be kept clean and dry, such as food packaging and textiles. Additionally, PFAAs possess surfactant-like properties due to the nature of their polar head and non-polar tail. As such, PFAAs act at lowering the surface tension of a solution (Kannan et al., 2002) and thus are used as emulsifiers in lubricants and firefighting foams.

It can generally be predicted where a compound will accumulate in the body based on partition coefficients. For instance, the octanol-water partition coefficient $\left(K_{\mathrm{OW}}\right)$ is often used as a basis for predicting a substance's partitioning preferences in the body by measuring either its hydrophobicity or hydrophilicity. Jing et al. (2009) recently determined the $K_{\mathrm{OW}}$ values for PFCAs $\left(\mathrm{C}_{4}-\mathrm{C}_{10}\right)$ for the first time. The experimentally determined $\log K_{\mathrm{OW}}$ values for $\mathrm{C}_{7}-\mathrm{C}_{10}$ PFCAs $\left(1.15<\log K_{\mathrm{OW}}<2.98\right)$, were quite higher than the $\log K_{\text {Ow }}$ values determined for the corresponding alkyl carboxylates $\left(-1.15<\log K_{\mathrm{OW}}<0.62\right)$, indicating that perfluorinated compounds have quite a higher lipophilicity than their non-perfluorinated alkylated equivalents. Other partitioning coefficients, such as $K_{\mathrm{OA}}$ and $K_{\mathrm{WA}}$ (octanol-air, and water-air, respectively) have been computationally estimated, with large variability, and are still poorly understood (Rayne et al., 2009a). Thus it is difficult to predict the partitioning of these compounds both in the environment and in biota. 


\subsubsection{Production}

Historically, PFAAs have been manufactured using two different processes: electrochemical fluorination (ECF), and telomerization. Until 2002, the major PFAA manufacturing process was ECF (Benskin et al., 2009a). In the ECF process, all of the hydrogen atoms on the original precursor compound are replaced with fluorine atoms by applying an electric current. During this fluorination process, approximately $70-80 \%$ of the compounds remain in their linear isomeric configuration, whereas the other $20-30 \%$ receives enough energy to undergo rearrangement from their linear form to a branched isomeric configuration (De Silva et al., 2009a; Lindstrom et al., 2011). ECF was largely phased out in North America in 2002, and since, telomerization has become the major manufacturing process. In the telomerization process, perfluoroethylene $\left(\mathrm{CF}_{2}=\mathrm{CF}_{2}\right)$ reacts with perfluoroethyliodide $\left(\mathrm{CF}_{3}-\mathrm{CF}_{2} \mathrm{I}\right)$ to form exclusively linear compounds, often of even-numbered chain lengths (Lindstrom et al., 2011).

Accurate production volumes have been difficult to estimate due to the nature of proprietary information, regulations, voluntary phase-outs, and shifts in manufacturing

processes over the years. Between 1970 and 2002, it is estimated that approximately $96,000 \mathrm{t}$ of perfluorooctanesulfonyl fluoride (POSF), a precursor of PFOS, was produced globally (Armitage et al., 2009a; Martin et al., 2010; Lindstrom et al., 2011). Additionally, approximately 2,700 t of PFOS was produced globally up until 2002 (Paul et al., 2009; Martin et al., 2010). In 2000, approximately $80 \%$ of the world's PFOS and POSF were being produced by the $3 \mathrm{M} \mathrm{Co}$., with other minor manufacturers in Europe and China (Martin et al., 2010; Gebbink et al., 2011). 
Since the early 2000 s there have been considerable efforts to assess and regulate PFSAs and PFCAs. The first known action taken to reduce the emission of PFSAs and PFCAs occurred between 2000 and 2002. At this time, the 3M Company, which was the major manufacturer of perfluorooctane sulfonyl fluoride (POSF, used to make PFOS and its precursors) voluntarily phased out the production of POSF as well as of PFOA (3M Company, 2003). In 2006, eight major manufacturers entered into a voluntary agreement with the US Environmental Protection Agency (USEPA) to reduce emissions of PFOA and its known precursors in products by $95 \%$ by 2010 and to work towards their complete elimination by 2015 (USEPA, 2012). A similar agreement was reached in Canada between Environment Canada/Health Canada and five major manufacturers (Environment Canada, 2010). Regulation of the longer-chained PFSAs and PFCAs and their precursors is also now in progress in Canada and the US (Canadian Gazette, 2010; USEPA, 2011). In 2009, PFOS and related compounds were included in Annex B of the Stockholm Convention on Persistent Organic Pollutants, which restricts manufacturing and use to a few specific applications (Buck et al., 2011; Lindstrom et al., 2011). In addition, regulatory and voluntary actions exist for these chemicals in countries throughout the world (Buck et al., 2011). Despite these restrictions, production of PFOS in Europe and China has since risen, such that production volumes are now estimated at $42-82 \mathrm{t}$ and $100 \mathrm{t}$ per year, respectively (Armitage et al., 2009a; Gebbink et al., 2011). It should be noted however, that Chinese production volumes are unreliable. It has also been estimated that the global production of fluorotelomer alcohols (FTOHs) has reached $11,000 \mathrm{t}-13,000 \mathrm{t}$ per year (Lindstrom et al., 2011). Armitage et al. (2009a) noted that if 
these production volumes are accurate, global manufacturing volumes of the $\mathrm{C}_{8}$-PFCs have risen back up to levels reported in the late 1990s before the $3 \mathrm{M}$ phase-out.

\subsection{Global Distribution of PFCs}

\subsubsection{Distribution of Persistent PFCs in the Environment}

PFCs are typically found at highest concentrations close to industrialized areas, since locations such as manufacturing plants, waste-water treatment plants, and landfills have all been identified as sources (Dreyer and Ebinghaus, 2009; Dreyer et al., 2010). Due to their production in North America, Europe, and China, perfluorinated compounds have been detected in surface waters, sediment, and air all across the northern hemisphere (Shoeib et al., 2006; Stock et al., 2007; Ahrens et al., 2009a, 2010; Dreyer et al., 2009, 2010; Kelly et al., 2009; Butt et al., 2010; Labadie and Chevreuil, 2011). Even though PFCs are manufactured in the northern hemisphere, they are ubiquitously present around the world. PFAAs have been detected in both biotic and abiotic samples on every continent, including remote regions such as the Arctic and Antarctica. Their global distribution suggests long-range transport potential, although debate still exists concerning their exact transportation processes.

Two hypotheses exist regarding the long-range transport of PFAAs in the environment. In the 'direct hypothesis', terminal compounds such as PFCAs and PFSAs are emitted directly from sources (ex: manufacturing plants, landfills, waste-water treatment plants) and are subsequently distributed around the world, either by oceanic or atmospheric currents. In the 'indirect hypothesis', precursor compounds such as fluorotelomers and perfluorosulfonamides are emitted from sources and are distributed 
around the world mainly by atmospheric currents. They are subsequently precipitated either by wet or dry deposition, and are degraded to their terminal PFAA compound (Lindstrom et al., 2011).

Credence is given to the 'indirect hypothesis' due to both experimental and modelling exercises. Studies have shown that atmospheric degradation of PFCs does occur. Fluorotelomer alcohols have been shown to degrade to PFCAs (Ellis et al., 2004), and perfluorinated sulfonamide alcohols have been shown to degrade to both PFCAs and PFSAs (D'Eon et al., 2006; Martin et al., 2006). It has also been noted that since both PFCAs and PFSAs are acids they would likely be found in their anionic forms in the environment (Rayne et al., 2009b; Woodcroft et al., 2010). As a result, PFCAs and PFSAs would have very low vapour pressures, and would therefore not likely partake in atmospheric transport (Rayne and Forest, 2009a). However, it has been shown that PFCAs and PFSAs are highly water soluble in their anionic form and can therefore partake in oceanic transport (Rayne and Forest, 2009a; Kannan, 2011). In fact, oceanic PFAA concentrations mirror global production volumes of PFAAs to such a degree that direct sources are entirely accounted for by oceanic PFAA inventories (Armitage et al., 2006).

Many studies have supported the 'direct hypothesis' due to the presence of PFAAs in water. All PFCA manufacturing is in the northern hemisphere (i.e.: United States, Europe, and China), and correspondingly, PFCAs have only been detected in oceanic water in the northern hemisphere (Ahrens et al., 2009a, 2010). A global modelling study was recently performed for oceanic coastal regions. It was found that the coastal regions of the north-eastern United States, the North Sea, and Japan had much 
higher levels of the $\mathrm{C}_{8^{-}}$and $\mathrm{C}_{9}$-PFCAs than open sea areas, corresponding with their direct sources (Armitage et al., 2009b). In fact, modelled scenarios of mass fluxes to the Arctic marine ecosystem show that direct transport of PFAAs by oceanic transport is significantly higher than indirect transport such that coastal areas have roughly ten times higher PFAA concentrations compared to inland areas with no oceanic input (Armitage et al., 2006, 2009b; Wania, 2007; Cousins et al., 2011).

The environmental transport pathways are much debated, due in part to the difficulties in determining the physico-chemical properties of PFCs. The acid dissociation constants $\left(\mathrm{p} K_{\mathrm{a}}\right)$ of PFAAs have been estimated by numerous computational methods, and are still debated (Rayne and Forest, 2009a). Since modelling studies are very sensitive to the physico-chemical properties of PFAAs, such as the $\mathrm{p} K_{\mathrm{a}}$ values, the accuracy of these modelling predictions remains uncertain.

\subsubsection{Distribution of PFCs in Biota}

Numerous PFCs have been found in wildlife at all trophic levels, particularly in aquatic environments, with PFOS being by far the most bioaccumulative PFC (Houde et al., 2011). It has generally been found that those at lower trophic levels have lower PFC concentrations than those at higher trophic levels, suggesting biomagnification of certain PFCs and in particular PFAAs, as further discussed in section 1.3. Although PFOS concentrations in benthic species have been reported as high as $280 \mathrm{ng} / \mathrm{g}$ ww in Lake Ontario (Martin et al., 2004), PFOS concentrations for the majority of benthic organisms are less than $13 \mathrm{ng} / \mathrm{g}$ ww (Martin et al., 2004; Tomy et al., 2004; Kannan et al., 2005a). 
Studies on both freshwater and saltwater fish have been performed and have shown large variability based on sampling site and species. Hepatic PFOS concentrations were examined in many piscivorous species from the Great Lakes (including rainbow smelt, brown trout, and lake trout) and ranged from 20 to $450 \mathrm{ng} / \mathrm{g}$ ww (Giesy and Kannan, 2001; Martin et al., 2004). A study in Japan showing PFOS concentrations in 23 species of fish from six different sampling sites found very large ranges of PFOS concentrations ( $3-7,900 \mathrm{ng} / \mathrm{g} \mathrm{ww})$ depending on the species, sampling site, and proximity to fire-fighting operations (Taniyasu et al., 2003). Arctic cod and redfish from the Eastern Arctic were shown to contain very low levels ( $<2 \mathrm{ng} / \mathrm{g}$ ww) of hepatic PFOS (Tomy et al., 2004).

There have been many recent studies looking at PFOS accumulation in avian species worldwide. Gebbink, Hebert and Letcher (2009) reported mean hepatic PFOS concentrations $(90-500 \mathrm{ng} / \mathrm{g} \mathrm{ww}$ ) for herring gulls from 15 colonies in the Great Lakes. Brown pelicans from Mississippi, USA and red-throat divers from the German Baltic Sea were shown to have hepatic PFOS concentrations in the same range $(460 \mathrm{ng} / \mathrm{g}$ ww and $183 \mathrm{ng} / \mathrm{g}$ ww, respectively) (Sturm and Ahrens, 2010; Rubarth et al., 2011). In contrast, more isolated species such as scoters from the Canadian Arctic, glaucous gulls from the Norwegian Arctic, and pelicans from Cartagena Bay, Colombia had lower hepatic PFOS concentrations ( $25 \mathrm{ng} / \mathrm{g} \mathrm{ww}, 70 \mathrm{ng} / \mathrm{g}$ ww and $37 \mathrm{ng} / \mathrm{g} \mathrm{ww}$, respectively) (Verreault et al., 2005; Olivero-Verbel et al., 2006; Sturm and Ahrens, 2010).

Some of the highest PFOS concentrations found to date have been in mammals. PFOS concentrations in mink from various watersheds in Illinois, USA $(1,176 \mathrm{ng} / \mathrm{g} \mathrm{ww})$, river otters from the Willamette River, Oregon, USA (579 ng/g ww), and bottlenose 
dolphins from the Gulf of Mexico and Sarasota Bay, Florida, USA (489 ng/g ww) all showed large exposure to PFCs (Kannan et al., 2001, 2002).

Most notable of all are PFOS concentrations found in some Arctic wildlife such as the polar bear. Smithwick et al. (2005a, 2005b) found an average PFOS concentration of 2,470 ng/g ww in liver samples from East Greenland polar bears, and similar concentrations for populations in the Canadian Arctic $(1,170-2,730 \mathrm{ng} / \mathrm{g} \mathrm{ww})$. Similarly, Dietz et al. (2008) recently showed that PFC concentrations in East Greenland polar bears have recently increased dramatically. Bears sampled in 1986 contained an average hepatic PFOS concentration of $560 \mathrm{ng} / \mathrm{g}$ ww, whereas by 2006 it had increased to $2,878 \mathrm{ng} / \mathrm{g} \mathrm{ww}$.

Numerous temporal studies have shown the persistence of PFCs in ecosystems, and their bioaccumulation in the environment and the food web (Martin et al., 2004; Bossi et al., 2005a; Holmstrom et al., 2005; Olsen et al., 2005; Houde et al., 2006a; Armitage et al., 2009a; Butt et al., 2010; Houde et al., 2011). These studies show clear increasing concentrations of PFAAs in biota from the 1960's up until 2000 when 3M introduced its phase-out of the $\mathrm{C}_{8}$-based chemistry. There is still debate as to the effect of the 2000 phase-out on the environment. PFOS concentrations in northern sea otters dropped from 2001 to 2007 suggesting immediate response to the $3 \mathrm{M}$ phase-out (Hart et al., 2009). Similarly, concentrations of PFOS, and PFCAs $\left(C_{9}-C_{11}\right)$ in Arctic ringed seal dropped from 2000 to 2005 (Butt et al., 2007). However, a recent study examining temporal trends in East Greenland polar bears from 1984 to 2006 showed that as of 2000 PFOS and some PFCA concentrations have been increasing exponentially (Dietz et al., 
2008). Similar trends have also been shown for polar bear populations in Baffin Bay and Alaska (1972-2002) (Smithwick et al., 2006).

\subsubsection{Wildlife Tissue Distributions}

With the numerous studies focusing on hepatic PFC concentrations, there have been very few studies examining the entire body distribution of these compounds in wildlife. The vast majority of free-ranging wildlife studies have focused on either the liver or the blood, since PFCs are known to accumulate in the enterohepatic system (Houde et al., 2006a; 2011). However, understanding how PFCs are distributed throughout the entire body pose two knowledge benefits: 1) understanding the whole body distribution of PFCs enables better understanding of the pharmacokinetics of these compounds, and 2) some predators may eat their whole prey (ex: seals eat whole fish) whereas other predators preferentially eat one type of tissue over others (ex: polar bears eat primarily seal blubber). Therefore, it is useful to understand the levels of contamination throughout the body to better appreciate the dietary exposure of predators, and to more accurately estimate biomagnification factors.

A few tissue-specific distribution studies have been done on avian and mammalian species including glaucous gulls from the Norwegian Arctic, herring gulls from the Great Lakes, red-throated divers from the German Baltic Sea, pelicans from the coast of Colombia, harbour porpoises from the Black Sea, and harbour seals from the German Bight and the Dutch Wadden Sea (Van de Vijver et al., 2005, 2007; Verreault et al., 2005; Olivero-Verbel et al., 2006; Ahrens et al., 2009b; Rubarth et al., 2011; Gebbink and Letcher, 2012). In all of the studies, the liver had either the highest or second-highest 
PFOS concentration (next to plasma), while concentrations in the brain were in the range of $1 / 3^{\text {rd }}$ to $1 / 20^{\text {th }}$ that of the liver. Of those avian studies examining the brain, a consistent trend was seen in the preferential enrichment of the long-chain PFCAs in the brain over the liver. After a comprehensive review of the published literature, Table 1.1 summarizes the main tissue distribution findings for all known mammalian and avian wildlife studies. 
Table 1.1 Summary of previous mammalian and avian tissue distribution studies. Concentrations provided are in $\mathrm{ng} / \mathrm{g}$ ww $( \pm \mathrm{SE}$, when available). For a complete list of compound abbreviations, please refer to Table 2.3.

\begin{tabular}{|c|c|c|c|c|c|c|c|c|c|c|c|c|}
\hline & & & ens et al. ( 2 & 109) & & Van $d$ & Viiver et al & $(2005)^{a}$ & Van & le Viive & et al 20 & \\
\hline . & & $(1$ & $\begin{array}{l}\text { arbour Sea } \\
\text { hoca vitulin } \\
\mathrm{n}=4\end{array}$ & & & & $\begin{array}{l}\text { arbour Sea } \\
\text { hoca vitulin } \\
\mathrm{n}=17-24\end{array}$ & & $(P h$ & $\begin{array}{l}\text { larbour } \\
\text { ena ph } \\
n=\end{array}$ & $\begin{array}{l}\text { orpoises } \\
\text { coena re } \\
31\end{array}$ & ta), \\
\hline & & Germ & n Bight, $\mathrm{Ge}$ & rmany & & Dutch W & dden Sea, & therlands & & lack Se & Ukraine & \\
\hline & Liver & Blood & Brain & Muscle & Fat & Liver & Muscle & Fat & Liver & Brain & Muscle & Fat \\
\hline PFOA & $0.70 \pm 0.30$ & $0.62 \pm 0.29$ & $0.06 \pm 0.05$ & $0.07 \pm 0.06$ & $0.03 \pm 0.02$ & n.d. & n.d. & n.d. & - & - & - & - \\
\hline PFNA & $15.3 \pm 11.5$ & $3.93 \pm 1.04$ & $1.20 \pm 0.25$ & $0.96 \pm 0.18$ & $0.61 \pm 0.14$ & n.d. - 14 & n.d. - 11.99 & n.d. & 3.4 & - & - & - \\
\hline PFDA & $15.2 \pm 2.25$ & $4.38 \pm 1.18$ & $1.55 \pm 0.24$ & $1.09 \pm 0.23$ & $0.29 \pm 0.11$ & $1.76-14.11$ & n.d. -15.4 & n.d. & 9.4 & - & - & - \\
\hline PFUA & $5.26 \pm 0.80$ & $1.71 \pm 0.42$ & $1.06 \pm 0.08$ & $0.26 \pm 0.08$ & $0.09 \pm 0.05$ & n.d. -7.88 & n.d. -6.35 & n.d. & 8.8 & - & - & - \\
\hline PFDoA & $1.47 \pm 0.25$ & $0.47 \pm 0.12$ & $0.51 \pm 0.18$ & $0.06 \pm 0.06$ & $0.04 \pm 0.03$ & n.d. & n.d. & n.d. & 4.2 & - & - & - \\
\hline
\end{tabular}

${ }^{a}$ Concentrations were estimated hased on tahles and fioures nrovided 
Table 1.1(continued) Summary of previous mammalian and avian tissue distribution studies. Concentrations provided are in $\mathrm{ng} / \mathrm{g}$ ww ( $\pm \mathrm{SE}$, when available). For a complete list of compound abbreviations, please refer to Table 2.3.

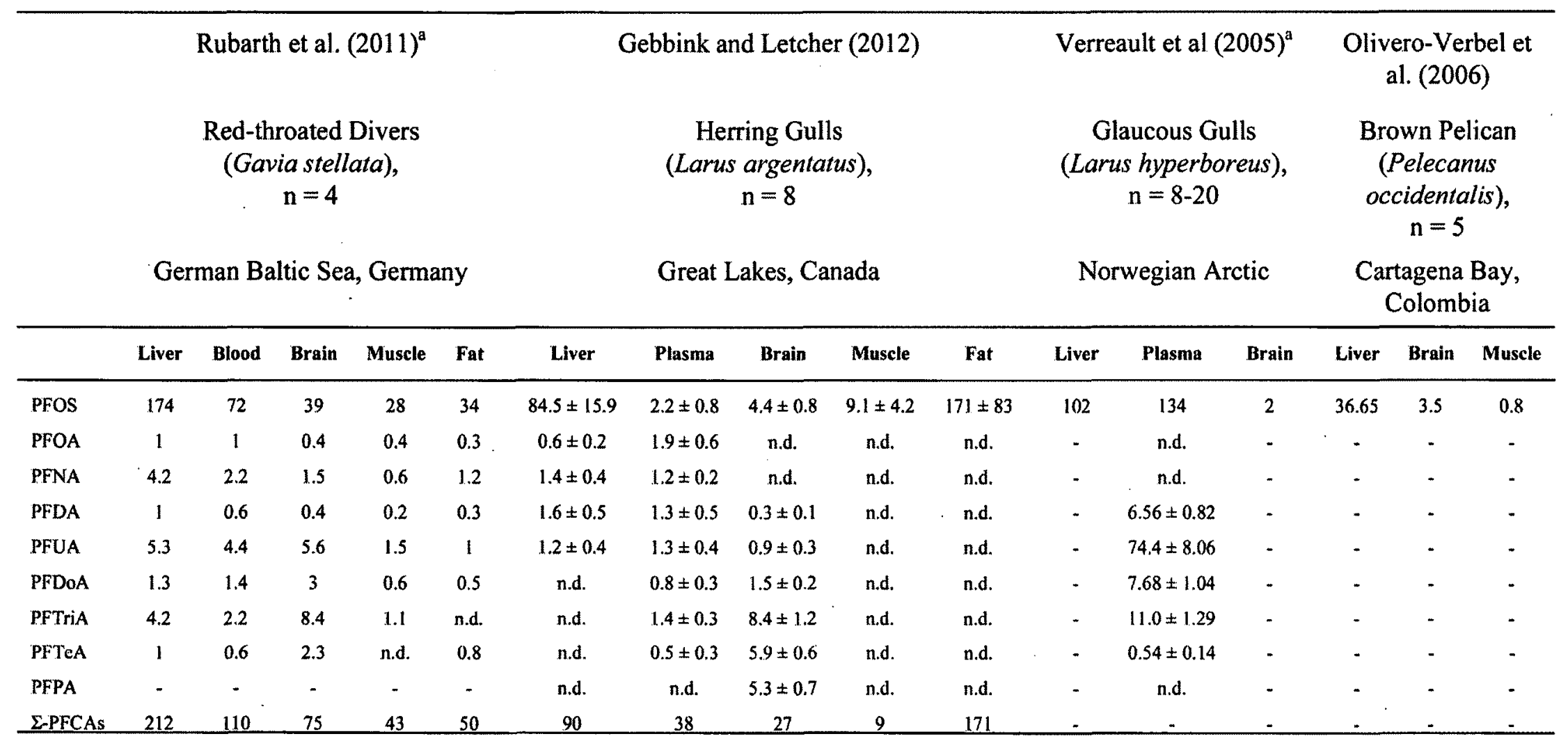

${ }^{a}$ Concentrations were estimated based on tables and figures provided 


\subsubsection{Lipid-Driven vs. Protein-Driven PFC Accumulation in Biota}

It is suspected that PFCs are distributed through the body by protein associations, although the exact manner in which this occurs is not fully understood. PFAAs have been shown to bind to serum albumin, fatty acid binding proteins and lipoproteins, and have a tendency to accumulate in protein-rich tissues, such as the liver and plasma (Luebker et al., 2002; Jones et al., 2003; Chen and Guo, 2009; Zhang et al., 2009; Mortensen et al., 2011; Cassone et al., 2012). Where it has actually been assessed, a few mammalian studies have reported that there were no correlations between lipid levels and PFC concentrations in either liver or plasma (Kannan et al., 2002; Kannan et al., 2005b; Houde et al., 2006b). Considering the structural similarities between long-chain PFCAs and saturated fatty acids, and the fact that long-chain PFCAs have been found to bind to serum albumin at the same sites as fatty acid binding (Chen and Guo, 2009), reports showing the lack of lipid correlations in the liver and plasma corroborates the importance of the role of protein interactions in the distribution of PFAAs in the body.

\subsubsection{Isomer Patterns}

As mentioned above, the ECF method for PFC manufacture produces $70-80 \%$ linear compounds, while the remaining $20-30 \%$ is often mono-methylated, di-methylated, or cyclic structural isomers. Reagan et al. (2007) reported on the batch-to-batch consistency of isomer ratios found in 3M's ECF perfluorooctane sulfonate (PFOS). Over a 10 year period and eight production lots, variability in PFOS isomer ratios was minimal, with 70\% (std dev 1.1\%) linear PFOS, and 30\% (std dev 0.8\%) branched PFOS (Reagen et al. 2007). It has been hypothesized that branched PFOS isomers may have 
different environmental transport potential, degradation, pharmacokinetics, and toxicity than their linear counterpart (Benskin et al., 2010).

Although more than 80 geometrical isomers of PFOS are possible, only 11 isomers have been detected in either the technical mixtures and/or environmental samples (Benskin et al., 2009b; Chu and Letcher, 2009; Gebbink and Letcher, 2010). There is still much debate over how local sources contribute to the global contamination profile of PFAAs, and it has been hypothesized that studying isomer profiles in the environment/biota may partially identify global sources. A dominant linear isomer profile would suggest exposure to a telomerization source, whereas a profile with large amounts of branched isomers would indicate exposure to an ECF source. However, the prediction of sources is complicated by the fact that over the last few years it was shown that branched PFOS isomers are cleared from the body much faster than linear PFOS in rats and chicken embryos (Benskin et al., 2009a; De Silva et al., 2009b; O’Brien et al., 2011). Due to these variations in biotic half-lives between linear and branched isomers, if presented with a dominantly linear biotic sample, it becomes difficult to distinguish if it is caused by a telomerization source or if it is due to a more efficient depuration of branched isomers.

Regardless of the above, few studies have been performed analyzing isomer patterns in wildlife. A recent study examining the accumulation of PFOS and PFOA isomers in rats found preferential enrichment of linear PFOS (n-PFOS) and linear PFOA (n-PFOA) over branched congeners (Benskin et al., 2009a; De Silva et al., 2009b). It was also seen that branched congeners were generally excreted faster than the linear congeners, with the exception of the PFOS isomer containing a perfluorinated methyl 
group at the acarbon (P1MHpS) whose half life was three times longer than the linear congener. In a recent study performed on herring gull eggs from the Great Lakes, n-PFOS concentrations accounted for 95.0 to $98.3 \%$ of all detected PFOS. The remaining $1.7-$ $5.0 \%$ was composed mainly of the mono-perfluoromethylated isomers, with hardly any di-perfluoromethylated isomers being detected (Gebbink and Letcher, 2010).

\subsection{Toxicity of PFCs}

Subsequent to studies demonstrating the persistence of PFCs, there has been a large push to understand their toxicity effects in humans and wildlife. In the last decade, many advances have been made in discovering toxicological effects at the cellular level, as well as at the organismal level in terms of physical and behavioural symptoms. Since manufacturers have focused their production on $\mathrm{C}_{8}$-based chemistry, many of the PFC toxicity studies performed to date have included PFOS and perfluorooctanoic acid (PFOA).

It has been hypothesized that PFCs are retained in the body through enterohepatic recirculation, and are therefore largely found in the liver and the blood. It has been shown that the half-lives of PFCs in the body depend on several factors including the chain length, functional group, and species. For example, the half-life of the $\mathrm{C}_{8}$ carboxylate, PFOA, is roughly 6 days in male rats, although the half-life of the $C_{8}$ sulfonate, PFOS, is roughly 30-103 days in male rats (Benskin et al., 2009a; De Silva et al., 2009b; Lindstrom et al., 2011). The half-life of PFOS in dolphins was estimated at 21 weeks, whereas it was much higher for harbor seals (5.6 years) and humans (5.4 years) (Genuis et al., 2010; Martin et al., 2010; Lindstrom et al., 2011). A study estimating 
bioconcentration factors of PFAAs using predictive equations estimated that PFSAs are more bioaccumulative than PFCAs of the same chain length (Rayne et al., 2009b). The study also estimated that PFCAs less than 7 carbons long and PFSAs less than 8 carbons long will not bioconcentrate, which is consistent with levels reported in wildlife. A study examining uptake rates of PFAAs in rainbow trout showed that for PFCAs between 8 and 12 carbons long, bioconcentration factors increase approximately by a factor of 8 for each carbon added (Martin et al., 2003).

PFOS has also been shown to bind to DNA (Zhang et al., 2009), indicating its potential as a genotoxin. In fact, PFOS has been found to increase peroxisome proliferation, increase peroxisome $\beta$-oxidation activity, cause hepatocellular hypertrophy, and alter gene expression (Berthiaume et al., 2002; Hoff et al., 2004; Zhang et al., 2009; Wang et al., 2010), as well as inhibit gap-junction intercellular communication, and alter levels of hormones including those in the thyroid hormone pathway (Hu et al., 2002; Vongphachan et al., 2011; Yu et al., 2011). In the brain, prenatal and neonatal PFOS exposure in rats has lead to abnormal motor neuron development, and alterations in calcium signalling pathways (Johansson et al., 2009; Liu et al., 2010; Wang et al., 2010; Zeng et al., 2011; Zhang et al., 2011). PFOA has been linked with increased incidence of liver, pancreatic, and testicular tumours (Lindstrom et al., 2011).

In rats, prenatal and neonatal PFOS exposure has also lead to such physical symptoms as decreased muscle strength in males, decreased locomotion in unfamiliar environments, and hyperactivity in adults (Johansson et al., 2008; Onishchenko et al., 2011). Exposure to large amounts of PFOS has also been shown to decrease body weight and increase liver weight in mice (Hoff et al., 2004). 


\subsection{East Greenland Polar Bears}

The polar bear (Ursus maritimus) is a good sentinel species for monitoring the distribution and effects of persistent organic pollutants (POPs) in the Arctic due to its apex position in the Arctic marine food web, as well as their circumpolar distribution. It has been noted that polar bears primarily feed on ringed seal (Pusa hispida) blubber, though they are also opportunistic feeders, and thus other food sources occasionally include bearded seals (Erignathus barbatus), harp seals (Pagophilus groenlandicus), walruses (Odobenus rosmarus), narwhals (Monodon monoceros), bowhead whales (Balaena mysticetus), and sperm whales (Physeter macrocephalus) (Verreault et al., 2008; McKinney et al., 2011a). Although immature polar bears often eat a protein-rich diet while growing, adults consume a very high fat diet. In fact, Stirling and McEwan (1975) estimated that an average adult polar bear (approx. $200 \mathrm{~kg}$ ) will consume approximately $1,000 \mathrm{~kg}$ of seal blubber every year. Polar bears reach sexual maturity at around 4 years for females, and 5 to 6 years for males (Rosing-Asvid et al., 2002; Kannan et al., 2005b). With a long life span usually ranging from 25 to 30 years (Kannan et al., 2005b) and their apex position in the food web, polar bears are highly exposed to persistent organic pollutants including PFCs, as well as PCBs and chlordanes (Letcher et al., 2010; McKinney et al., 2011b).

\subsubsection{Physiology of the Brain}

The average weight of the adult polar bear brain has been estimated to be 459.44 $\mathrm{g}$ (Gittleman, 1986), although the weight of a subadult polar bear brain has been recorded as low as $146 \mathrm{~g}$ (this study). The neocortex encompasses the frontal, temporal, occipital 
and parietal lobes. It is the most massive region of the brain, accounting for roughly $60 \%$ of the total brain mass in the closely related Malayan sun bear (Ursus malayanus) (Kamiya and Pirlot, 1988). The cerebellum is the other massive region of the brain, accounting for roughly $15 \%$ of the total brain mass of the sun bear.

The blood-brain barrier (BBB) surrounds the entire brain and acts as a selective barrier between the blood and the brain. The BBB is composed of cerebral endothelial cells with specialized tight junctions that limit the passive diffusion of blood-borne solutes. The BBB freely allows small substances to pass, such as oxygen, carbon dioxide and small lipophilic substances, while being impermeable to hydrophilic molecules such as glucose and amino acids (Cipolla, 2010). The high electrical resistance of the BBB $\left(1500-2000 \Omega \mathrm{cm}^{2}\right)$ only allows small lipid-soluble molecules $(<400 \mathrm{Da})$ to cross by passive diffusion (Cipolla, 2010). In order for the brain to receive the essential nutrients it requires for normal functioning, the BBB also contains transporters that actively control the transport of nutrients. Carrier-mediated transport (facilitated diffusion) allows nutrients such as glucose, amino acids, and vitamins to travel down their concentration gradient from the blood to the brain. Receptor-mediated transport allows larger molecules such as peptides and proteins to travel across the BBB. Finally, active-efflux transporters allow the removal of molecules from the brain back into the blood (Cipolla, 2010).

PFAAs have been detected in the brains of mice, rats, and zebrafish embryos after either single-dose or repeated exposure to PFOS or PFOA, indicating their ability to cross the BBB (Austin et al., 2003; Johansson et al., 2008, 2009; Sato et al., 2009; Liu et al., 2010; Wang et al., 2010; Onishchenko et al., 2011; Zeng et al., 2011; Zhang et al., 2011; Cassone et al., 2012). Thus, the question arises as to what transport mechanisms allow 
PFAAs to cross the BBB. PFAAs have been shown to bind to serum proteins in the blood. PFOS has been shown to strongly bind to serum albumin (Jones et al., 2003). PFOA and PFDoA have also been shown to bind to serum albumin at the same sites as fatty acid binding, and with similar affinities $\left(10^{4}-10^{6} \mathrm{M}^{-1}\right)$ perhaps due to the structural similarities between PFCAs and saturated fatty acids (Chen et al., 2009; Fromme et al., 2009). How fatty acids are transported across the BBB is still debated. There are two dominant hypotheses for the transport of long-chain fatty acids. The first hypothesis involves passive diffusion of the fatty acids using a flip-flop mechanism, independent of transport proteins. The second hypothesis involves protein-mediated transport mechanisms, in particular fatty acid transport proteins (FATPs), fatty acid binding proteins (FABPs) and plasma membrane fatty acid binding proteins (Mitchell and Hatch, 2011).

\subsubsection{PFC Trends in Polar Bears}

Although studies have mainly examined spatial PFC trends in polar bears (Kannan et al., 2001, 2005b; De Silva and Mabury, 2004; Bossi et al., 2005b; Smithwick et al., 2005a, 2005b, 2006; Dietz et al., 2008), and have been summarized in recent reviews (Butt et al., 2010; Letcher et al., 2010; Houde et al., 2011), only a brief overview is given here. Circumpolar studies examining the distribution of PFCs across the Arctic have shown that the East Greenland polar bear population contains extremely high levels of PFCs, second-only to the Southern Hudson Bay population (Smithwick et al., 2005b). Additionally, temporal trends in both the North American Arctic (1972-2002), and East Greenland (1984-2006) have shown recent exponential increases of PFOS, and PFCAs 
$\left(C_{8}-C_{12}\right)$ in polar bear populations (Smithwick et al., 2006; Dietz et al., 2008). Hepatic PFOS concentrations have reached as high as $6.3 \mathrm{ppm}$ wet weight (Smithwick et al., 2005b) and are consistently found over $1 \mathrm{ppm}$, on the same order of magnitude as PCBs and chlordanes (Dietz et al., 2008; Benskin et al., 2009b; Letcher et al., 2010). In rats, the non-observable adverse effect level (NOAEL) was found to be between $358-370 \mathrm{ppm}$, approximately 100 times higher than current levels in East Greenland polar bears (Seacat et al., 2003). However in monkeys, the lowest observable adverse effect level (LOAEL) was much lower $(59-70 \mathrm{ppm}$ ) (Seacat et al., 2002; Dietz et al., 2008). It is not known what the NOAEL or LOAEL is in polar bears but Beach et al. (2006) predict that population effects will be seen when hepatic concentrations reach about $5 \mathrm{ppm}$. According to the temporal trend study done by Dietz et al. (2008), hepatic PFOS concentrations in polar bears will reach these levels sometime between 2012 and 2024 if the current exponential trend continues.

\subsection{PFC Analysis}

\subsubsection{Liquid Chromatography-Mass Spectrometry}

Liquid chromatography-mass spectrometry (LC-MS) is a well used analytical technique for measuring PFCs in wildlife samples. Taniyasu et al. (2005), Chu and Letcher (2008), and Gebbink and Letcher (2012) reported on the use of LC-MS/MS for the determination of PFSAs, PFCAs, FOSAs, FTOHs and FTUCAs in various tissue sample matrices including liver, plasma, fat and brain. In those studies, electrospray ionization (ESI) was used for the ionization of PFSAs, PFCAs, and FTUCAs, while 
atmospheric pressure photoionization (APPI) was used for ionization of FOSAs and FTOHs.

\subsubsection{Electrospray Ionization}

Electrospray ionization (ESI) is an ionization technique used in mass spectrometry. After analyte separation on a given LC column, the eluent is passed through a small capillary, which results in the nebulisation of the mobile phase into a fine droplet spray. The metal capillary is also subjected to a high voltage, and thus all applicable components, including the target analytes, are ionized either positively or negatively depending on the polarity of the capillary, thus explaining the name, electrospray ionization. The ESI droplets undergo a process of solvent evaporation by a drying gas or by the heated chamber. As the droplets diminish in size, any ions (which are involatile) are concentrated. As the droplet is reduced in size, repulsion of ions of like charge increases until the solvated ions are desorbed. All evaporated solvent or neutral mobile phase vapour is removed, and the desorbed ions are drawn to the mass analyzer by acceleration via accelerating plates of increasing potential.

\subsubsection{Atmospheric Pressure Photoionization}

The process of atmospheric pressure photoionization (APPI), similar to atmospheric pressure chemical ionization (APCI), requires a heated nebulizer for spraying and partially desolvating the LC eluent. Analyte ionization occurs via UV radiation. However, since the probability of direct ionization of the analyte is low, an easily-ionizable substance (a dopant; e.g. toluene or acetone) is generally added. These 
dopant photoions significantly increase the number of analyte molecules ionized by initiating a cascade of ion-molecule reactions leading to the formation of the ionized analytes in the form $[\mathrm{MH}]^{-}$(by proton transfer) or $[\mathrm{M}]^{-}$(by charge transfer).

\subsubsection{Triple-Quadrupole Mass Spectrometry}

After ionization, either by ESI or APPI, the analyte ions undergo mass separation using mass analyzers such as low mass resolution analyzers (e.g., quadrupoles), or higher resolution mass analyzers (e.g., time of flight). For PFC quantification, the common mass analyzers used are quadrupoles, and often triple quadrupole mass analyzer systems are used. In such systems, the first and the third quadrupoles are mass-selective analyzers, while the second quadrupole serves as a collision cell. The first quadrupole serves as a mass-selective analyzer for molecular, or parent, ions of the target analytes. The molecular ions are accelerated and collide with neutral molecules (argon) in the collision cell, causing fragmentation of the molecular ions to produce daughter ions. These daughter ions are subsequently analyzed in the third mass selective quadrupole. For each of the target compounds unique parent-daughter ion multiple reaction monitoring (MRM) channels can be generated in order to identify and quantify the target analytes. For example, for perfluoroalkyl sulfonates, after molecular ions are fragmented, the $\mathrm{SO}_{3}{ }^{-}$ daughter ion is an abundant fragment and molecular-to- $\mathrm{SO}_{3}{ }^{-}$transition channels are used. For perfluoroalkyl carboxylates, the molecular-to- $\left[\mathrm{M}-\mathrm{CO}_{2}\right]^{-}$transitions are the most frequently used transition channels. 


\subsubsection{Quadrupole Time of Flight Mass Spectrometry}

After ionization by ESI, the ions selectively enter the quadrupole based on their mass-to-charge ratios. The quadrupole serves as a collision chamber. The ions collide with neutral molecules (argon) in the collision cell, causing fragmentation of the

molecular ions to produce daughter ions. The daughter ions are then accelerated as a function of their charge and mass. Thus, their velocity depends on their unique mass-tocharge ratio. Smaller ions are accelerated faster than heavier ions, and thus they reach the detector first. By measuring the time it takes for the daughter ions to reach the detector, the mass-to-charge ratios of the daughter ions can be determined.

\subsection{Thesis Objectives}

Although data has shown hepatic PFC concentrations in polar bears to be extremely high, very little information is known about their distribution in the rest of the body. There is also very little information available about the distribution of PFCs in the brain even though laboratory studies have shown PFAA exposure to cause genotoxic effects in rodents. With this in mind, this M.Sc. thesis has two main objectives and hypotheses:

Objective 1: To examine the distribution patterns of PFAAs within the brain of East Greenland polar bears. Eight different regions of the brain were analyzed (pons/medulla, cerebellum, frontal cortex, occipital cortex, temporal cortex, striatum, thalamus, and hypothalamus). This will be addressed in Chapter 3 . 
Hypothesis 1: There are region-specific accumulation differences between brain compartments due to the chemically-selective nature of the brain and the blood-brain barrier.

Objective 2: To examine the distribution patterns of PFAAs throughout the body. Five different tissues were examined including the brain (analyzed in Chapter 3), liver, whole blood, muscle, and adipose tissue. This will be addressed in Chapter 4 .

Hypothesis 2: Due to the different biochemistry, physiology and function of these five tissues, there are different PFAA distribution patterns in each tissue. Liver contains the highest levels of PFAAs (especially PFOS), whereas the adipose contains the lowest levels of PFAAs, consistent with what has been found in other mammalian species. 


\section{References}

3M Company, 2003. Environmental and health assessment of perfluorooctanesulfonate and its salts. U.S. EPA Administrative Record AR226-1486.

Ahrens, L., Barber, J.L., Xie, Z.Y., Ebinghaus, R., 2009a. Longitudinal and latitudinal distribution of perfluoroalkyl compounds in the surface water of the Atlantic Ocean. Environmental Science \& Technology 43, 3122-3127.

Ahrens, L., Siebert, U., Ebinghaus, R., 2009b. Total body burden and tissue distribution of perfluorinated compounds in harbor seals (Phoca vitulina) from the German Bight. Marine Pollution Bulletin 58, 520-525.

Ahrens, L., Xie, Z.Y., Ebinghaus, R., 2010. Distribution of perfluoroalkyl compounds in seawater from Northern Europe, Atlantic Ocean, and Southern Ocean. Chemosphere 78, 1011-1016.

Armitage, J.M., Cousins, I.T., Buck, R.C., Prevedouros, K., Russell, M.H., MacLeod, M., Korzeniowski, S.H., 2006. Modelling global-scale fate and transport of perfluorooctanoate emitted from direct sources. Environmental Science \& Technology 40, 6969-6975.

Armitage, J.M., Schenker, U., Scheringer, M., Martin, J.W., MacLeod, M., Cousins, I.T., 2009a. Modelling the global fate and transport of perfluorooctane sulfonate (PFOS) and precursor compounds in relation to temporal trends in wildlife exposure. Environmental Science \& Technology 43, 9274-9280.

Armitage J.M., MacLeod, M., Cousins, I.T., 2009b. Comparative assessment of the global fate and transport pathways of long-chain perfluorocarboxylic acids (PFCAs) and perfluorocarboxylates (PFCs) emitted from direct sources. Environmental Science \& Technology 43, 5830-5836.

Austin, M.E., Kasturi, B.S., Barber, M., Kannan, K., MohanKumar, P.S., MohanKumar, S.M.J., 2003. Neuroendocrine effects of perfluorooctane sulfonate in rats. Environmental Health Perspectives 111, 1485-1489.

Beach, S.A., Newsted, J.L., Coady, K., Giesy, J.P., 2006. Ecotoxicological evaluation of perfluorooctanesulfonate (PFOS). Reviews of Environmental Contamination and Toxicology 186, 133-174.

Benskin, J.P., De Silva, A.O., Martin, L.J., Arseneault, G., Mccrindle, R., Riddell, N., Mabury, S.A., Martin, J.W., 2009a. Disposition of perfluorinated acid isomers in Sprague-Dawley rats; Part 1: single dose. Environmental Toxicology and Chemistry 28, 542-554. 
Benskin, J.P., Holt, A., Martin, J.W., 2009b. Isomer-specific biotransformation rates of a perfluorooctane sulfonate (PFOS)-precursor by cytochrome P450 isozymes and human liver microsomes. Environmental Science \& Technology 43, 8566-8572.

Benskin, J.P., De Silva, A.O., Martin, J.W., 2010. Isomer profiling of perfluorinated substances as a tool for source tracking: a review of early findings and future applications. Review of Environmental Contamination and Toxicology 208, 111160.

Berthiaume, J., Wallace, K.B., 2002. Perfluorooctanoate, perfluorooctanesulfonate, and N-ethyl perfluorooctanesulfonamido ethanol: peroxisome proliferation and mitochondrial biogenesis. Toxicology Letters 129, 23-32.

Bossi, R., Riget, F.F., Dietz, R., 2005a. Temporal and spatial trends of perfluorinated compounds in ringed seals (Pusa hispida) from Greenland. Environmental Science \& Technology 39, 7416-7422.

Bossi, R., Riget, F.F., Dietz, R., Sonne, C., Fauser, P., Dam, M., Vorkamp, K., 2005b. Preliminary screening of perfluorooctane sulfonate (PFOS) and other fluorochemicals in fish, birds and marine mammals from Greenland and the Faroe Islands. Environmental Pollution 136, 323-329.

Buck, R.C., Franklin, J., Berger, U., Conder, J.M., Cousins, I.T., de Voogt, P., Astrup Jensen, A., Kannan, K., Mabury, S.A., van Leeuwen, S.P.J., 2011. Perfluoroalkyl and polyfluoroalkyl substances in the environment: Terminology, classification, and origins. Integrated Environmental Assessment and Management 7, 513-541.

Butt, C.M., Muir, D.C.G., Stirling, I., Kwan, M., Mabury, S.A., 2007. Rapid response of arctic ringed seals to changes in perfluoroalkyl production. Environmental Science \& Technology 41, 42-49.

Butt, C.M., Berger, U., Bossi, R., Tomy, G.T., 2010. Levels and trends of poly- and perfluorinated compounds in the Arctic environment. Science of the Total Environment 408, 2936-2965.

Canadian Gazette, 2010. Part 1: Notices and Proposed Regulations. Publication after screening assessment of long-chain perfluorocarboxylic acids (PFCAs) that contain from 9 to 20 carbon atoms, their salts and their precursors. 144:44.

Cassone, C.G., Vongphachan, V., Chiu, S.Z., Williams, K.L., Letcher, R.J., Pelletier, E., Crump, D., Kennedy, S., 2012. In ovo effects of perfluorohexane sulfonate and perfluorohexanoate on toxicity, development, mRNA expression and thyroid hormone levels in chicken embryos. Toxicological Sciences. In Review.

Chen, Y.M., Guo, L.H., 2009. Fluorescence study on site-specific binding of perfluoroalkyl acids to human serum albumin. Archives of Toxicology 83, 255-261. 
Chu, S.G., Letcher, R.J. 2008. Analysis of fluorotelomer alcohols and perfluorinated sulfonamides in biotic samples by liquid chromatography-atmospheric pressure photoionization-mass spectrometry. Journal of Chromatography A 1215, 92-99.

Cipolla, M.J., 2010. The cerebral circulation. Colloquium Series on Integrated Systems Physiology: from Molecule to Function to Disease, 2. Morgan \& Claypool Life Sciences.

Conder, J.M., Hoke, R.A., De Wolf, W., Russell, M.H., Buck, R.C., 2008. Are PFCAs bioaccumulative? A critical review and comparison with lipophilic compounds. Environmental Science \& Technology 42, 995-1003.

Cousins, I.T., Kong, D., Vestergren, R., 2011. Reconciling measurement and modelling studies of the sources and fate of perfluorinated carboxylates. Environmental Chemistry 8, 339-354.

D’Eon, J.C., Hurley, M.D., Wallington, T.J., Mabury, S.A., 2006. Atmospheric chemistry of $\mathrm{N}$-methyl perfluorobutane sulfonamidoethanol, $\mathrm{C}_{4} \mathrm{~F}_{9} \mathrm{SO}_{2} \mathrm{~N}\left(\mathrm{CH}_{3}\right) \mathrm{CH}_{2} \mathrm{CH}_{2} \mathrm{OH}$ : kinetics and mechanism of reaction with $\mathrm{OH}$. Environmental Science \& Technology 40, 1862-1868.

De Silva, A.O., Mabury, S.A., 2004. Isolating isomers of perfluorocarboxylates in polar bears (Ursus maritimus) from two geographical locations. Environmental Science $\&$ Technology $38,6538-6545$.

De Silva, A.O., Muir, D.C.G., Mabury, S.A., 2009a. Distribution of perfluorocarboxylate isomers select samples from the North American Environment. Environmental Toxicology and Chemistry 28, 1801-1814.

De Silva, A.O., Benskin, J.P., Martin, L.J., Arsenault, G., Mccrindle, R., Riddell, N., Martin, J.W., Mabury, S.A., 2009b. Disposition of perfluorinated acid isomers in Sprague-Dawley rats; part 2: subchronic dose. Environmental Toxicology and Chemistry 28, 555-567.

Dietz, R., Bossi, R., Riget, F.F., Sonne, C., Born, E.W., 2008. Increasing perfluoroalkyl contaminants in East Greenland polar bears (Ursus maritimus): a new toxic threat to the Arctic bears. Environmental Science \& Technology 42, 2701-2707.

Dinglasan, M.J.A., Ye, Y., Edwards, E.A., Mabury, S.A., 2004. Fluorotelomer alcohol biodegradation yields poly- and perfluorinated acids. Environmental Science \& Technology 38, 2857-2864.

Dreyer, A., Ebinghaus, R., 2009. Polyfluorinated compounds in ambient air from shipand land-based measurements in Northern Germany. Atmospheric Environment 43, $1527-1535$. 
Dreyer, A., Matthias, V., Weinberg, I., Ebinghaus, R., 2010. Wet deposition of poly- and perfluorinated compounds in Northern Germany. Environmental Pollution 158, 1221-1227.

Ellis, D.A., Martin, J.W., De Silva, A.O., Mabury, S.A., Hurley, M.D., Andersen, M.P.S., Wallington, T.J., 2004. Atmospheric lifetime of fluorotelomer alcohols. Environmental Science \& Technology 37, 3816-3820.

Environment Canada, 2010. Active agreements: Environmental performance agreement ("agreement") respecting perfluorinated carboxylic acids (PFCAs) and their precursors in perfluorochemical products sold in Canada. http://ec.gc.ca/epeepa/default.asp?lang=En\&n=81AE80CE-1. Date accessed: Mar 9, 2012.

Fromme, H., Tittlemier, S.A., Volkel, W., Wilhelm, M., Twardella, D., 2009. Perfluorinated compounds - Exposure assessment for the general population in western countries. International Journal of Hygiene and Environmental Health 212, 239-270.

Gebbink, W.A., Hebert, C.E., Letcher, R.J., 2009. Perfluorinated carboxylates and sulfonates and precursor compounds in herring gull eggs from colonies spanning the Laurentian Great Lakes of North America. Environmental Science \& Technology 43, 7443-7449.

Gebbink, W.A., Letcher, R.J., Burgess, N.M., Champoux, L., Elliott, J.E., Hebert, C.E., Martin, P., Wayland, M., Chip Weseloh, D.V., Wilson, L., 2011. Perfluoroalkyl carboxylates and sulfonates and precursors in relation to dietary source tracers in the eggs of four species of gulls (Larids) from breeding sites spanning Atlantic to Pacific Canada. Environment International 37, 1175-1182.

Gebbink, W.A., Letcher, R.J., 2012. Comparative tissue and body compartment accumulation and maternal transfer to eggs of perfluoroalkyl sulfonates and carboxylates in Great Lakes herring gulls. Environmental Pollution 162, 40-47.

Genuis, S.J., Birkholz, D., Ralitsch, M., Thibault, N., 2010. Human detoxification of perfluorinated compounds. Public Health 124, 367-375.

Giesy, J.P., Kannan, K., 2001. Global distribution of perfluorooctane sulfonate in wildlife. Environmental Science \& Technology 35, 1339-1342.

Gittleman, 1986. Carnivore brain size, behavioral ecology, and phylogeny. Journal of Mammology 67, 23-36.

Hart, K., Gill, V.A., Kannan, K., 2009. Temporal trends (1992-2007) of perfluorinated chemicals in northern sea otters (Enhydra lutris kenyoni) from South-Central Alaska. Archieves of Environmental Contamination and Toxicology 56, 607-614. 
Hoff, P.T., Scheirs, J., Van de Vijver, K., Van Dongen, W., Esmans, E.L., Blust, R., De Coen, W., 2004. Biochemical effect evaluation of perfluorooctane sulfonic acidcontaminated wood mice (Apodemus sylvaticus). Environmental Health Perspectives 112, 681-686.

Holmstrom, K.E., Jarnberg, U., Bignert, A., 2005. Temporal trends of PFOS and PFOA in guillemot eggs from the Baltic Sea, 1968-2003. Environmental Science \& Technology $39,80-84$.

Houde, M., Martin, J.W., Letcher, R.J., Solomon, K.R., Muir, D.C.G., 2006a. Biological monitoring of perfluoroalkyl substances: a review. Environmental Science \& Technology 40, 3463-3473.

Houde, M., Balmer, B.C., Brandsma, S., Wells, R.S., Rowles, T.K., Solomon, K.R., Muir, D.C.G., 2006b. Perfluoroalkyl compounds in relation to life-history and reproductive parameters in bottlenose dolphins (Tursiops truncatus) from Sarasota Bay, Florida, USA. Environmental Toxicology and Chemistry 25, 2405-2412.

Houde, M., De Silva, A.O., Muir, D.C.G., Letcher, R.J., 2011. Monitoring of perfluorinated compounds in aquatic biota : an updated review of PFCs in aquatic biota. Environmental Science \& Technology 45, 7962-7973.

Hu, W.Y., Jones, P.D., Upham, B.L., Trosko, J.E., Lau, C., Giesy, J.P., 2002. Inhibition of gap junctional intercellular communication by perfluorinated compounds in rat liver and dolphin kidney epithelial cell lines in vitro and Sprague-Dawley rats in vivo. Toxicological Sciences 68, 429-436.

Johansson, N., Fredriksson, A., Eriksson, P., 2008. Neonatal exposure to perfluorooctane sulfonate (PFOS) and perfluorooctanoic acid (PFOA) causes neurobehavioural defects in adult mice. Neurotoxicology 29, 160-169.

Johansson, N., Eriksson, P., Viberg, H., 2009. Neonatal exposure to PFOS and PFOA in mice results in changes in proteins which are important neuronal growth and synaptogenesis in the developing brain. Toxicological Sciences 108, 412-418.

Jones, P.D., Hu, W.Y., De Coen, W., Newsted, J.L., Giesy, J.P., 2003. Binding of perfluorinated fatty acids to serum proteins. Environmental Toxicology and Chemistry 22, 2639-2649.

Kamiya, T., Pirlot, P., 1988. The brain of the Malayan bear (Helactaros-Malayanus). Zeitschrift fur Zoologische Systematik und Evolutionsforschung 26, 225-235.

Kannan, K., Koistinen, J., Beckman, K., Evans, T., Gorzelany, J.F., Hansen, K.J., Jones, P.D., Helle, E., Nyman, M., Giesy, J.P., 2001. Accumulation of perfluorooctane 
sulfonate in marine mammals. Environmental Science \& Technology 35, 15931598.

Kannan, K., Newsted, J., Halbrook, R.S., Giesy, J.P. 2002. Perfluorooctanesulfonate and related fluorinated hydrocarbons in mink and river otters from the United States. Environmental Science \& Technology 36, 2566-2571.

Kannan, K., Tao, L., Sinclair, E., Pastva, S.D., Jude, D.J., Giesy, J.P., 2005a. Perfluorinated compounds in aquatic organisms at various trophic levels in a Great Lakes food chain. Archieves of Environmental Contamination and Toxicology 48, $559-566$.

Kannan, K., Yun S.H., Evans, T.J., 2005b. Chlorinated, brominated, and perfluorinated contaminants in livers of polar bears from Alaska. Environmental Science \& Technology 39, 9057-9063.

Kannan, K., 2011. Perfluoroalkyl and polyfluoroalkyl substances: current and future perspectives. Environmental Chemistry 8, 333-338.

Kelly, B.C., Ikonomou, M.G., Blair, J.D., Surridge, B., Hoover, D., Grace, R., Gobas, F.A.P.C., 2009. Perfluoroalkyl contaminants in the Arctic marine food web: trophic magnification and wildlife exposure. Environmental Science \& Technology 43, 4037-4043.

Labadie, P., Chevreuil, M., 2011. Partitioning behaviour of perfluorinated alkyl contaminants between water, sediment and fish in the Urge River (nearby Paris, France). Environmental Pollution 159, 391-397.

Letcher, R.J., Gebbink, W.A., Sonne, C., Born, E.W., Mckinney, M.A., Dietz, R., 2009. Bioaccumulation and biotransformation of brominated and chlorinated contaminants and their metabolites in ringed seals (Pusa hispida) and polar bears (Ursus maritimus) from East Greenland. Environment International 35, 1118-1124.

Letcher, R.J., Bustnes, J.O., Dietz, R., Jenssen, B. M., Jorgensen, E.H., Sonne, C., Verreault, J., Vijayan, M.M., Gabrielsen, G.W., 2010. Exposure and effects assessment of persistent organohalogen contaminants in arctic wildlife and fish. Science of the Total Environment 408, 2995-3043.

Lindstrom, A.B., Strynar, M.J., Libelo, E.L., 2011. Perfluorinated compounds: past, present, and future. Environmental Science \& Technology 45, 7954-7961.

Liu, X.H., Liu, W., Jin, Y.H. Yu, W.G., Wang, F.Q., Liu, L., 2010. Effects of gestational and lactational exposure to perfluorooctanesulfonate on calcium-dependent signalling molecules gene expression in rats' hippocampus. Archives of Toxicology 84, 71-79. 
Loveless, S.E., Finlay, C., Everds, N.E., Frame, S.R., Gillies, P.J., O'Connor, J.C., Powley, C.R., Kennedy, G.L., 2006. Comparative responses from rats and mice exposed to linear/branched, linear, or branched ammonium perfluorooctanoate (APFO). Toxicology 220, 203-217.

Luebker, D.J., Hansen, K.J., Bass, N.M., Butenhoff, J.L., Seacat, A.M., 2002. Interactions of fluorochemicals with rat liver fatty acid-binding protein. Toxicology $176,175-185$.

Martin, J.W., Mabury, S.A., Solomon, K.R., Muir, D.C.G., 2003. Bioconcentration and tissue distribution of perfluorinated acids in rainbow trout (Oncorhynchus mykiss). Environmental Toxicology and Chemistry 22, 196-204.

Martin, J.W., Whittle, D.M., Muir, D.C.G., Mabury, S.A., 2004. Perfluoroalkyl contaminants in a food web from Lake Ontario. Environmental Science \& Technology $38,5379-5385$.

Martin, J.W., Ellis, D.A., Mabury, S.A., Hurley, M.D., Wallington, T.J., 2006. Atmospheric chemistry of perfluoroalkanesulfonamides: kinetic and product studies of the $\mathrm{OH}$ radical and $\mathrm{Cl}$ atom initiated oxidation of N-ethyl perfluorobutanesulfonamide. Environmental Science \& Technology 40, 864-872.

Martin, J.W., Asher, B.J., Beesoon, S., Benskin, J.P., Ross, M.S., 2010. PFOS or PreFOS? Are perfluorooctane sulfonate precursors (PreFOS) important determinants of human and environmental perfluorooctane sulfonate (PFOS) exposure? Journal of Environmental Monitoring 12, 1979-2004.

McKinney, M.A., Letcher, R.J., Aars, J., Born, E.W., Branigan, M., Dietz, R., Evans, T.J., Gabrielsen, G.W., Muir, D.C.G., Peacock, E., Sonne, C., 2011a. Regional contamination versus regional dietary differences: understanding geographic variation in bominated and chlorinated contaminant levels in polar bears. Environmental Science \& Technology 45, 896-902.

McKinney, M.A., Letcher, R.J., Aars, J., Born, E.W., Branigan, M., Dietz, R., Evans, T.J., Gabrielsen, G.W., Peacock, E., Sonne, C., 201lb. Flame retardants and legacy contaminants in polar bears from Alaska, Canada, East Greenland and Svalbard, 2005-2008. Environment International 37, 365-374.

Mitchell, R.W., Hatch, G.M., 2011. Fatty acid transport into the brain: of fatty acid fables and lipid tales. Prostaglandins Leukotrienes and Essential Fatty Acids 85, 293-302.

Mortensen, A.S., Letcher, R.J., Cangialosi, M.V., Chu, S.G., Arukwe, A., 2011. Tissue bioaccumulation patterns, xenobiotic transformation and steroid hormone levels in Atlantic salmon (Salmo salar) fed a diet containing perfluorooctane sulfonic or perfluorooctane carboxylic acids. Chemosphere 83, 1035-1044. 
O'Brien, J.M., Kennedy, S.W., Chu, S.G., Letcher, R.J., 2011. Isomer-specific accumulation of perfluorooctane sulfonate in the liver of chicken embryos exposed in ovo to a technical mixture. Environmental Toxicology and Chemistry 30, 226231.

Olivero-Verbel, J., Tao, L., Johnston-Restrepo, B., Guette-Fernandez, J., Baldiris-Avila, R., O'byrne-Hoyos, I., Kannan, K., 2006. Perfluorooctanesulfonate and related fluorochemicals in biological samples from the north coast of Colombia. Environmental Pollution 142, 367-372.

Olsen, G.W., Huang, H.Y., Helzlsouer, K.J., Hansen, K.J., Butenhoff, J.L., Mandel, J.H., 2005. Historical comparison of perfluorooctanesulfonate, perfluorooctanaote, and other fluorochemicals in the blood. Environmental Health Perspectives 113, 539545 .

Onishchenko, N., Fischer, C., Ibrahim, W.N.W., Negri, S., Spulber, S., Cottica, D., Ceccatelli, S., 2011. Prenatal exposure to PFOS and PFOA alters motor function in mice in a sex-related manner. Neurotoxicity Research 19, 452-461.

Paul, A.G., Jones, K.C., Sweetman, A.J., 2009. A first global production, emission, and environmental inventory for perfluorooctane sulfonate. Environmental Science \& Technology 43, 386-392.

Powley, C.R., George, S.W., Russell, M.H., Hoke, R.A., Buck, R.C., 2008. Perfluorinated chemicals in spatially and temporally integrated food webs in the Western Arctic. Chemosphere 70, 664-672.

Rayne, S., Forest, K., 2009a. Perfluoroalkyl sulfonic and carboxylic acids: a critical review of physicochemical properties, levels and patterns in waters and wastewaters, and treatment methods. Journal of Environmental Science and Health Part A - Toxic/Hazardous Substances \& Environmental Engineering 44, 11451199.

Rayne, S., Forest, K., Friesen, K.J., 2009b. Estimated bioconcentration factors (BCFs) for the $\mathrm{C} 4$ through $\mathrm{C} 8$ perfluorinated alkylsulfonic acid (PFSA) and alkylcarboxylic acid (PFCA) congeners. Journal of Environmental Science and Health Part A Toxic/Hazardous Substances \& Environmental Engineering 44, 598-604.

Reagen, W.K., Lindstrom, K.R., Jacoby, C.B., Purcell, R.G., Kestner, T.A., Payfer, R.M., Miller, J.W., 2007. Environmental characterization of $3 \mathrm{M}$ electrochemical fluorination derived perfluorooctanoate and perfluorooctane sulfonate. Society of Environmental Toxicology and Chemistry 28th North American Meeting, Milwaukee,WI, USA, November 11-15. Abstract.

Remde, A., Debus, R., 1996. Biodegradability of fluorinated surfactants under aerobic and anaerobic conditions. Chemosphere 32, 1563-1574. 
Rosing-Asvid, A., Born, E.W., Kingsley, M.C.S., 2002. Age at sexual maturity of males and timing of the mating season of polar bears (Ursus maritimus) in Greenland. Polar Biology 25, 878-883.

Rubarth, J., Dreyer, A., Guse, N., Einax, J.W., Ebinghaus, R., 2011. Perfluorinated compounds in red-throated divers from the German Baltic Sea: new findings from their distribution in 10 different tissues. Environmental Chemistry 8, 419-428.

Sato, I., Kawamoto, K., Nishikawa, Y., Tsuda, S., Yoshida, M., Yaegahi, K., Saito, N., Liu, W., Jin, Y.H., 2009. Neurotoxicity of perfluorooctane sulfonate (PFOS) in rats and mice after single oral exposure. Journal of Toxicological Sciences 34, 569-574.

Seacat, A.M., Thomford, P.J., Hansen, K.J., Olsen, G.W., Case, M.T., Butenhoff, J.L., 2002. Subchronic toxicity studies on perfluorooctanesulfonate potassium salt in cynomolgus monkeys. Toxicological Sciences 68, 249-264.

Seacat, A.M., Thomford, P.J., Hansen, K.J., Clemen, L.A., Eldridge, S.R., Elcombe, C.R., Butenhoff, J.L., 2003. Sub-chronic dietary toxicity of potassium perfluorooctanesulfonate in rats. Toxicology 183, 117-131.

Sherman, P.O., Smith, S., 1971. Block and graft copolymers containing water-solvatable polar groups and fluoroaliphatic groups. United States Patent 3,574,791.

Shoeib, M., Harner, T., Vlahos, P., 2006. Perfluorinated chemicals in the Arctic atmosphere. Environmental Science \& Technology 40, 7577-7583.

Slotkin, T.A., MacKillop, E.A., Melnick, R.L., Thayer, K.A., Seidler, F.J., 2008. Developmental neurotoxicity of perfluorinated chemicals modelled in vitro. Environmental Health Perspectives 116, 716-722.

Smithwick, M., Muir, D.C.G., Mabury, S.A., Solomon, K.R., Martin, J.W., Sonne, C., Born, E.W., Letcher, R.J., Dietz, R., 2005a. Perfluoroalkyl contaminants in liver tissue from East Greenland polar bears (Ursus maritimus). Environmental Toxicology and Chemistry 24, 981-986.

Smithwick, M., Mabury, S.A., Solomon, K.R., Sonne, C., Martin, J.W., Born, E.W., Dietz, R., Derocher, A.E., Letcher, R.J., Evans, T.J., Gabrielsen, G.W., Nagy, J., Stirling, I., Taylor, M.K., 2005b. Circumpolar study of perfluoroalkyl contaminants in polar bears (Ursus maritimus). Environmental Science \& Technology 39, 55175523.

Smithwick, M., Norstrom, R.J., Mabury, S.A., Solomon, K., Evans, T.J., Stirling, I., Taylor, M.K., Muir, D.C.G., 2006. Temporal trends of perfluoroalkyl contaminants in polar bears (Ursus maritimus) from two locations in the North American Arctic, 1972-2002. Environmental Science \& Technology 40, 1139-1143. 
Stock, N.L., Furdui, V.I., Muir, D.C.G., Mabury, S.A., 2007. Perfluoroalkyl contaminants in the Canadian Arctic: evidence of atmospheric transport and local contamination. Environmental Science \& Technology 41, 3529-3536.

Sturm, R., Ahrens, L., 2010. Trends of polyfluoroalkyl compounds in marine biota and in humans. Environmental Chemistry 7, 457-484.

Taniyasu, S., Kannan, K., Horii, Y., Hanari, N., Yamashita, N., 2003. A survey of perfluorooctane sulfonate and related perfluorinated organic compounds in water, fish, birds, and humans from Japan. Environmental Science \& Technology 37, 2634-2639.

Taniyasu, S., Kannan, K., So, M.K., Gulkowska, A., Sinclair, E., Okazawa, T., Yamashita, N., 2005. Analysis of fluorotelomer alcohols, fluorotelomer acids, and short- and long-chain perfluorinated acids in water and biota. Journal of Chromatography A 1093, 89-97.

Tomy, G.T., Budakowski, W., Halldorson, T., Helm, P.A., Stern, G.A., Friesen, K., Pepper, K., Tittlemier, S.A., Fisk, A.T., 2004. Fluorinated organic compounds in the Arctic marine food web. Environmental Science \& Technology 38, 6475-6481.

U.S. Environmental Protection Agency (USEPA), 2011. Long-chain perfluorinated chemicals (PFCs) action plan summary. http://www.epa.gov/oppt/existingchemicals/pubs/actionplans/pfcs.html. Date accessed: Mar 9, 2012.

U.S. Environmental Protection Agency (USEPA), 2012. 2010/2015 PFOA Stewardship Program. http://www.epa.gov/oppt/pfoa/pubs/stewardship/index.html, Date accessed: Mar 9, 2012.

Van de Vijver, K.I., Hoff, P., Das, K., Brasseur, S., Van Dongen, W., Esmens, E., Reijnders, P., Blust, R., De Coen, W., 2005. Tissue distribution of perfluorinated chemicals in harbor seals (Phoca vitulina) from the Dutch Wadden Sea. Environmental Science \& Technology 39, 6978-6984.

Van de Vijver, K.I., Holsbeek, L., Das, K., Blust, R., Joiris, C., De Coen, W., 2007. Occurrence of perfluorooctane sulfonate and other perfluorinated alkylated substances in harbor porpoises from the Black Sea. Environmental Science \& Technology 41, 315-320.

Verreault, J., Houde, M., Gabrielsen, G.W., Berger, U., Haukas, M., Letcher, R.J., Muir, D.C.G., 2005. Perfluorinated alkyl substances in plasma, liver, brain, and eggs of glaucous gulls (Larus hyperboreus) from the Norwegian Arctic. Environmental Science \& Technology 39, 7439-7445. 
Verreault, J., Dietz, R., Sonne, C., Gebbink, W.A., Shahmiri, S., Letcher, R.J., 2008. Comparative fate of organohalogen contaminants in two top carnivores in Greenland: captive sledge dogs and wild polar bears. Comparative Biochemistry and Physiology C-Toxicology \& Pharmacology 147, 306-315.

Volkel, W., Genzel-Boroviczeny, O., Demmelmair, H., Gebauer, C., Koletzko, B., Twardella, D., Raab, U., Fromme, H., 2008. Perfluorooctane sulfonate (PFOS) and perfluorooctanoic acid (PFOA) in human breast milk: results of a pilot study. International Journal of Hygiene and Environmental Health 211, 440-446.

Vongphachan, V., Cassone, C.G., Wu, D.M., Chiu, S.Z., Crump, D., Kennedy, S.W., 2011. Effects of perfluoroalkyl compounds on mRNA expression levels of thyroid hormone-responsive genes in primary cultures of avian neuronal cells. Toxicological Sciences 120, 392-402.

Wang, F.Q., Liu, W., Jin, Y.H., Dai, J.Y., Yu, W.G., Liu, X.H., Liu, L., 2010. Transcriptional effets of prenatal and neonatal exposure to PFOS in developing rat brain. Environmental Science \& Technology 44, 1847-1853.

Wania, F., 2007. A global mass balance analysis of the source of perfluorocarboxylic acids in the Arctic ocean. Environmental Science \& Technology 41, 4529-4535.

Woodcroft, M.W., Ellis, D.A., Rafferty, S.P., Burns, D.C., March, R.E., Stock, N.L., Trumpour, K.S., Yee, J., Munro, K., 2010. Experimental characterization of the mechanism of perfluorocarboxylic acids' liver protein bioaccumulation: the key role of the neutral species. Environmental Toxicology and Chemistry 29, 16691677.

Yu, W.G., Liu, W., Liu, L., Jin, Y.H., 2011. Perfluorooctane sulfonate increased hepatic expression of OAPT2 and MRP2 in rats. Archives of Toxicology 85, 613-621.

Zeng, H.C., Zhang, L., Li, Y.Y., Wang, Y.J., Xia, W., Lin, Y., Wei, J., Xu, S.Q., 2011. Inflammation-like glial response in rat brain induced by prenatal PFOS exposure. Neurotoxicology 32, 130-139.

Zhang, L., Li, Y.Y., Chen, T., Xia, W., Zhou, Y., Wan, Y.J., Lv, Z.Q., Li, G.Q., Xu, S.Q., 2011. Abnormal development of motor neurons in perfluorooctane sulfonate exposed zebrafish embryos. Ecotoxicology 20, 643-652.

Zhang, X., Chen, L., Fei, X.C., Ma, Y.S., Gao, H.W., 2009. Binding of PFOS to serum albumin and DNA: insight into the molecular toxicity of perfluorochemicals. BMC Molecular Biology 10:16. 


\section{CHAPTER 2 \\ Materials and Methods}

\subsection{Polar Bears and Tissue Sampling}

Located on the eastern coast of Greenland, Ittoqqortoormiit (Scoresby Sound) is a branching inlet system to the Greenland Sea, with a main body of water approximately $110 \mathrm{~km}$ long, and some branches extending more than $290 \mathrm{~km}$ (Figure 2.1). The region is known for its diverse fauna due to the availability of open water and relatively fertile grounds. This biodiversity hotspot is home to many species including the polar bear, ringed seal, bearded seal, harbour seal, walrus, narwhal, and beluga whale. As a result of the fauna diversity, polar bears, the apex predator of the Arctic marine ecosystem, are present in large numbers.

All samples (Table 2.1) were collected from polar bears harvested from the region of Scoresby Sound, Greenland $\left(69^{\circ}-74^{\circ} \mathrm{N}, 20^{\circ}-25^{\circ} \mathrm{W}\right)$. Under the Marine Mammal Protection Act (1972), the polar bear is a protected species and proper licenses and permits were obtained prior to sample collection. All samples from Scoresby Sound were collected from bears harvested between January and March 2006 during the Inuit subsistence hunt. In total, samples were collected from 20 bears ( 14 males, 6 females). Ages were determined by counting the annual growth layer in the cementum of the $I_{3}$ tooth after decalcification, thin layer sectioning $(14 \mu \mathrm{m})$, and staining with toluidine blue, as previously described (Dietz et al., 2004). Males ranged from 3 to 19 years, and females ranged from 4 to 15 years (Table 2.1). For certain statistical purposes, it was necessary to classify bears as adult females ( $\geq 5$ years), adult males ( $\geq 6$ years), or subadults. 


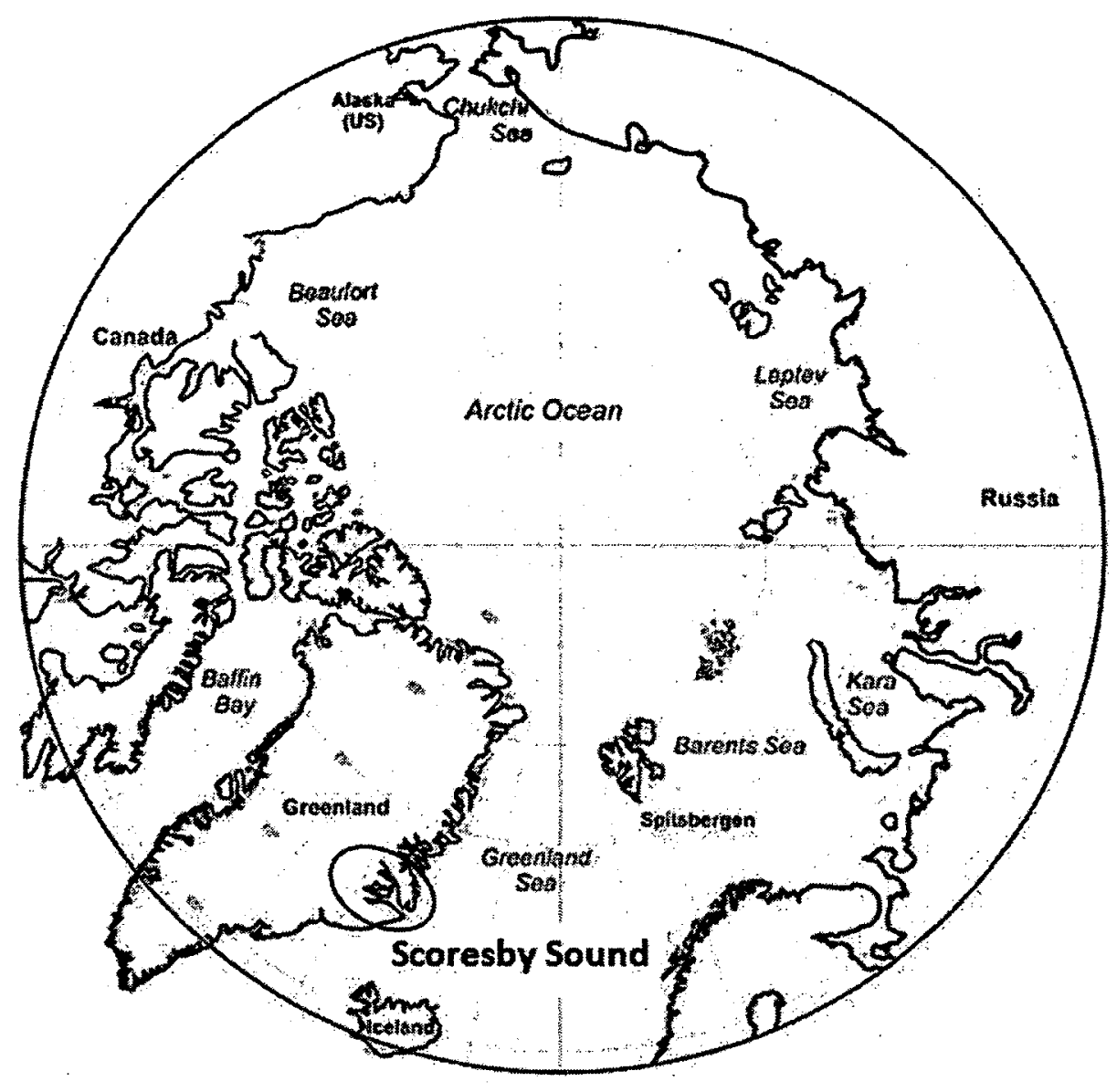

Figure 2.1 Polar bear sampling site for this study: Scoresby Sound, Eastern Greenland. Figure modified from Piquet et al., 2010.

The tissues examined in this study were chosen to expand upon the findings of previous studies. The liver has been repeatedly shown to be a large repository for PFCs in the body, including in polar bears (Letcher et al., 2010; Houde et al., 2011). Numerous studies have also identified PFCs in the blood of wildlife and humans (Butt et al., 2010; Sturm and Ahrens, 2010; Haug et al., 2011). As a result, both the liver and whole blood were of interest to this study.

It has been shown that PFC concentrations in adipose tissue were very low in mammals such as harbour seals and harbour porpoises (Van de Vijver et al., 2005, 2007; 
Ahrens et al., 2009). However, adipose tissue is extremely important to polar bears, as it is their sole source of energy for the long hibernation months of winter (Dyck and Kebreab, 2009). Similarly, PFC concentrations have been shown to be low in muscle tissue of marine mammals (Van de Vijver et al., 2005, 2007; Ahrens et al., 2009), although this has not been investigated in polar bears. It was therefore deemed important to investigate concentrations in the both the adipose muscle tissues.

Only a few studies to date have examined the concentrations of PFCs in the brain, and no study has examined the intra-brain distribution of PFCs (Verreault et al., 2005a; Ahrens et al., 2009; Rubarth et al., 2011, Gebbink and Letcher, 2012). PFCs have been shown to accumulate in the brain, as well as cause neurotoxicity and substantial alterations in gene expression (Johansson et al., 2009; Liu et al., 2010; Wang et al., 2010; Zeng et al., 2011; Zhang et al., 2011). Therefore, brain samples were collected from multiple brain regions.

In total, the tissues collected included liver $(n=19)$, whole blood $(n=19)$, muscle $(n=20)$, adipose $(n=20)$, and brain $(8$ regions; $n=115)$. Of the 115 samples of the brain, samples consisted of eight distinct brain regions: pons/medulla $(n=14)$, cerebellum $(n=15)$, frontal cortex $(n=16)$, occipital cortex $(n=17)$, temporal cortex (n $=15)$, striatum $(n=11)$, thalamus $(n=8)$, and hypothalamus $(n=4)$. The remaining 15 samples consisted of brain tissue left over from dissection. These samples were only included in statistical analyses when examining whole brain trends. A complete list of all tissues sampled can be found in Table 2.1.

All samples were collected on-site less than 1 hour post-mortem. The tissues were stored in polyethylene bags, while whole blood samples were stored in Vacutainers. 
Both the polyethylene bags and Vacutainers had been tested for PFCs with none being detectable at the method limits of quantification (Tables 2.2, 2.3). All samples were stored between $-5^{\circ} \mathrm{C}$ and $-20^{\circ} \mathrm{C}$ until their arrival at the Department of Biosciences, Aarhus University, Denmark. There they were processed and a portion was shipped to the Letcher/Organic Contaminants Research Laboratory (OCRL) at the National Wildlife Research Centre (NWRC), Carleton University, Canada. Located at the NWRC is Environment Canada's National Specimen Bank, where the polar bear samples were archived and stored at $-40^{\circ} \mathrm{C}$. 
Table 2.1 Complete sampling list of all polar bear tissues collected from Scoresby Sound, Greenland, from January to March 2006.

\begin{tabular}{|c|c|c|c|c|c|c|c|c|c|c|c|c|c|c|c|c|c|}
\hline \multirow{3}{*}{$\begin{array}{l}\text { Bear } \\
\text { ID }\end{array}$} & \multirow{3}{*}{ Sex } & \multirow{3}{*}{$\underset{\text { (Vears) }}{\text { Age }}$} & \multirow{3}{*}{$\begin{array}{c}\text { Collection } \\
\text { Date } \\
\text { (yyyy-nmm-dd) }\end{array}$} & \multirow{3}{*}{$\begin{array}{c}\text { Brain } \\
\text { Mass } \\
\text { (g) }\end{array}$} & \multicolumn{13}{|c|}{ Tissues Collected } \\
\hline & & & & & \multirow[b]{2}{*}{ Liver } & \multirow[b]{2}{*}{ Blood } & \multirow[b]{2}{*}{ Muscle } & \multirow[b]{2}{*}{ Adipose } & \multicolumn{9}{|c|}{ Brain } \\
\hline & & & & & & & & & $\begin{array}{l}\text { Pons/ } \\
\text { Medulla }\end{array}$ & Cerebellum & $\begin{array}{l}\text { Frontal } \\
\text { Cortex }\end{array}$ & $\begin{array}{l}\text { Occipital } \\
\text { Corlex }\end{array}$ & $\begin{array}{l}\text { Temporal } \\
\text { Cortex }\end{array}$ & Striatum & Thalamus & Hypothalamus & Remains \\
\hline 1 & $\mathbf{M}$ & 6 & $2006 / 02 / 11$ & 460 & $\bullet$ & $\bullet$ & $\bullet$ & $\bullet$ & $\bullet$ & $\bullet$ & $\bullet$ & $\bullet$ & $\bullet$ & $\bullet$ & $\bullet$ & $\bullet$ & $\bullet$ \\
\hline 2 & $\mathbf{M}$ & 3 & $2006 / 01 / 30$ & 364 & $\bullet$ & $\bullet$ & $\bullet$ & $\bullet$ & - & $\bullet$ & $\bullet$ & $\bullet$ & $\bullet$ & $\bullet$ & & & $\cdot$ \\
\hline 3 & $\mathbf{M}$ & 12 & $2006 / 02 / 01$ & 473 & $\bullet$ & $\bullet$ & - & $\bullet$ & - & $\bullet$ & $\bullet$ & $\bullet$ & $\bullet$ & $\bullet$ & $\bullet$ & $\bullet$ & - \\
\hline 4 & $M$ & 9 & $2006 / 02 / 27$ & 375 & $\bullet$ & $\bullet$ & $\bullet$ & $\bullet$ & $\bullet$ & $\bullet$ & $\bullet$ & $\bullet$ & $\bullet$ & $\bullet$ & & & $\bullet$ \\
\hline 5 & $\mathbf{M}$ & 8 & $2006 / 01 / 07$ & 484 & $\bullet$ & $\bullet$ & $\bullet$ & $\bullet$ & $\bullet$ & - & $\bullet$ & $\bullet$ & $\bullet$ & $\bullet$ & $\bullet$ & $\bullet$ & \\
\hline 6 & $\mathbf{F}$ & 5 & $2006 / 03 / 14$ & 333 & $\bullet$ & $\bullet$ & $\bullet$ & $\bullet$ & & $\bullet$ & $\bullet$ & $\bullet$ & $\bullet$ & & & & $\bullet$ \\
\hline 7 & $\mathbf{M}$ & 17 & $\mathrm{~N} / \mathrm{A}$ & 470 & $\bullet$ & $\bullet$ & $\bullet$ & $\bullet$ & $\bullet$ & - & $\bullet$ & $\bullet$ & $\bullet$ & - & $\bullet$ & & \\
\hline 8 & $F$ & 7 & $2006 / 02 / 21$ & $\mathrm{~N} / \mathrm{A}$ & $\cdot$ & $\bullet$ & $\bullet$ & $\bullet$ & & & & & & & & & $\bullet$ \\
\hline 9 & $\mathrm{M}$ & 4 & $2006 / 02 / 28$ & $\mathrm{~N} / \mathrm{A}$ & $\bullet$ & $\bullet$ & $\bullet$ & $\bullet$ & & & & & & & & & \\
\hline 10 & $\mathrm{~F}$ & 12 & $2006 / 02 / 08$ & 448 & & $\bullet$ & $\cdot$ & $\bullet$ & $\bullet$ & $\bullet$ & $\bullet$ & $\bullet$ & $\bullet$ & $\bullet$ & $\bullet$ & & $\bullet$ \\
\hline 11 & $\mathbf{M}$ & 4 & $2006 / 02 / 20$ & 442 & $\bullet$ & $\bullet$ & $\bullet$ & $\bullet$ & $\bullet$ & $\bullet$ & $\bullet$ & $\bullet$ & $\bullet$ & & & & $\bullet$ \\
\hline 12 & $\mathbf{M}$ & 4 & $2006 / 01 / 24$ & 428 & $\bullet$ & $\bullet$ & $\bullet$ & $\bullet$ & $\bullet$ & $\bullet$ & $\bullet$ & $\bullet$ & $\bullet$ & $\cdot$ & $\bullet$ & & $\bullet$ \\
\hline 13 & $\mathbf{F}$ & 15 & $2006 / 02 / 22$ & 336 & $\bullet$ & $\bullet$ & $\bullet$ & $\bullet$ & - & $\bullet$ & $\bullet$ & $\bullet$ & $\bullet$ & $\cdot$ & & $\bullet$ & $\bullet$ \\
\hline 14 & $M$ & 4 & $2006 / 02 / 23$ & 279 & $\bullet$ & $\bullet$ & $\bullet$ & $\bullet$ & - & - & & & & & & & $\cdot$ \\
\hline 15 & $\mathbf{M}$ & 13 & $2006 / 02 / 08$ & $46 \dot{3}$ & $\bullet$ & $\bullet$ & $\bullet$ & $\bullet$ & $\bullet$ & $\bullet$ & $\bullet$ & $\bullet$ & $\bullet$ & $\bullet$ & - & & $\cdot$ \\
\hline 16 & $F$ & 4 & $2006 / 03 / 16$ & 407 & $\bullet$ & $\cdot$ & $\bullet$ & $\bullet$ & $\bullet$ & $\bullet$ & $\bullet$ & - & $\bullet$ & $\bullet$ & $\cdot$ & & $\bullet$ \\
\hline 17 & $\mathrm{M}$ & 6 & $2006 / 02 / 23$ & N/A & $\bullet$ & $\bullet$ & $\bullet$ & $\bullet$ & & & $\bullet$ & $\bullet$ & $\bullet$ & & & & \\
\hline 18 & $\mathrm{~F}$ & 8 & $2006 / 01 / 29$ & 365 & $\bullet$ & & $\bullet$ & $\bullet$ & $\bullet$ & - & $\bullet$ & $\bullet$ & $\bullet$ & & & & $\bullet$ \\
\hline 19 & $\mathbf{M}$ & 19 & $2006 / 03 / 01$ & N/A. & $\bullet$ & $\bullet$ & $\bullet$ & $\bullet$ & & & $\bullet$ & $\bullet$ & & & & & \\
\hline 20 & $\mathrm{M}$ & 4 & $2006 / 02 / 22$ & 146 & $\bullet$ & $\bullet$ & $\bullet$ & $\bullet$ & & & & $\bullet$ & & & & & \\
\hline
\end{tabular}

N/A : Not Available 


\subsection{Chemicals and Standards}

Target compounds were obtained from Wellington Laboratories (Guelph, ON, Canada). Target compounds included perfluoroalkyl sulfonates $\left(\mathrm{C}_{4}, \mathrm{C}_{6}, \mathrm{C}_{8}, \mathrm{C}_{10}\right)$, perfluoroalkyl carboxylates $\left(\mathrm{C}_{6}-\mathrm{C}_{15}\right)$, and precursor compounds including perfluorosulfonamides (PFOSA, $N$-Me-PFOSA), fluorotelomer alcohols $(6: 2,8: 2,10: 2$ FTOHs), and fluorotelomer unsaturated acids (6:2, 8:2, 10:2 FTUCAs). Labelled standards were added to all samples as internal standards. Labelled standards consisted of ${ }^{13} \mathrm{C}$-PFCAs $\left(\mathrm{C}_{6}, \mathrm{C}_{8}-\mathrm{C}_{12}\right),{ }^{18} \mathrm{O}-\mathrm{PFHxS},{ }^{13} \mathrm{C}$-PFOS, ${ }^{13} \mathrm{C}$-PFOSA, ${ }^{13} \mathrm{C}-\mathrm{N}$-Me-FOSA ${ }^{13} \mathrm{C}$ FTOHs $(6: 2,8: 2,10: 2)$, and ${ }^{13}$ C-FTUCAs $(6: 2,8: 2,10: 2)$ (Wellington Laboratories, Guelph, ON, Canada). A full list of target compounds and internal standards can be found in Tables 2.2 and 2.3 .

Chemicals used for extraction were all analytical grade or higher, including formic acid "(98-100\%) from Sigma-Aldrich (Oakville, ON, Canada); ammonium hydroxide $(28-30 \%$ w/v) from EMD (Mississauga, ON, Canada); ammonium acetate from Fisher Scientific (Ottawa, Canada); and acetonitrile from Caledon Laboratories (Georgetown, ON, Canada). All solvents used were HPLC grade, including methanol obtained from Caledon Laboratories (Georgetown, ON, Canada) and Milli-Q water, treated on-site.

\subsection{PFC Extraction and Clean-up}

The extraction and clean-up procedure for the various tissues has been described in detail in Chu and Letcher (2008) and also in Gebbink and Letcher (2012). Between 0.1 $\mathrm{g}$ (liver samples) and $1.0 \mathrm{~g}$ (brain, muscle, fat, blood) of tissue was spiked with $10 \mathrm{ng}$ of 
labelled internal standard (see Tables 2.2 and 2.3). All tissue samples were subsequently homogenized for 1 minute in $3 \mathrm{~mL}$ of a $10 \mathrm{mM}$ potassium hydroxide solution $(80 / 20 \mathrm{v} / \mathrm{v}$ acetonitrile/water) to extract the PFCs. After centrifugation, the supernatant was collected into a pre-weighed glass tube. The pellet was homogenized another two times in the same manner and the total weight of all supernatant collected in the glass tube was recorded. Subsequently, a portion of the supernatant was cleaned by solid-phase extraction using an Oasis weak anion exchange (WAX) cartridge. The PFCs were eluted in two fractions: the first fraction was eluted with $1 \mathrm{~mL}$ of HPLC grade methanol and contained all neutral PFCs including FTOHs, PFOSA, and $N$-Me-PFOSA. The second fraction was eluted with $2 \mathrm{~mL}$ of $1 \%$ ammonium hydroxide in methanol and contained all acidic PFCs including PFCAs, PFSAs, and FTUCAs. Approximately $20 \mathrm{mg}$ of active carbon was added to the first fraction. After mixing and letting stand for at least 5 minutes, the solution was filtered using a centrifugal filter. The second fraction was evaporated to dryness under a stream of nitrogen, reconstituted with $200 \mu \mathrm{L}$ of HPLC grade methanol, and filtered using a centrifugal filter. These fractions were transferred to glass HPLC vials and were stored at $4^{\circ} \mathrm{C}$ until analysis by HPLC-MS/MS.

\subsection{Quantification of PFCs}

\subsubsection{Instrumentation for PFC Analysis}

The first fraction containing all neutral PFCs was analysed using HPLC-APPIMS/MS in negative ion mode with a krypton UV lamp. Analysis was done using a Waters 2695 high performance liquid chromatograph (HPLC) coupled with a WatersMicromass, Quatro Ultima triple quadrupole, with an atmospheric pressure 
photoionization (APPI(-)) source. The column used was an $A C E C_{18}(50 \mathrm{~mm} \mathrm{~L} \times 2.11$ mm i.d., $3 \mu \mathrm{m}$ particle size), with an $A C E C_{18}$ guard column (10 mm L x $2.1 \mathrm{~mm}$ i.d., 3 $\mu \mathrm{m}$ particle size), both from Canadian Life Science (Peterborough, ON, Canada). The column temperature was kept at $40^{\circ} \mathrm{C}$ while the sample temperature was kept at $22^{\circ} \mathrm{C}$. The injection volume was $20 \mu \mathrm{L}$. The source and probe temperatures were kept at $150^{\circ} \mathrm{C}$ and $250^{\circ} \mathrm{C}$, respectively. The cone gas flow was set to $100 \mathrm{~L} / \mathrm{hr}$, and the desolvation gas flow was set to $700 \mathrm{~L} / \mathrm{hr}$. The mobile phase gradient was composed of (A) HPLC grade methanol and (B) Milli-Q water, with a flow rate of $0.2 \mathrm{~mL} / \mathrm{min}$. The initial mobile phase was $5 / 95 \mathrm{~A} / \mathrm{B}(\%)$, and increased all the way to $100 / 0 \mathrm{~A} / \mathrm{B}$ by minute 10 . The $100 / 0 \mathrm{~A} / \mathrm{B}$ was held until minute 20 , where it linearly dropped back to $5 / 95 \mathrm{~A} / \mathrm{B}$ by minute 21 , and was held there until the run finished at minute 35 . HPLC grade toluene was added to the mobile phase as a dopant with a flow rate of $5 \mu \mathrm{L} / \mathrm{min}$.

The second fraction containing all acidic PFCs was analyzed using HPLC-ESIMS/MS in negative ion mode. Similar to the first fraction, analysis was done using a Waters 2695 HPLC coupled with a Waters-Micromass, Quattro Ultima triple quadrupole, with an electrospray ionization $(\operatorname{ESI}(-))$ source. The column used was the same as for the first fraction. The column temperature was kept at $40^{\circ} \mathrm{C}$ while the sample temperature was kept at $22^{\circ} \mathrm{C}$. The injection volume was $10 \mu \mathrm{L}$. The source and desolvation temperatures were kept at $120^{\circ} \mathrm{C}$ and $350^{\circ} \mathrm{C}$, respectively. The cone gas flow was set to $100 \mathrm{~L} / \mathrm{hr}$, and the desolvation gas flow was set to $600 \mathrm{~L} / \mathrm{hr}$. The mobile phase gradient was composed of (A) $2 \mathrm{mM}$ ammonium acetate in HPLC grade methanol and (B) $2 \mathrm{mM}$ ammonium acetate in Milli-Q water. The mobile phases were filtered through a Millipore Fluoropore $0.45 \mu \mathrm{m}$ membrane filter before use. The initial mobile phase was $5 / 95 \mathrm{~A} / \mathrm{B}$ 
(\%), and increased to $80 / 20 \mathrm{~A} / \mathrm{B}$ by minute 10 . It was then increased to $100 / 0 \mathrm{~A} / \mathrm{B}$ by minute 20 , and stayed at $100 / 0 \mathrm{~A} / \mathrm{B}$ until minute 25 , where it decreased back to $5 / 95 \mathrm{~A} / \mathrm{B}$ by minute 26 , and stayed there until the end of the run at minute 40 . Between each sample, a solvent blank (methanol) was run to ensure the optimum cleanliness of the column.

\subsubsection{Monitored Ion Transitions}

To accurately identify compounds, PFCs were ionized by ESI(-) or APPI(-), followed by ion mass analysis by multiple reaction monitoring (MRM) scanning. MRM ions were chosen based on the characteristic fragmentation patterns of each compound. For example, all MRM transitions for the PFSAs monitor from the $\mathrm{M}^{-}$ion (parent ion) to the $\mathrm{SO}_{3}{ }^{-}$ion (daughter ion). All MRM transitions for the PFCAs monitor the $\mathrm{M}^{-}$ion (parent ion) to the $\mathrm{M}-\mathrm{CO}_{2}$ ion (daughter ion). A full list of parent and daughter ions for each compound analyzed is shown below in Tables 2.2 and 2.3. Compounds are divided according to their fraction (neutral compounds vs. acidic compounds). An example of all ion transition chromatograms can be found in Appendix I. 
Table 2.2 List of monitored ion transitions and retention times for all compounds analyzed by HPLC-APPI(-)-MS/MS.

\begin{tabular}{|c|c|c|c|c|c|c|}
\hline Compound & Name & Chemical Formula & $\begin{array}{c}\text { Retention } \\
\text { Time } \\
\text { (min) } \\
\end{array}$ & $\begin{array}{c}\text { Parent } \\
\text { Ion } \\
\text { (Da) } \\
\end{array}$ & $\begin{array}{c}\text { Daughter } \\
\text { Ion } \\
\text { (Da) } \\
\end{array}$ & $\begin{array}{c}\text { MLOQ }^{\mathrm{a}} \\
\text { (ng/g ww) }\end{array}$ \\
\hline \multicolumn{7}{|c|}{ Perfluorosulfonamides (FOSAs) } \\
\hline PFOSA & $\begin{array}{l}\text { Perfluorooctane } \\
\text { sulfonamide }\end{array}$ & $\mathrm{CF}_{3}\left(\mathrm{CF}_{2}\right)_{7} \mathrm{SO}_{2} \mathrm{NH}_{2}$ & 13.72 & 497.7 & 78.1 & 0.7 \\
\hline${ }^{13} C_{8}-$ PFOSA & $\begin{array}{l}\text { M-perfluorooctane } \\
\text { sulfonamdide }\end{array}$ & ${ }^{13} \mathrm{CF}_{3}\left({ }^{13} \mathrm{CF}_{2}\right)_{7} \mathrm{SO}_{2} \mathrm{NH}_{2}$ & 13.72 & 505.9 & 78.0 & - \\
\hline N-Me-PFOSA & $\begin{array}{l}\text { N-Methyl- } \\
\text { perfluorooctane } \\
\text { sulfonamide }\end{array}$ & $\mathrm{CF}_{3}\left(\mathrm{CF}_{2}\right)_{h} \mathrm{SO}_{2} \mathrm{NHCH}_{3}$ & 14.14 & 511.8 & 168.9 & 0.6 \\
\hline$d_{3}$-N-Me-PFOSA & $\begin{array}{l}\text { M-N-Methyl- } \\
\text { perfluorooctane } \\
\text { sulfonamide }\end{array}$ & $\mathrm{CF}_{3}\left(\mathrm{CF}_{2}\right)_{7} \mathrm{SO}_{2} \mathrm{NHCD}_{3}$ & 14.14 & 514.8 & 168.9 & - \\
\hline \multicolumn{7}{|c|}{ Fluorotelomer Alcohols (FTOHs) } \\
\hline 6:2 FTOH & $\begin{array}{l}1 \mathrm{H}, 1 \mathrm{H}, 2 \mathrm{H}, 2 \mathrm{H}- \\
\text { perfluorooctanol }\end{array}$ & $\mathrm{CF}_{3}\left(\mathrm{CF}_{2}\right)_{5}\left(\mathrm{CH}_{2}\right)_{2} \mathrm{OH}$ & 13.38 & 362.9 & 302.9 & 0.8 \\
\hline $\mathrm{d}_{2} z^{13} \mathrm{C}_{2}-6: 2$ FTOH & $\begin{array}{l}\text { M-1H,1H,2H,2H- } \\
\text { perfluorooctanol }\end{array}$ & $\mathrm{CF}_{3}\left(\mathrm{CF}_{2}\right)_{5}{ }^{13} \mathrm{CH}_{2}{ }^{13} \mathrm{CD}_{2} \mathrm{OH}$ & 13.38 & 366.9 & 305.9 & - \\
\hline 8:2 FTOH & $\begin{array}{l}1 \mathrm{H}, 1 \mathrm{H}, 2 \mathrm{H}, 2 \mathrm{H}- \\
\text { perfluorodecanol }\end{array}$ & $\mathrm{CF}_{3}\left(\mathrm{CF}_{2}\right)_{7}\left(\mathrm{CH}_{2}\right)_{2} \mathrm{OH}$ & 14.10 & 462.8 & 402.8 & 0.9 \\
\hline $\mathrm{d}_{2-}{ }^{13} \mathrm{C}_{2}-8: 2$ FTOH & $\begin{array}{l}\text { M-1H,1H,2H,2H- } \\
\text { perfluorodecanol }\end{array}$ & $\mathrm{CF}_{3}\left(\mathrm{CF}_{2}\right)_{7}{ }^{13} \mathrm{CH}_{213} \mathrm{CD}_{2} \mathrm{OH}$ & 14.10 & 466.8 & 405.9 & - \\
\hline 10:2 FTOH & $\begin{array}{l}1 \mathrm{H}, 1 \mathrm{H}, 2 \mathrm{H}, 2 \mathrm{H}- \\
\text { perfluorododecanol }\end{array}$ & $\mathrm{CF}_{3}\left(\mathrm{CF}_{2}\right)_{9}\left(\mathrm{CH}_{2}\right)_{2} \mathrm{OH}$ & 14.60 & 562.8 & 502.8 & 0.5 \\
\hline$d_{2}{ }^{13} C_{2}-10: 2$ FTOH & $\begin{array}{l}\mathrm{M}-1 \mathrm{H}, 1 \mathrm{H}, 2 \mathrm{H}, 2 \mathrm{H}- \\
\text { perfluorododecanol }\end{array}$ & $\mathrm{CF}_{3}\left(\mathrm{CF}_{2}\right)_{9}{ }^{13} \mathrm{CH}_{2}{ }^{13} \mathrm{CD}_{2} \mathrm{OH}$ & 14.60 & 566.8 & 502.8 & - \\
\hline
\end{tabular}

\footnotetext{
${ }^{\mathrm{a}} \mathrm{MLOQ}=$ method limit of quantification
} 
Table 2.3 List of monitored ion transitions and retention times for all compounds analyzed by HPLC-ESI(-)-MS/MS.

\begin{tabular}{|c|c|c|c|c|c|c|}
\hline Compound & Name & Chemical Formula & $\begin{array}{c}\text { Retention } \\
\text { Time } \\
\text { (min) } \\
\end{array}$ & $\begin{array}{l}\text { Parent } \\
\text { Ion } \\
\text { (Da) } \\
\end{array}$ & $\begin{array}{l}\text { Daughter } \\
\text { Ion (Da) }\end{array}$ & $\begin{array}{c}\text { MLOQ }^{\mathrm{a}} \\
(\mathrm{ng} / \mathrm{g} \mathbf{w} \text { ) }\end{array}$ \\
\hline \multicolumn{7}{|c|}{ Perfluorosulfonates (PFSAs) } \\
\hline PFBS & Perfluorobutane sulfonate & $\mathrm{CF}_{3}\left(\mathrm{CF}_{2}\right)_{3} \mathrm{SO}_{3}^{-}$ & 10.61 & 298.8 & 80.1 & 0.2 \\
\hline PFHxS & Perfluorohexane sulfonate & $\mathrm{CF}_{3}\left(\mathrm{CF}_{2}\right)_{5} \mathrm{SO}_{3}^{-}$ & 13.00 & 399.0 & 80.1 & 0.1 \\
\hline${ }^{18} \mathrm{O}_{2}$-PFHxS & $\begin{array}{l}\text { M-Perfluorohexane } \\
\text { sulfonate }\end{array}$ & $\mathrm{CF}_{3}\left(\mathrm{CF}_{2}\right)_{5} \mathrm{SO}^{18} \mathrm{O}_{2}^{-}$ & 13.00 & 403.0 & 84.1 & - \\
\hline PFOS & Perfluorooctane sulfonate & $\mathrm{CF}_{3}\left(\mathrm{CF}_{2}\right)_{7} \mathrm{SO}_{3}^{-}$ & 14.30 & 499.0 & 80.1 & 3.1 \\
\hline${ }^{13} \mathrm{C}_{4}$-PFOS & M-Perfluorooctane sulfonate & $\mathrm{CF}_{3}\left(\mathrm{CF}_{2}\right)_{3}\left({ }^{13} \mathrm{CF}_{2}\right)_{4} \mathrm{SO}_{3}^{-}$ & 14.30 & 503.0 & 80.1 & - \\
\hline PFDS & Perfluorodecane sulfonate & $\mathrm{CF}_{3}\left(\mathrm{CF}_{2}\right)_{9} \mathrm{SO}_{3}^{-}$ & 15.44 & 598.9 & 80.1 & 0.2 \\
\hline \multicolumn{7}{|c|}{ Perfluorocarboxylates (PFCAs) } \\
\hline PFHXA & Perfluorohexanoic acid & $\mathrm{CF}_{3}\left(\mathrm{CF}_{2}\right)_{4} \mathrm{COO}^{*}$ & 11.82 & 312.8 & 268.8 & 0.2 \\
\hline${ }^{13} \mathrm{C}_{2}$-PFHxA & M-Perfluorohexanoic acid & $\mathrm{CF}_{3}\left(\mathrm{CF}_{2}\right)_{3}\left({ }^{13} \mathrm{CF}_{2}\right)^{13} \mathrm{COO}^{-}$ & 11.82 & 314.8 & 269.9 & - \\
\hline PFHрA & Perfluoroheptanoic acid & $\mathrm{CF}_{3}\left(\mathrm{CF}_{2}\right)_{5} \mathrm{COO}^{-}$ & 12.92 & 362.9 & 318.9 & 0.2 \\
\hline PFOA & Perfluorooctanoic acid & $\mathrm{CF}_{3}\left(\mathrm{CF}_{2}\right)_{6} \mathrm{COO}^{-}$ & 13.71 & 412.8 & 368.9 & 0.2 \\
\hline${ }^{13} \mathrm{C}_{4}-\mathrm{PFOA}$ & M-Perfluorooctanoic acid & $\left.\mathrm{CF}_{3}\left(\mathrm{CF}_{2}\right)_{3}{ }^{13} \mathrm{CF}_{2}\right)_{3}{ }^{13} \mathrm{COO}^{-}$ & 13.71 & 416.9 & 371.9 & - \\
\hline PFNA & Perfluorononanoic acid & $\mathrm{CF}_{3}\left(\mathrm{CF}_{2}\right)_{7} \mathrm{COO}^{-}$ & 14.30 & 462.8 & 418.9 & 0.1 \\
\hline${ }^{13} \mathrm{C}_{5}$-PFNA & M-Perfluorononanoic acid & $\left.\mathrm{CF}_{3}\left(\mathrm{CF}_{2}\right)_{3}{ }^{13} \mathrm{CF}_{2}\right)_{4}{ }^{13} \mathrm{COO}^{-}$ & 14.30 & 467.9 & 423.0 & - \\
\hline PFDA & Perfluorodecanoic acid & $\mathrm{CF}_{3}\left(\mathrm{CF}_{2}\right)_{8} \mathrm{COO}^{-}$ & 14.91 & 512.8 & 468.9 & 0.1 \\
\hline${ }^{13} \mathrm{C}_{2}$-PFDA & M-Perfluorodecanoic acid & $\mathrm{CF}_{3}\left(\mathrm{CF}_{2}\right)_{7}{ }^{13} \mathrm{CF}_{2}{ }^{13} \mathrm{COO}^{-}$ & 14.91 & 514.8 & 469.9 & - \\
\hline PFUA & Perfluoroundecanoic acid & $\mathrm{CF}_{3}\left(\mathrm{CF}_{2}\right)_{9} \mathrm{COO}^{-}$ & 15.46 & 562.8 & 518.9 & 0.1 \\
\hline${ }^{13} C_{2}$-PFUA & M-Perfluoroundecanoic acid & $\mathrm{CF}_{3}\left(\mathrm{CF}_{2}\right)_{8}{ }^{13} \mathrm{CF}_{2}{ }^{13} \mathrm{COO}^{-}$ & 15.46 & 564.9 & 519.9 & - \\
\hline PFDoA & Perfluorododecanoic acid & $\mathrm{CF}_{3}\left(\mathrm{CF}_{2}\right)_{10} \mathrm{COO}^{-}$ & 16.02 & 612.9 & 568.9 & 0.1 \\
\hline${ }^{13} \mathrm{C}_{2}$-PFDoA & M-Perfluorododecanoic acid & $\mathrm{CF}_{3}\left(\mathrm{CF}_{2}\right)_{9}\left({ }^{13} \mathrm{CF}_{2}\right)^{13} \mathrm{COO}^{-}$ & 16.02 & 614.9 & 570.0 & - \\
\hline PFTria & Perfluorotridecanoic acid & $\mathrm{CF}_{3}\left(\mathrm{CF}_{2}\right)_{11} \mathrm{COO}^{-}$ & 16.61 & 662.9 & 619.0 & 0.1 \\
\hline PFTeA & Perfluorotetradecanoic acid & $\mathrm{CF}_{3}\left(\mathrm{CF}_{2}\right)_{12} \mathrm{COO}^{-}$ & 17.26 & 712.8 & 669.0 & 0.2 \\
\hline PFPA & Perfluoropentadecanoic acid & $\mathrm{CF}_{3}\left(\mathrm{CF}_{2}\right)_{13} \mathrm{COO}^{-}$ & 17.91 & 762.9 & 719.0 & 0.2 \\
\hline \multicolumn{7}{|c|}{ Fluorotelomer Unsaturated Carboxylic Acids (FTUCAs) } \\
\hline 6:2 FTUCA & $\begin{array}{l}\text { 2H-Perfluoro-2-octenoic } \\
\text { acid }\end{array}$ & $\mathrm{CF}_{3}\left(\mathrm{CF}_{2}\right)_{4} \mathrm{CFCHCOO}^{-}$ & 13.12 & 356.9 & 293.0 & 0.1 \\
\hline${ }^{13} C_{2}-6: 2$ FTUCA & $\begin{array}{l}\text { M-2H-Perfluoro-2-octenoic } \\
\text { acid }\end{array}$ & $\mathrm{CF}_{3}\left(\mathrm{CF}_{2}\right)_{4} \mathrm{CF}^{13} \mathrm{CH}^{13} \mathrm{COO}^{-}$ & 13.12 & 358.9 & 294.0 & - \\
\hline 8:2 FTUCA & $\begin{array}{l}\text { 2H-Perfluoro-2-decenoic } \\
\text { acid }\end{array}$ & $\mathrm{CF}_{3}\left(\mathrm{CF}_{2}\right)_{6} \mathrm{CFCHCOO}^{-}$ & 14.56 & 456.9 & 393.0 & 0.1 \\
\hline${ }^{13} \mathrm{C}_{2}-8: 2$ FTUCA & $\begin{array}{l}\text { M-2H-Perfluoro-2-decenoic } \\
\text { acid }\end{array}$ & $\mathrm{CF}_{3}\left(\mathrm{CF}_{2}\right)_{6} \mathrm{CF}^{13} \mathrm{CH}^{13} \mathrm{COO}^{-}$ & 14.56 & 458.9 & 394.0 & - \\
\hline 10:2 FTUCA & $\begin{array}{l}\text { 2H-Perfluoro-2-dodecenoic } \\
\text { acid }\end{array}$ & $\mathrm{CF}_{3}\left(\mathrm{CF}_{2}\right)_{8} \mathrm{CFCHCOO}^{-}$ & 15.68 & 556.9 & 493.0 & 0.1 \\
\hline${ }^{13} \mathrm{C}_{2}-10: 2$ FTUCA & $\begin{array}{l}\text { M-2H-Perfluoro-2- } \\
\text { dodecenoic acid }\end{array}$ & $\mathrm{CF}_{3}\left(\mathrm{CF}_{2}\right)_{8} \mathrm{CF}^{13} \mathrm{CH}^{13} \mathrm{COO}^{-}$ & 15.68 & 558.9 & 494.0 & - \\
\hline
\end{tabular}

\footnotetext{
${ }^{a} \mathrm{MLOQ}=$ method limit of quantification
} 


\subsubsection{Internal Standards and Percent Recoveries}

All samples were spiked with $10 \mathrm{ng}$ of labelled internal standards to ensure proper peak identification and facilitate quantification calculations when performing analysis by HPLC-MS/MS. Quantification of the target compounds by labelled internal standards permitted the correction of any ionization suppression or enhancement that may have occurred as a result of matrix-dependent effects such as co-eluting ions. An internal standard was available for most of the target compounds. A surrogate internal standard was used for those target compounds where an identical labelled standard was not available. The surrogate internal standard was chosen based on similarity of retention time. ${ }^{13} \mathrm{C}$-PFHxA was chosen as a surrogate for PFBS and PFHpA, ${ }^{13} \mathrm{C}$-PFUA was chosen as a surrogate for PFDS, and ${ }^{13} \mathrm{C}-\mathrm{PFDoA}$ was chosen as a surrogate for PFTriA, PFTeA and PFPA.

Spiking samples with internal standard also allowed percent recoveries to be calculated. Percent recoveries $(\% \pm \mathrm{SE})$ of compounds consistently found above the detection limit can be found in Table 2.4. All concentrations were quantified by an internal standard isotope dilution approach where relative response factors were generated. Thus, the quantification of all applicable PFCs in the samples was inherently recovery-corrected. 
Table 2.4 Percent Recoveries $(\% \pm \mathrm{SE})$ for all internal standards of detected compounds.

\begin{tabular}{cc}
\hline Compound & $\begin{array}{c}\text { Percent Recovery } \\
(\% \pm \text { SE })\end{array}$ \\
\hline${ }^{13}$ C-PFHxA & $51.9 \pm 1.0$ \\
${ }^{13}$ C-PFOA & $68.9 \pm 1.2$ \\
${ }^{13}$ C-PFNA & $76.5 \pm 1.9$ \\
${ }^{13}$ C-PFDA & $72.0 \pm 1.5$ \\
${ }^{13}$ C-PFUA & $84.9 \pm 1.8$ \\
${ }^{13}$ C-PFDoA & $78.0 \pm 1.4$ \\
${ }^{18}$ O-PFHXS & $71.4 \pm 1.3$ \\
${ }^{13}$ C-PFOS & $74.3 \pm 1.5$ \\
${ }^{13}$ C-PFOSA & $47.2 \pm 1.6$ \\
${ }^{13} C_{2}$-6:2 FTUCA & $36.3 \pm 0.8$ \\
${ }^{13} \mathbf{C}_{2}$-8:2 FTUCA & $52.7 \pm 1.2$ \\
${ }^{13} \mathbf{C}_{2}$-10:2 FTUCA & $65.9 \pm 1.6$ \\
\hline
\end{tabular}

\subsubsection{Quantification of PFOSA}

Prior to 2009, an isotope-labelled internal standard (IS) was not available for perfluorooctane sulfonamide (PFOSA). As a result, in almost all previous studies, quantification of PFOSA was calculated based on the labelled surrogate, N-methyl perfluorooctane sulfonamide (N-Me-FOSA). The difference in retention times between PFOSA and N-Me-FOSA is approximately 25 seconds for the method used in this study. The use of a labelled surrogate is never ideal due to differences in co-eluting ions and matrix effects. Additionally, the current instrumental method of PFOSA determination, HPLC-APPI-MS/MS, is a relatively new technique, and has only been in use since 2009 
(Chu and Letcher, 2008). Prior to 2009, the majority of PFOSA concentrations were determined by GC-MS (which showed relatively poor sensitivity), or by HPLC-ESIMS/MS (Smithwick et al., 2005; Chu and Letcher, 2008). In December 2009, Wellington Laboratories released a new ${ }^{13} \mathrm{C}$-labelled PFOSA internal standard. In contrast to previous studies, this study determined PFOSA concentrations employing HPLC-APPIMS/MS, using the ${ }^{13} \mathrm{C}$-labelled PFOSA internal standard.

The liver samples used in this study were homogenized in 2007 and kept at $-20^{\circ} \mathrm{C}$ until analysis. These liver samples were analyzed for PFCs twice, once for Chapter 4 (2011), and once in 2007. In this study, the PFOSA internal standard was available, and the PFOSA concentration in the liver averaged $151.4 \mathrm{ng} / \mathrm{g}$ ww. In 2007, the N-Me-FOSA internal standard was used instead, and the PFOSA concentration in the liver only averaged $25.1 \mathrm{ng} / \mathrm{g}$ ww. To confirm the PFOSA concentrations found in Chapter 4 , the liver samples were run with both the HPLC-APPI-MS/MS (Table 4.1), as well as the HPLC-Q-TOF (Quadrupole Time of Flight, data not shown). PFOSA concentrations for both instrumentations were within $23 \pm 5 \%$ of each other. The small discrepancies between the HPLC-APPI-MS/MS PFOSA concentrations and the HPLC-Q-TOF PFOSA concentrations were attributed to normal experimental uncertainties. Consequently, the PFOSA concentrations found in this study were confirmed, and can be regarded as accurate.

\subsection{Lipid Extraction}

The lipid content of all samples was determined. The method used to extract the lipid content in liver, brain, muscle, and adipose samples has been described (Chu et al., 
2003; Gebbink et al., 2008), although slight modifications were made, namely replacing anhydrous sodium sulphate with diatomaceous earth as the extraction medium. The sample taken for PFC analysis was not suitable for lipid content determination due to the non-volatile nature of the solvent used $(10 \mathrm{mM} \mathrm{KOH})$. Therefore, between $0.1 \mathrm{~g}$ and 1.0 $\mathrm{g}$ of a separate tissue sample was taken from the area directly surrounding the original tissue sample for PFC analysis. The sample was ground with diatomaceous earth, obtained from VWR International (Mississauga, ON, Canada), using a mortar and pestle. The mixture was then loaded into a chemically cleaned accelerated solvent extractor cell. The lipids were extracted using a Dionex ASE 200 accelerated solvent extractor at $100^{\circ} \mathrm{C}$ and 1,500 psi using approximately $50 \mathrm{~mL}$ of a 1:1 hexane:dicholoromethane solution. The solution was then evaporated to approximately $5 \mathrm{~mL}$ using a nitrogen stream. It was filtered through anhydrous sodium sulphate, and then made up to $10 \mathrm{~mL}$. A portion of the solution was then transferred to a pre-weighed aluminum dish. The solvent was left to evaporate in the fume hood for 1 hour, followed by a drying time of approximately 12 hours (overnight) in a $100^{\circ} \mathrm{C}$ oven. The following morning, the aluminum dish was weighed, and the lipid content was determined gravimetrically.

The lipid content in blood samples was determined spectrophotometrically using a phospho-vanillin reagent, as previously described by Verreault et al. (2005b). In brief, 20 $\mu \mathrm{L}$ of blood was combined with $200 \mu \mathrm{L}$ of sulphuric acid, and placed in a boiling water bath for 10 minutes. After cooling for 5 minutes, $10 \mathrm{~mL}$ of the phospho-vanillin reagent was added, and the colour was left to develop for 15 minutes, at which time its absorbance was recorded at a wavelength of $540 \mathrm{~nm}$. The phospho-vanillin reagent was a 
$2.1 \mathrm{~g} / \mathrm{L}$ solution of vanillin in 2:3 water:0-phosphoric acid. Quantification was done using an olive oil calibration curve.

\subsection{Quality Assurance and Quality Control}

PFC compounds were identified by comparing their characteristic retention times to those of authenticated reference standards. Identification was also possible by monitoring characteristic ion transitions, as mentioned in section 2.4.2.

Method limits of quantification (MLOQs) were based on signal to noise (S/N) ratios of 10 and varied by compound. For a complete list of MLOQs for all target compounds, see Tables 2.2 and 2.3 .

A sample blank was run every 10 samples to reduce background interference. The sample blank was treated identically to all other samples but excluded any tissue. The following compounds were consistently found (i.e. $>70 \%$ of sample blanks) over the MLOQ: PFHxA (0.90 ng/g ww), PFHpA (0.80 ng/g ww), PFOA (0.92 ng/g ww), PFNA (1.04 ng/g ww), PFDA (0.93 ng/g ww), and PFUA (1.03 ng/g ww).

A NWRC in-house standard reference material (SRM) was used to ensure reproducibility and to monitor batch-to-batch fluctuations. Pooled bird egg homogenate, collected from double-crested cormorants, DCCO (Phalacrocorax auritus), from the Great Lakes in 2003, was chosen as the SRM. For $\Sigma$-PFSAs $\left(\mathrm{C}_{6}, \mathrm{C}_{8}, \mathrm{C}_{10}\right)$ good reproducibility was seen with an RSD of $15 \%(n=13)$. Reproducibility was similar for $\Sigma$-PFCAs $\left(\mathrm{C}_{8}-\mathrm{C}_{15}\right)$, with an RSD of $14 \%$. The $\mathrm{C}_{6}$ and $\mathrm{C}_{7}$ PFCAs were not quantifiable in the SRM. 
At the NWRC, the Letcher/Organic Contaminants Research Laboratory (OCRL) regularly participates in inter-laboratory QA/QC exercises for PFC analysis. From 2007 to present, the OCRL participated in several PFC QA/QC exercises. For several PFCAs, PFSAs, and PFOSA, NIST SRM 1945 analysis results were within $10 \%$ of the interlab mean values, and reported in the 2007 NIST/NOAA Interlaboratory Comparison Exercise Program for Organic Contaminants in Marine Mammal Tissues (Kucklick et al., 2009). PFC QA/QC inter-lab exercises for the Letcher/OCRL have also included annual participation in the Northern Contaminants Program (NCP, Aboriginal Affairs and Northern Development Canada (AANDC)). The Letcher/OCRL lab has participated in the NCP III Phase 1 (2006), 2 (2007), 3 (2008), 4 (2009), 5 (2010) and most recently 6 (2011) QA/QC Assurance Programs (coordinated by the OMOE, Laboratory Services Branch). For the most recent NCP III Phase 5 (2010) exercise, for matrices such as NIST SRM 1947 (Lake Michigan fish homogenate), the compliancy percentage for the Letcher/OCRL was $100 \%$ for all PFSAs, PFCAs and PFOSA under study in this thesis, and the top lab in terms of result compliances with respect to the mean values for all participating labs (Farig et al., 2010).

\subsection{Data Analysis}

Quantification of HPLC-MS/MS data was done using MassLynx 4.0 (Waters, 2002). Quantification was based on comparisons to calibration curves run the same day, and by comparisons to the internal standard peaks.

All statistical analysis was performed using Statistica 8.0 (StatSoft, 2008; Tulsa, OK, USA). All concentrations were first $\log _{10}$-transformed, and tested for normal 
distribution using a Shapiro-Wilk's $W$ test, with $\alpha=0.05$. For data analysis done in Chapter 3 , concentrations were first corrected for lipid content, and were then $\log _{10^{-}}$ transformed since lipid was deemed to be a confounding factor. After $\log _{10^{-}}$ transformation, the majority of PFCAs and PFSAs were normally distributed.

Statistical analysis was only performed on compounds for which more than half (> 50\%) of samples were above the method limit of quantification (MLOQ). For the compounds where more than half of the samples are above the MLOQ, any samples found below the MLOQ were assigned values of MLOQ $\div 3$. No statistical differences in compound distribution were found between assigning values of $M L O Q \div 3$ and assigning randomly generated values between 0 to MLOQ.

Correlations between PFC wet weight concentrations and extractable lipid content were assessed using product-moment correlational matrices. The same tests were used for correlations between PFC concentration and age. Differences between (a) males and females (Chapters 3, 4), (b) all eight brain compartments (Chapter 3), and (c) all tissues (Chapter 4) were examined using one-way ANOVA, followed by a Tukey HSD test ( $\alpha=$ $0.05)$. 


\section{References}

Marine Mammals Protection Act. (1972). National Oceanic and Atmospheric Administration, United States, 1361-1423. 16.

Ahrens, L., Siebert, U., Ebinghaus, R., 2009. Total body burden and tissue distribution of polyfluorinated compounds in harbor seals (Phoca vitulina) from the German Bight. Marine Pollution Bulletin 58, 520-525.

Butt, C.M., Berger, U., Bossi, R., Tomy, G.T., 2010. Levels and trends of poly- and perfluorinated compounds in the arctic environment. Science of the Total Environment 408, 2936-2965.

Chu, S.G., Covaci, A., Jacobs, W., Haraguchi, K., Schepens, P., 2003. Distribution of methyl sulfone metabolites of polychlorinated biphenyls and $\mathrm{p}, \mathrm{p}$ '-DDE in human tissues. Environmental Health Perspectives 111, 1222-1227.

Chu, S., Letcher, R.J., 2008. Analysis of fluorotelomer alcohols and perfluorinated sulfonamides in biotic samples by liquid chromatography-atmospheric pressure photoionization mass spectrometry. Journal of Chromatography A 1215, 92-99.

Dietz, R., Riget, F.F., Sonne, C., Letcher, R., Born, E.W., Muir, D.C.G., 2004. Seasonal and temporal trends in polychlorinated biphenyls and organochlorine pesticides in East Greenland polar bears (Ursus maritimus), 1990-2001. Science of the Total Environment 331, 107-124.

Dyck, M.G., Kebreab, E., 2009. Estimating the energetic contribution of polar bear (Ursus maritimus) summer diets to the total energy budget. Journal of Mammalogy 90, 585-593.

Farig, R., Selliah, S., Ali, B., Reiner, E., Northern Contaminants Program (NCP; AANDC), interlaboratory quality assurance programrReport (November 2010), NCP III - Phase 5, pp. 37-42.

Gebbink, W.A., Sonne, C., Dietz, R., Kirkegaard, M., Riget, F.F., Born, E.W., Muir, D.C.G., Letcher, R.J., 2008. Tissue-specific congener composition of organohalogen and metabolite contaminants in East Greenland polar bears (Ursus maritimus). Environmental Pollution 152, 621-629.

Gebbink, W.A., Letcher, R.J., 2010. Linear and nranched rerfluorooctane sulfonate isomer patterns in herring gull eggs from colonial sites across the Laurentian Great Lakes. Environmental Science \& Technology 44, 3739-3745.

Gebbink, W.A., Letcher, R. 2012. Comparative tissue and body compartment accumulation and maternal transfer to eggs of perfluoroalkyl sulfonates and carboxylates in Great Lakes herring gulls. Environmental Pollution 162, 40-47. 
Haug, L.S., Huber, S., Becher, G., Thomsen, C., 2011. Characterisation of human exposure pathways to perfluorinated compounds - Comparing exposure estimates with biomarkers of exposure. Environment International 37, 687-693.

Houde, M., De Silva, A.O., Muir, D.C.G., Letcher, R.J., 2011. Monitoring of perfluorinated compounds in aquatic biota: An updated review PFCs in aquatic biota. Environmental Science \& Technology 45, 7962-7973.

Johansson, N., Eriksson, P., Viberg, H., 2009. Neonatal exposure to PFOS and PFOA in mice results in changes in proteins which are important neuronal growth and synaptogenesis in the developing brain. Toxicological Sciences 108, 412-418.

Letcher, R.J., Bustnes, J.O., Dietz, R., Jenssen, B.M., Jorgensen, E.H., Sonne, C., Verreault, J., Vijayan, M.M., Gabrielsen, G.W., 2010. Exposure and effects assessment of persistent organohalogen contaminants in arctic wildlife and fish. Science of the Total Environment 408, 2995-3043.

Liu, X.H., Liu, W., Jin, Y.H. Yu, W.G., Wang, F.Q., Liu, L., 2010. Effects of gestational and lactational exposure to perfluorooctanesulfonate on calcium-dependent signalling molecules gene expression in rats' hippocampus. Archives of Toxicology $84,71-79$.

Kucklick, J.R., Pugh, R.S., Becker, P.R., Schantz, M.M., Wise, S.A., Rowles, T.K., 2009. Description and results of the 2007 NIST/NOAA interlaboratory comparison exercise program for organic contaminants in marine mammal tissues (Rep. No. NISTIR 7642). National Institute of Standards and Technology.

Piquet, A.M.T., Scheepens, J.F., Bolhuis, H., Wiencke, C., Buma, A.G.J., 2010. Variability of protistan and bacterial communities in two Arctic fjords (Spitsbergen). Polar Biology 33, 1521-1536.

Rubarth, J., Dreyer, A., Guse, N., Einax, J.W., Ebinghaus, R., 2011. Perfluorinated compounds in red-throated divers from the German Baltic Sea: new findings from their distribution in 10 different tissues. Environmental Chemistry 8, 419-428.

Smithwick, M., Muir, D.C.G., Mabury, S.A., Solomon, K.R., Martin, J.W., Sonne, C., Born, E.W., Letcher, R.J., Dietz, R., 2005. Perfluoroalkyl contaminants in liver tissue from East Greenland polar bears (Ursus maritimus). Environmental Toxicology and Chemistry 24, 981-986.

Sturm, R., Ahrens, L., 2010. Trends of polyfluoroalkyl compounds in marine biota and in humans. Environmental Chemistry 7, 457-484.

Van de Vijver, K.I., Hoff, P., Das, K., Brasseur, S., Van Dongen, W., Esmans, E., Reijnders, P., Blust, R., De Coen, W., 2005. Tissue distribution of perfluorinated 
chemicals in harbor seals (Phoca vitulina) from the Dutch Wadden Sea. Environmental Science \& Technology 39, 6978-6984.

Van de Vijver, K.I., Hoslbeek, L., Das, K., Blust, R., Joiris, C., De Coen, W., 2007. Occurrence of perfluorooctane sulfonate and other perfluorinated alkylated substances in harbor porpoises from the Black Sea. Environmental Science \& Technology $41,315-320$.

Verreault, J., Houde, M., Gabrielsen, G.W., Berger, U., Haukas, M., Letcher, R.J., Muir, D.C.G., 2005a. Perfluorinated alkyl substances in plasma, liver, brain, and eggs of glaucous gulls (Larus hyperboreus) from the Norwegian Arctic. Environmental Science \& Technology 39, 7439-7445.

Verreault, J., Gabrielsen, G.V., Chu, S.G., Muir, D.C.G., Andersen, M., Hamaed, A., Letcher, R.J., 2005b. Flame retardants and methoxylated and hydroxylated polybrominated diphenyl ethers in two Norwegian Arctic top predators: Glaucous gulls and polar bears. Environmental Science \& Technology 39, 6021-6028.

Wang, F.Q., Liu, W., Jin, Y.H., Dai, J.Y., Yu, W.G., Liu, X.H., Liu, L., 2010. Transcriptional effets of prenatal and neonatal exposure to PFOS in developing rat brain. Environmental Science \& Technology 44, 1847-1853.

Zeng, H.C., Zhang, L., Li, Y.Y., Wang, Y.J., Xia, W., Lin, Y., Wei, J., Xu, S.Q., 2011. Inflammation-like glial response in rat brain induced by prenatal PFOS exposure. Neurotoxicology 32, 130-139.

Zhang, L., Li, Y.Y., Chen, T., Xia, W., Zhou, Y., Wan, Y.J., Lv, Z.Q., Li, G.Q., Xu, S.Q., 2011. Abnormal development of motor neurons in perfluorooctane sulfonate exposed zebrafish embryos. Ecotoxicology 20, 643-652. 


\section{CHAPTER 3 \\ Brain Region Distribution and Patterns of Bioaccumulative Perfluoroalkyl Carboxylates and Sulfonates in East Greenland Polar Bears}

\subsection{Introduction}

The polar bear (Ursus maritimus) is the top predator in the Arctic marine ecosystem. In general, PFOS concentrations as high as $4,000 \mathrm{ng} / \mathrm{g}$ wet weight (ww; or $\sim 40,000 \mathrm{ng} / \mathrm{g}$ lipid weight (lw)) have been reported in the liver of East Greenland polar bears collected in 2006 (Smithwick et al., 2005a; Dietz et al., 2008; Letcher et al., 2010). Furthermore, from 1986 to 2006, PFOS levels in East Greenland polar bear liver have been reported to have increased exponentially, despite the voluntary phase-out of all $\mathrm{C}_{8}$ chemistry by the 3M Company between 2001-2002 (Smithwick et al., 2006; Dietz et al., 2008). In polar bears sampled from East Greenland in 2006, PFOS levels were comparable to or exceeded that of the most concentrated and lipophilic persistent organic pollutants (POPs) reported in the adipose of the same bears, namely mean $\Sigma$-PCBs $(10,500 \mathrm{ng} / \mathrm{g}$ lw or $\mathrm{ww})$ and mean $\Sigma$-chlordanes ( $\Sigma$-CHLs; $1,700 \mathrm{ng} / \mathrm{g} \mathrm{lw}$ or ww) (Gebbink et al., 2008; Letcher et al., 2010; McKinney et al., 2011).

The liver has always been considered the major repository in the body for PFSAs, PFCAs, and possibly other PFCs. It is believed that PFSAs and PFCAs are retained in the body by enterohepatic recirculation and protein binding (Houde et al., 2006a). This hypothesis has been supported by studies on free-ranging mammals, including polar bears, which reported no correlation between PFAA concentrations and extractable lipid levels in either liver or plasma samples (Kannan et al., 2002, 2005; Houde et al., 2006b). The polar extremity of the PFSA and PFCA molecule preferentially binds with proteins, 
specifically fatty acid binding proteins, lipoproteins, and albumin, and is sequestered into protein-rich tissues such as liver and blood (Luebker et al., 2002; Jones et al., 2003; Ahrens et al., 2009). Very recently, Cassone et al. (2012) reported that chicken egg embryos injected with perfluorohexane sulfonate (PFHxS) and perfluorohexanoic acid (PFHxA) had greater accumulation in protein-rich compartments (i.e. yolk sac and liver). Also, PFHxS and PFHxA were detected in the cerebral cortex of chicken embryos, suggesting that they are able to cross the blood-brain barrier (BBB).

Although concentrations of PFOS and other PFAAs in the liver of polar bears have been shown to be extremely high (Letcher et al., 2010; Houde et al., 2011), no studies have investigated the levels of any PFC in other tissues including in the brain, or among brain regions. A select few studies have examined the tissue distribution of PFCs in mammalian and avian species, although no intra-brain distribution was performed (Van de Vijver et al., 2005, 2007; Verreault et al., 2005; Olivero-Verbel et al., 2006; Ahrens et al., 2009; Rubarth et al., 2011; Gebbink and Letcher, 2012). PFOS has been detected in the brain following laboratory animal exposure studies (Austin et al., 2003). Adult female rats intraperitoneally-injected with PFOS at $1 \mathrm{mg} / \mathrm{kg}$ body weight (BW) and $10 \mathrm{mg} / \mathrm{kg}$ BW demonstrated a dose-dependent accumulation of PFOS in all brain regions measured (i.e. hypothalamus, cerebral cortex, hippocampus, brain stem, and cerebellum), compared to the control group. Recent studies with rodents have found that neonatal exposure to PFOS or perfluorooctanoic acid (PFOA) can cause disruption to the central nervous system, resulting in abnormal development of motor neurons and significant changes in gene expression (Wang et al., 2010; Vongphachan et al., 2011). Furthermore, in in vitro neurotoxicity studies in both differentiated and undifferentiated $\mathrm{PC} 12$ cells, 
exposure to both PFOS and PFOSA showed disruption to DNA synthesis (Slotkin et al., 2008).

Given the high PFSA and PFCA exposures in polar bears and the high concern for possible effects in the brain, in this study we examined the brain compartment levels and patterns of a suite of PFCAs and PFSAs and selected PFC precursors in eight different brain regions of East Greenland polar bears (i.e.: pons/medulla, cerebellum, striatum, thalamus, hypothalamus, and frontal, occipital and temporal cortices). In addition, we evaluate their distribution patterns, gender differences, correlations with extractable lipid content, and correlations with age.

\subsection{Results and Discussion}

\subsection{Relationship between PFAA Concentrations and Extractable Lipid Content}

PFCA chain lengths of $\mathrm{C}_{8}-\mathrm{C}_{15}$, and PFSA chain lengths of $\mathrm{C}_{6}, \mathrm{C}_{8}$ and $\mathrm{C}_{10}$, as well as PFOSA were detected above the MLOQ in all brain compartments (Table 3.1). All other PFCs were either below the detection limit, detected with low frequency, or were detected near the detection limit (Table 3.2). The lipid content in all samples ranged from $8.38 \pm 0.64 \%$ to $18.48 \pm 0.95 \%$ (Table 3.1 ). 
Table 3.1 Arithmetic mean lipid contents and concentrations ( $\mathrm{ng} / \mathrm{g}$ wet weight $\pm \mathrm{SE}$ ), including concentration ranges, of all detected perfluorinated compounds in brain regions of 19 East Greenland polar bears collected in 2006.

\begin{tabular}{|c|c|c|c|c|c|c|c|c|c|c|}
\hline $\begin{array}{c}\text { Brain } \\
\text { Compartmen }\end{array}$ & & $\begin{array}{l}\text { Pons/ } \\
\text { Medulla } \\
(n=14)\end{array}$ & $\begin{array}{l}\text { Cerebellum } \\
(n=15)\end{array}$ & $\begin{array}{l}\text { Frontal } \\
\text { Cortex } \\
(n=16)\end{array}$ & $\begin{array}{c}\text { Occipital } \\
\text { Cortex } \\
(n=17)\end{array}$ & $\begin{array}{c}\text { Temporal } \\
\text { Cortex }(n=15)\end{array}$ & $\begin{array}{c}\text { Striatum } \\
(n=11)\end{array}$ & $\begin{array}{c}\text { Thalamus } \\
(\mathrm{n}=\mathbf{8})\end{array}$ & $\begin{array}{l}\text { Hypothalamus } \\
\qquad(n=4)\end{array}$ & $\begin{array}{c}\text { Whole Brain, } \\
\text { Average } \\
(n=115)\end{array}$ \\
\hline \multicolumn{2}{|c|}{ Lipid Content $(\% \pm \mathrm{SE})^{*}$} & $18.48 \pm 0.95$ & $9.49 \pm 1.03$ & $8.38 \pm 0.64$ & $10.54 \pm 0.57$ & $9.17 \pm 0.69$ & $11.44 \pm 0.89$ & $12.65 \pm 0.63$ & $15.55 \pm 0.15$ & $11.20 \pm 0.39$ \\
\hline \multirow{2}{*}{ PFOA } & Mean: & $0.23 \pm 0.06$ & $0.25 \pm 0.06$ & $0.28 \pm 0.08$ & $0.19 \pm 0.05$ & $0.25 \pm 0.05$ & $0.23 \pm 0.14$ & $0.86 \pm 0.79$ & n.d. & $0.27 \pm 0.06$ \\
\hline & Range: & n.d. -0.86 & n.d. -0.84 & n.d. -0.91 & n.d. -0.69 & n.d. -0.67 & n.d. -1.59 & n.d. -6.34 & n.d. & n.d. -6.34 \\
\hline \multirow{2}{*}{ PFNA } & Mean: & $2.35 \pm 0.30$ & $2.29 \pm 0.4 \mathrm{I}$ & $1.71 \pm 0.24$ & $1.74 \pm 0.26$ & $1.88 \pm 0.35$ & $1.31 \pm 0.19$ & $2.49 \pm 1.45$ & $1.6 \pm 0.27$ & $1.87 \pm 0.14$ \\
\hline & Range: & $1.29-4.74$ & $0.90-6.44$ & $0.56-4.01$ & $0.65-5.14$ & $0.61-6.19$ & $0.31-2.46$ & $0.23-12.53$ & $0.81 \cdot 2.00$ & $0.23-12.53$ \\
\hline \multirow{2}{*}{ PFDA } & Mean: & $2.93 \pm 0.39$ & $2.07 \pm 0.34$ & $1.81 \pm 0.29$ & $1.94 \pm 0.26$ & $1.71 \pm 0.19$ & $1.89 \pm 0.23$ & $3.37 \pm 1.19$ & $2.91 \pm 0.49$ & $2.12 \pm 0.13$ \\
\hline & Range: & $1.19-6.22$ & $0.46-5.74$ & $0.42-5.05$ & $0.53-4.46$ & $0.69-3.54$ & $0.86-3.24$ & $0.82-11.35$ & $1.62-3.98$ & $0.42-11.35$ \\
\hline \multirow{2}{*}{ PFUA } & Mean: & $25.66 \pm 2.71$ & $14.09 \pm 1.53$ & $13.43 \pm 1.60$ & $15.06 \pm 1.51$ & $12.89 \pm 1.29$ & $15.85 \pm 1.63$ & $19.48 \pm 2.66$ & $23.42 \pm 4.40$ & $16.02 \pm 0.72$ \\
\hline & Range: & $14.85-49.11$ & $5.6-24.24$ & $5.27-28.07$ & $6.95-31.45$ & $6.88-24.38$ & $7.99 \cdot 23.72$ & $6.35-29.88$ & $11.27 \cdot 32.33$ & $5.27-49.11$ \\
\hline \multirow{2}{*}{ PFDoA } & Mean: & $11.42 \pm 1.15$ & $6.00 \pm 0.60$ & $5.95 \pm 0.67$ & $6.81 \pm 0.84$ & $5.78 \pm 0.50$ & $7.30 \pm 0.68$ & $9.64 \pm 1.18$ & $10.72 \pm 1.73$ & $7.21 \pm 0.33$ \\
\hline & Range: & $6.98-20.73$ & $2.73-10.48$ & $2.62-12.62$ & $2.90-16.63$ & $2.92-8.59$ & $3.50-10.31$ & $3.57-13.49$ & $5.54-12.75$ & $2.62-20.73$ \\
\hline \multirow{2}{*}{ PFTriA } & Mean: & $48.64 \pm 4.49$ & $25.03 \pm 2.43$ & $25.97 \pm 3.25$ & $29.71 \pm 3.91$ & $24.11 \pm 2.72$ & $32.21 \pm 3.67$ & $43.28 \pm 4.90$ & $48.56 \pm 2.72$ & $31.38 \pm 1.47$ \\
\hline & Range: & $23.96-80.07$ & $13.33-45.11$ & $12.22-47.31$ & $11.72-72.16$ & $10.70-43.46$ & $11.87-47.37$ & $19.75-59.39$ & $21.64 \cdot 70.39$ & $10.70-80.07$ \\
\hline \multirow{2}{*}{ PFTeA } & Mean: & $10.69 \pm 1.11$ & $6.46 \pm 0.57$ & $6.33 \pm 0.72$ & $7.44 \pm 0.93$ & $6.13 \pm 0.63$ & $7.33 \pm 1.00$ & $10.52 \pm 1.94$ & $8.13 \pm 1.35$ & $7.45 \pm 0.34$ \\
\hline & Range: & $6.01-19.14$ & $2.98-9.55$ & $2.39-11.90$ & $3.13-16.63$ & $2.84-12.04$ & $3.01-12.08$ & $5.58-22.63$ & $4.75-10.94$ & $2.39 \cdot 22.63$ \\
\hline \multirow{2}{*}{ PFPA } & Mean: & $13.81 \pm 1.31$ & $9.24 \pm 1.04$ & $9.02 \pm 1.19$ & $11.39 \pm 1.58$ & $9.23 \pm 1.07$ & $10.21 \pm 1.55$ & $11.81 \pm 2.41$ & $10.17 \pm 2.18$ & $10.41 \pm 0.48$ \\
\hline & Range: & $6.71-22.91$ & $3.24-17.18$ & $3.10-20.40$ & $4.34-31.15$ & $3.43-17.51$ & $2.36-18.80$ & $2.01-20.09$ & $6.77-16.35$ & $2.01-31.15$ \\
\hline \multirow{2}{*}{ 乏-PFCA } & Mean: & $115.85 \pm 10.29$ & $65.53 \pm 6.11$ & $64.64 \pm 7.29$ & $74.40 \pm 8.64$ & $62.12 \pm 5.93$ & $76.81 \pm 8.02$ & $102.41 \pm 12.87$ & $105.79 \pm 18.90$ & $76.96 \pm 3.25$ \\
\hline & Range: & $69.59-186.23$ & $35.62-113.45$ & $32.07-116.96$ & $31.56-166.44$ & $30.78-111.69$ & $32.96-108.94$ & $45.57-155.65$ & $52.49-140.52$ & $30.78-186.23$ \\
\hline \multirow{2}{*}{ PFHxS } & Mean: & $1.32 \pm 0.21$ & $1.82 \pm 0.31$ & $1.52 \pm 0.28$ & $1.40 \pm 0.20$ & $1.46 \pm 0.21$ & $0.89 \pm 0.35$ & $1.31 \pm 0.77$ & $1.29 \pm 0.13$ & $1.37 \pm 0.10$ \\
\hline & Range: & $0.28-2.52$ & $0.24-3.94$ & $0.21-4.07$ & $0.38-2.80$ & $0.51-2.75$ & nd. -4.16 & n.d. -6.51 & $0.92-1.49$ & n.d. -6.51 \\
\hline \multirow{2}{*}{ PFOS } & Mean: & $46.89 \pm 7.01$ & $36.51 \pm 6.46$ & $32.83 \pm 4.93$ & $32.49 \pm 4.11$ & $30.52 \pm 4.45$ & $31.91 \pm 5.29$ & $38.81 \pm 6.86$ & $58.77 \pm 11.84$ & $35.17 \pm 1.97$ \\
\hline & Range: & $18.32-100.30$ & $10.78-99.32$ & $7.95-74.94$ & $8.79-65.84$ & $8.87-77.19$ & $9.3-70.04$ & $12.70-71.41$ & $29.93-87.84$ & $7.94-100.30$ \\
\hline \multirow{2}{*}{ PFDS } & Mean: & $1.37 \pm 0.31$ & $1.15 \pm 0.27$ & $1.21 \pm 0.28$ & $1.19 \pm 0.26$ & $1.12 \pm 0.28$ & $1.53 \pm 0.48$ & $2.54 \pm 1.62$ & $0.64 \pm 0.23$ & $1.30 \pm 0.15$ \\
\hline & Range: & $0.15-3.55$ & n.d. -3.19 & n.d. -3.18 & n.d. $\cdot 3.11$ & n.d. -3.66 & n.d. -5.12 & ndd. -13.63 & n.d. -1.06 & n.d. -13.63 \\
\hline \multirow{2}{*}{ E-PFSA } & Mean: & $4.9 .61 \pm 7.13$ & $40.06 \pm 6.66$ & $35.78 \pm 5.10$ & $35.27 \pm 4.25$ & $33.48 \pm 4.76$ & $34.36 \pm 5.30$ & $42.68 \pm 7.72$ & $60.72 \pm 11.87$ & $38.03 \pm 2.02$ \\
\hline & Range: & $9.18-105.56$ & $13.46-105.19$ & $8.27-80.80$ & $9.42-70.77$ & $9.47-80.03$ & $10.43-71.46$ & $13.02-72.38$ & $31.36-89.39$ & $8.27-105.56$ \\
\hline \multirow{2}{*}{ PFOSA } & Mean: & $1.46 \pm 0.38$ & $1.40 \pm 0.24$ & $1.19 \pm 0.22$ & $1.26 \pm 0.22$ & $1.12 \pm 0.28$ & $1.13 \pm 0.27$ & $1.81 \pm 0.57$ & $2.07 \pm 0.58$ & $1.33 \pm 0.10$ \\
\hline & Range: & $0.11-5.43$ & n.d. -3.72 & n.d. -3.07 & n.d. -3.30 & n.d. -4.14 & n.d. -2.89 & n.d. -4.72 & $1.18-3.78$ & n.d. -5.50 \\
\hline
\end{tabular}

${ }^{\mathrm{a}} \mathrm{Lipid}$ content $=(\mathrm{g} \text { lipid } / \mathrm{g} \text { tissue })^{\star} 100 \%$ 
Table 3.2 Range of concentrations (ng/g ww) for all non-detected perfluorinated compounds. Compounds were considered not detected if less than $50 \%$ of samples were above the method limit of quantification (MLOQ).

\begin{tabular}{|c|c|c|c|c|c|c|c|c|c|c|}
\hline $\begin{array}{c}\text { Brain } \\
\text { Compartment }\end{array}$ & & $\begin{array}{l}\text { Pons/Medulla } \\
(n=14)\end{array}$ & $\begin{array}{c}\text { Cerebellum } \\
(n=15)\end{array}$ & $\begin{array}{c}\text { Frontal } \\
\text { Cortex } \\
(n=16)\end{array}$ & $\begin{array}{c}\text { Occipital } \\
\text { Cortex } \\
(n=17)\end{array}$ & $\begin{array}{c}\text { Temporal } \\
\text { Cortex } \\
(n=15)\end{array}$ & $\begin{array}{c}\text { Striatum } \\
(n=11)\end{array}$ & $\begin{array}{c}\text { Thalamus } \\
(n=8)\end{array}$ & $\begin{array}{l}\text { Hypothalamus } \\
\qquad(n=4)\end{array}$ & $\begin{array}{l}\text { Whole } \\
\text { Brain, } \\
\text { Average } \\
(n=115)\end{array}$ \\
\hline \multirow{2}{*}{ PFBS } & Range: & n.d. & n.d. -2.97 & n.d. -3.14 & n.d. -2.86 & n.d. -2.82 & n.d. & n.d. & n.d. & n.d. -3.14 \\
\hline & $\%>M^{\prime} O Q^{a}:$ & 0 & 20 & 6.3 & 5.9 & 13.3 & 0 & 0 & 0 & 6.1 \\
\hline \multirow{2}{*}{ PFHXA } & Range: & n.d. -0.16 & n.d. & n.d. $=0.10$ & n.d. -0.17 & n.d. & n.d. -1.28 & n.d. -0.45 & n.d. & n.d. -1.28 \\
\hline & $\%>M^{2} O Q^{a}:$ & 7.1 & 0 & 6.3 & 5.9 & 0 & 9.1 & 12.5 & 0 & 6.1 \\
\hline \multirow{2}{*}{ PFHpA } & Range: & n.d. -0.24 & n.d. -0.20 & n.d. -0.33 & n.d. -0.58 & n.d. -0.20 & n.d. -2.51 & n.d. -6.66 & n.d. -0.80 & n.d. -6.66 \\
\hline & $\%>M_{L O Q}:$ & 28.6 & 40 & 37.5 & 23.5 & 6.7 & 45.5 & 25 & 25 & 31.3 \\
\hline \multirow{2}{*}{ 6:2 FTOH } & Range: & n.d. & n.d. & n.d. & n.d. & n.d. -3.25 & n.d. & n.d. & n.d. & n.d. -3.25 \\
\hline & $\%>M L O Q^{a}:$ & 0 & 0 & 0 & 0 & 6.7 & 0 & 0 & 0 & 0.9 \\
\hline \multirow{2}{*}{ 8:2 FTOH } & Range: & n.d. -12.79 & n.d. & n.d. -3.46 & n.d. & n.d. -16.72 & n.d. & n.d. -3.72 & n.d. & n.d. -28.39 \\
\hline & $\%>\mathrm{MLOQ}^{\mathrm{a}}:$ & 21.4 & 0 & 6.3 & 0 & 13.3 & 0 & 12.5 & 0 & 8.7 \\
\hline \multirow{2}{*}{ 10:2 FTOH } & Range: & n.d. -2.02 & n.d. & n.d. & n.d. & n.d. -3.23 & n.d. & n.d. & n.d. & n.d. -3.23 \\
\hline & $\%>\mathrm{MLOQ}^{\mathrm{a}}:$ & 7.1 & 0 & 0 & 0 & 13.3 & 0 & 0 & 0 & 3.5 \\
\hline \multirow{2}{*}{ 6:2 FTUCA } & Range: & n.d. & n.d. -0.013 & n.d. & n.d. & n.d. -0.014 & n.d. -0.013 & n.d. -0.710 & n.d. & n.d. -0.710 \\
\hline & $\%>M L O Q^{a}:$ & 0 & 13.3 & 0 & 0 & 6.7 & 18.2 & 12.5 & 0 & 7 \\
\hline \multirow{2}{*}{ 8:2 FTUCA } & Range: & n.d. -0.024 & n.d. -0.018 & n.d. -0.019 & n.d. -0.025 & n.d. -0.095 & n.d. -0.236 & n.d. -1.347 & n.d. -0.024 & n.d. -1.347 \\
\hline & $\%>M^{\prime} O Q^{\mathrm{a}}:$ & 7.1 & 6.7 & 6.3 & 11.8 & 26.7 & 27.3 & 37.5 & 25 & 15.7 \\
\hline \multirow{2}{*}{ 10:2 FTUCA } & Range: & n.d. & n.d. -0.031 & n.d. -0.018 & n.d. & n.d. -0.025 & n.d. -0.079 & n.d. -0.804 & n.d. & n.d. -0.804 \\
\hline & $\%>M^{2}{ }^{2}:$ & 0 & 13.3 & 18.8 & 0 & 26.7 & 18.2 & 12.5 & 0 & 12.2 \\
\hline \multirow{2}{*}{ N-Me-FOSA } & Range: & n.d. -1.98 & n.d. & n.d. & n.d. & n.d. -1.66 & n.d. & n.d. -9.44 & n.d. & n.d. -9.44 \\
\hline & $\%>M^{\prime} O Q^{a}:$ & 14.3 & 0 & 0 & 0 & 13.3 & 0 & 12.5 & 0 & 5.2 \\
\hline
\end{tabular}

$\infty \%>$ MLOQ: The percentage of samples above the method limit of quantification 
To date, wildlife studies have shown no correlative relationship between any PFAA concentration and extractable lipid content in the liver (polar bears, mink (Mustela vison)), or plasma (bottlenose dolphins (Tursiops truncatus)) (Kannan et al., 2002, 2005; Houde et al., 2006b). However, such relationships had yet to be investigated in the brain until the present study. Wet weight concentrations of PFCAs $\left(C_{10}-C_{15}\right)$ were all significantly ( $\mathrm{p} \leq 0.002)$ correlated with lipid content throughout the entire brain, with Pearson coefficient r-values ranging from 0.29 (PFDA) to 0.51 (PFTeA) (Table 3.3). Concentrations of PFOS were also weakly correlated with lipid content $(p=0.013)$.

Although strong and significant lipid content-[PFAA] correlations existed within the whole brain (Figure 3.1), only a few compounds were correlated within an individual compartment. $\mathrm{C}_{13}-\mathrm{C}_{15}$ PFCAs were strongly correlated in the pons/medulla (r-values $=$ $0.53-0.66) ; \mathrm{C}_{12}-\mathrm{C}_{14}$ PFCAs were strongly correlated in the temporal cortex (r-values $=$ $0.59-0.66) ; \mathrm{C}_{13}$ PFCA was strongly correlated in the frontal cortex (r-value $=0.60$ ); and $\mathrm{C}_{14}-\mathrm{C}_{15}$ PFCAs were strongly correlated in the cerebellum (r-values $=0.61$ and 0.60 , respectively) (Figure 3.1).

A complete list of $r$ - and p-values can be found in Table 3.3. These compartmental correlations accounted for much of the lipid content-[PFAA] correlations in the entire brain. When the pons/medulla, temporal cortex, and cerebellum were removed from the whole brain analysis, all lipid content-[PFAA] correlations either disappeared, as was the case for PFOS, PFDA, PFDoA, and PFPA, or became much weaker, as was the case for PFUA, PFTriA and PFTeA. Pearsons' product-moment correlation coefficient r-values ranged from 0.24 to 0.29 . 


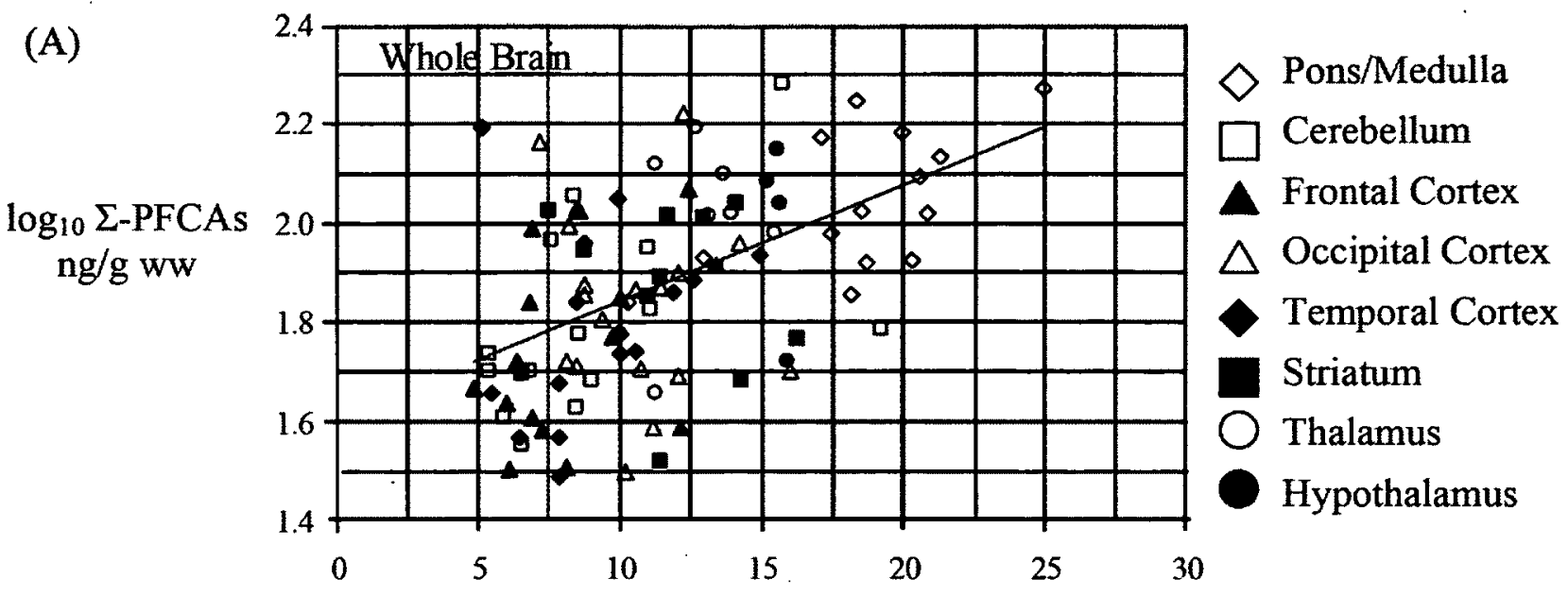

(B)

$\log _{10}$ PFTeA
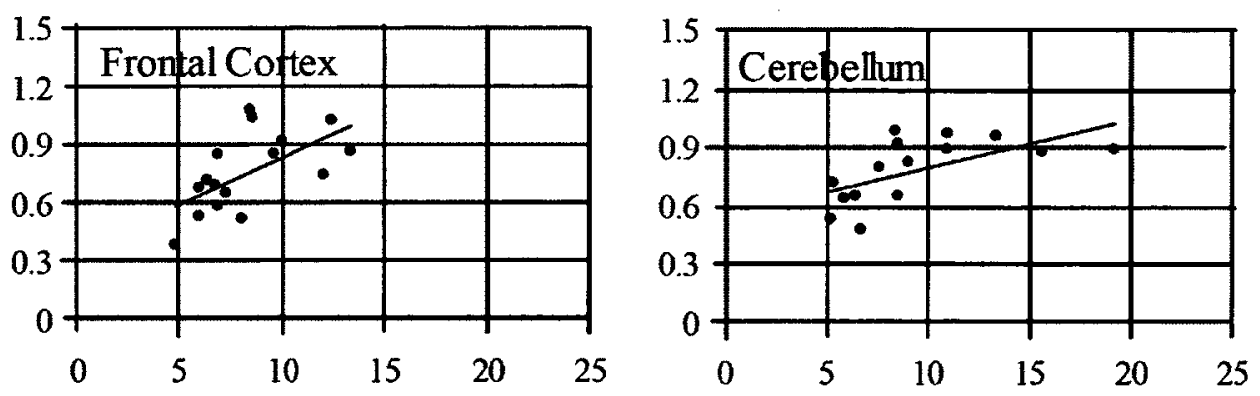

$\mathrm{ng} / \mathrm{g}$ ww
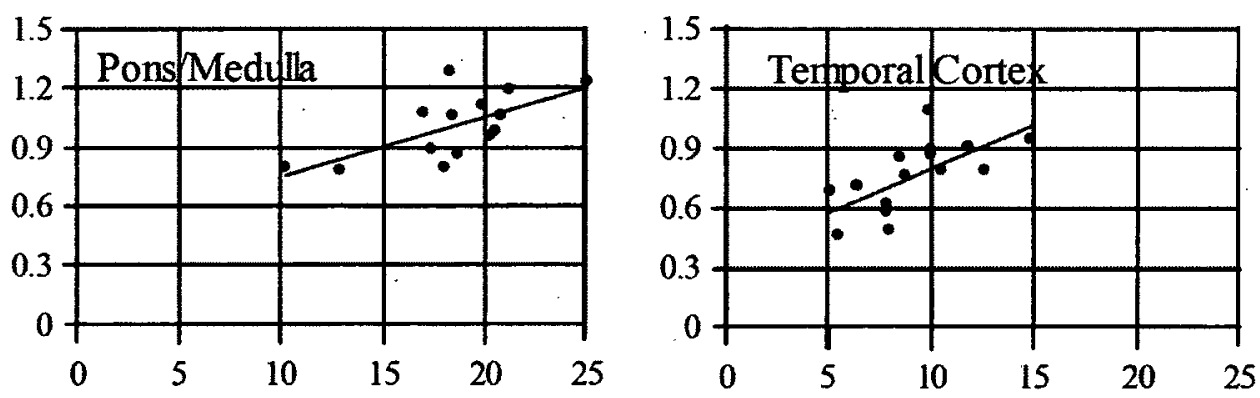

$\%$ Lipid, (g lipid/g tissue) $\times 100 \%$

Figure 3.1 Lipid-PFAA correlations. (A) Correlation between extractable lipid content $(\%)$ and concentration ( $\mathrm{ng} / \mathrm{g}$ wet $\mathrm{wt})$ of the sum of all perfluoroalkyl carboxylates $(\Sigma$ PFCAs) across the whole brain ( $n=115, r=0.47)$. (B) Correlation between lipid content (\%) and concentration (ng/g wet wt) of perfluorotetradecanoic acid (PFTeA) for the frontal cortex, $(n=16, r=0.60)$; cerebellum $(n=15, r=0.61)$; pons/medulla $(n=14, r=$ $0.65)$ and temporal cortex, $(n=15, r=0.60)$. 
Table 3.3 Correlations of lipid content (\%) and perfluoroalkyl acid concentrations (ng/g wet wt) for all brain samples tested $(n=115)$. $r$ - and $p$-values of all statistically significant correlations are shown. $\mathrm{p} \leq 0.05$ was considered to be statistically significant, and $\mathrm{r}>0.50$ was considered a strong correlation.

\begin{tabular}{lcc}
\hline & $\begin{array}{c}\text { Pearson } \\
\text { Coefficient, } \mathbf{r}\end{array}$ & $\begin{array}{c}\text { Significance } \\
\text { Level, } \mathbf{p}\end{array}$ \\
\hline & Whole Brain $(\mathrm{n}=115)$ \\
PFOS & 0.23 & 0.013 \\
PFDA & 0.29 & 0.002 \\
PFUA & 0.48 & $<0.00001$ \\
PFDoA & 0.48 & $<0.00001$ \\
PFTriA & 0.49 & $<0.00001$ \\
PFTeA & 0.51 & $<0.00001$ \\
PFPA & 0.35 & 0.0001 \\
\hline \multicolumn{3}{c}{ Pons/Medulla $(\mathrm{n}=14)$} \\
PFTriA & 0.66 & 0.010 \\
PFTeA & 0.65 & 0.012 \\
PFPA & 0.53 & 0.049 \\
\hline \multicolumn{3}{c}{ Temporal Cortex $(\mathrm{n}=15)$} \\
PFDoA & 0.59 & 0.021 \\
PFTriA & 0.66 & 0.008 \\
PFTeA & 0.66 & 0.007 \\
\hline \multicolumn{3}{c}{ Frontal Cortex $(\mathrm{n}=16)$} \\
PFTeA & 0.60 & 0.014 \\
\hline \multicolumn{3}{c}{ Cerebellum $(\mathrm{n}=14)$} \\
PFTeA & 0.61 & 0.017 \\
PFPA & 0.60 & 0.018 \\
\hline \multicolumn{3}{c}{} \\
\hline
\end{tabular}

The lipid extraction method used in the present study primarily extracts non-polar (free) fatty acids such as triglycerides rather than polar lipids. Although there are many types of fatty acids in the brain, including phospholipids, triglycerides, gangliosides, and sphingolipids, several are not extractable by the lipid extraction method used. It is likely that the presently observed relationships between PFAA concentrations and extractable 
lipid content are in fact between long-chain PFCAs and non-polar free fatty acids. The major fatty acids found in the brain are often between 12 and 26 carbons long, closely resembling the long-chain PFCAs detected in this study (Siegel et al., 1999).

This is the first study to our knowledge that has linked PFAA concentrations with lipid content, regardless of tissue or species. As a result of the correlation found between PFAA concentrations and extractable lipid, lipid content was considered a confounding factor in this study. In order to examine differences in PFC accumulation in different regions of the brain, all concentrations (ng/g ww) were normalized for lipid content, e.g., ng/g lipid weight (lw), for subsequent statistical analysis.

\subsubsection{Gender Differences}

Only three regions of the brain showed any significant differences between males and females in mean PFAA or PFOSA (lw) concentrations. These regions were the cerebellum, the hypothalamus and the temporal cortex. In the cerebellum, $\mathrm{PFHxS}$, PFDoA, and PFTriA mean levels were significantly higher $(\mathrm{p}<0.03)$ in males relative to females. Similarly, in the hypothalamus, PFNA, PFUA, PFDoA, and PFTriA mean levels were all found to be significantly higher $(p<0.05)$ in males relative to females. However, the small sample set size of the hypothalmus $(n=4)$ should be noted. The temporal cortex showed a significantly higher mean concentration of PFNA in females relative to males $(p=0.04)$. Of the 96 gender differences for PFCs examined $(12$ compounds for each of the 8 brain regions), there were only 8 significantly different concentrations between males and females. Therefore it was concluded that overall, gender was not considered a 
confounding factor of the relative PFCA, PFSA and PFOSA concentrations among brain regions.

\subsubsection{Age Correlations}

In the whole brain, positive correlations $(\mathrm{p}<0.04)$ with age were observed for PFOS and $\mathrm{C}_{10}-\mathrm{C}_{15}$ PFCA concentrations. The strongest correlation was found for PFTriA ( $\mathrm{r}=0.37$ ) (Figure 3.2). PFCAs and PFSAs have a large range of half-lives, ranging from hours in rats and rabbits to years in humans and other larger mammals (Benskin et al., 2009; De Silva et al., 2009). Although half-lives of bioaccumulative PFCAs and PFSAs in polar bears have not been reported, these age correlations suggest half-lives in the order of years for PFOS and long-chain PFCAs, such that they accumulate in the brain faster than they can be eliminated. This may be due in part to the selectivity of the blood-brain barrier (BBB). The BBB serves to limit the transportation of substances to and from the brain, making it difficult for PFAAs to leave the brain. Although these correlations are present for the whole brain, the only significant age correlation seen for an individual brain region was PFDoA in the occipital cortex $(p=$ 0.037). No other brain region showed a single significant age correlation. Since the focus of this chapter is on the PFAA distribution among brain regions, the correlations with age for the whole brain were not deemed influential to the study, and therefore age was not considered a confounding factor. 
(A)

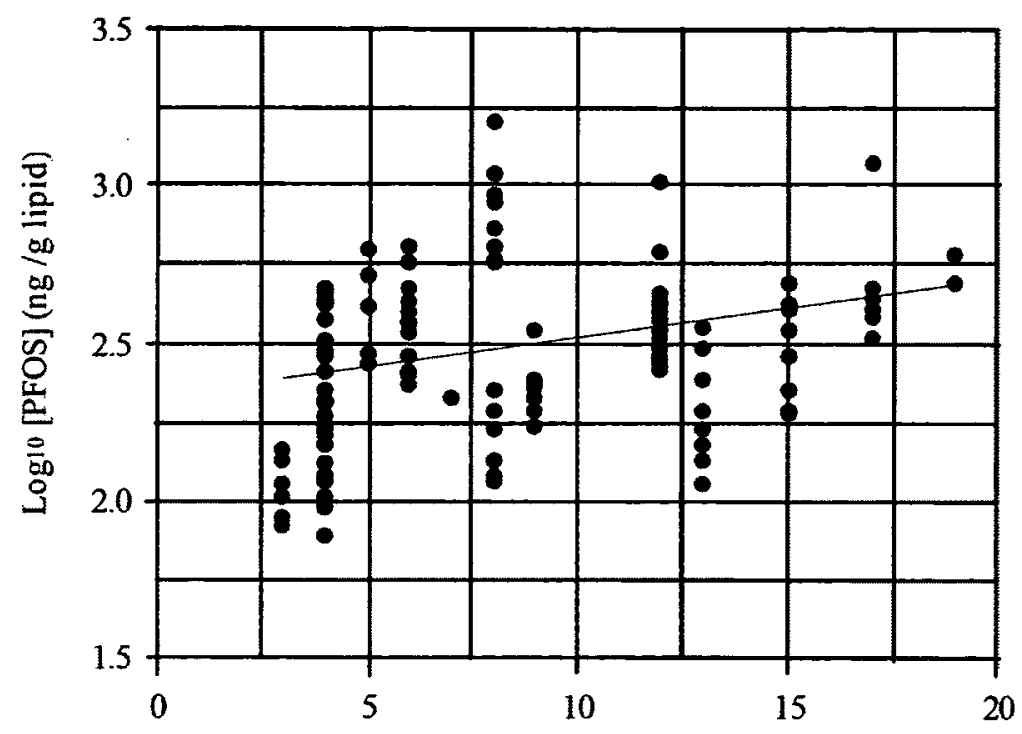

(B)

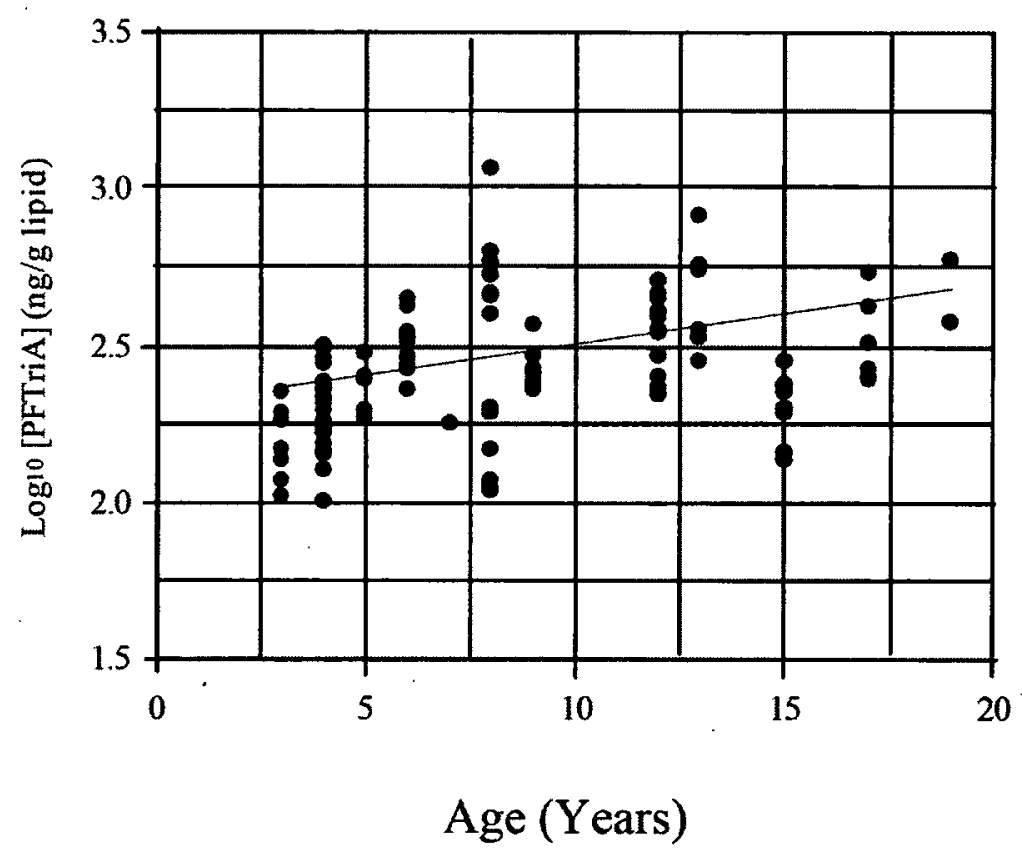

Figure 3.2 (A) Perfluorooctane sulfonate (PFOS) and (B) perfluorotridecanoic acid (PFTriA) concentrations ( $\log _{10}$-transformed, lipid corrected) versus age (years) across all brain samples from East Greenland polar bears sampled in 2006. 


\subsubsection{Relationship between PFOS and PFOSA Concentrations}

PFOSA is the ultimate precursor that is degraded to PFOS (Martin et al., 2010; Gebbink et al., 2011). PFOSA was detected in $87 \%$ of the polar bear brain samples. In all brain compartments tested, a positive, statistically significant correlation between PFOS and PFOSA existed for all samples for which both PFOS and PFOSA were above the MLOQ. Across the whole brain, PFOS was strongly correlated with PFOSA $(r=0.70)$, with a mean PFOS:PFOSA concentration ratio of $25 \pm 1: 1$ (Figure 3.3). Correlations between PFOS and PFOSA were also seen for every individual brain region with the exception of the hypothalamus $(n=4)$, most likely due to its small sample set size. The region with the strongest PFOS:PFOSA concentration correlation was the thalamus $(r=$ 0.85), although differences among compartments were not statistically significant (Table 3.4). Previously, both Dietz et al. (2008), and Smithwick et al. (2005a,b) showed PFOS:PFOSA concentration ratios in the liver of East Greenland polar bears to be in the range of $100-250$. These ratios in the liver are an order of magnitude higher than the finding for the present brain samples and can be hypothesized as being due to one of three possibilities. Either (1) PFOSA is much more permeable and transportable across the BBB than PFOS, (2) PFOSA metabolism is extensive in the liver relative to any PFOS elimination and/or (3) PFOSA metabolism in the brain is much less effective than in the liver. 


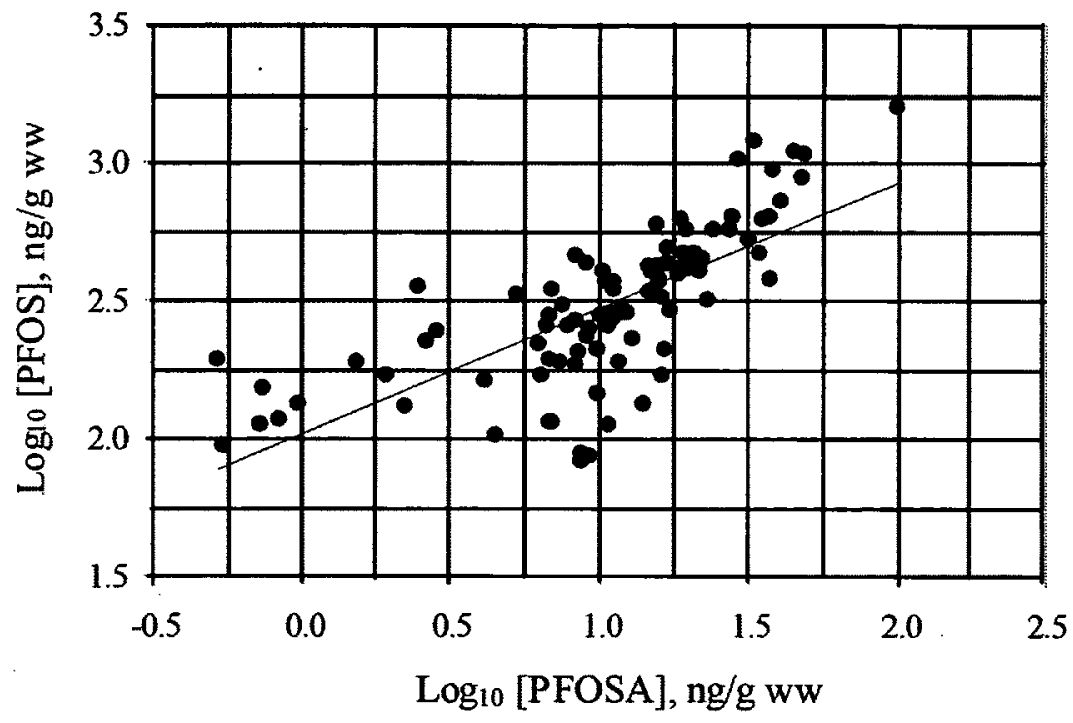

Figure 3.3 Pearsons' product-moment correlation analysis between perfluorooctane sulfonate (PFOS) and perfluorooctane sulfonamide (PFOSA) across the entire brain. $r=$ 0.70 . Concentrations were $\log _{10}$-transformed, and not lipid corrected. The PFOS:PFOSA ratio across all brain samples was $25 \pm 1: 1$. 
Table 3.4 Pearsons' product-moment correlation analyses between perfluorooctane sulfonate (PFOS) and perfluorooctane sulfonamide (PFOSA) (ng/g ww) for all brain regions and their respective PFOS:PFOSA ratios. $r$ - and $p$-values of all statistically significant correlations are shown.

\begin{tabular}{lccc}
\hline & $\begin{array}{c}\text { Pearson } \\
\text { Coefficient, } r\end{array}$ & $\begin{array}{c}\text { Significance } \\
\text { Level, } p\end{array}$ & $\begin{array}{c}\text { PFOS to PFOSA } \\
\text { conc. Ratio ( } \mathbf{S E})\end{array}$ \\
\hline Whole Brain & 0.70 & $<0.0001$ & $25 \pm 1$ \\
Pons/Medulla & 0.71 & 0.013 & $34 \pm 4$ \\
Cerebellum & 0.80 & 0.0009 & $25 \pm 2$ \\
Frontal Cortex & 0.69 & 0.014 & $25 \pm 3$ \\
Occipital Cortex & 0.72 & 0.0056 & $23 \pm 1$ \\
Temporal Cortex & 0.68 & 0.046 & $25 \pm 4$ \\
Striatum & 0.80 & 0.018 & $23 \pm 2$ \\
Thalamus & 0.85 & 0.032 & $20 \pm 2$ \\
Hypothalamus & 0.88 & 0.12 & $30 \pm 4$ \\
\hline
\end{tabular}

The neurotoxicity of PFOS and PFOSA was recently investigated in vitro in both differentiated and undifferentiated PC12 cells. The study showed that at the same exposure concentrations, PFOSA was more disruptive to DNA synthesis than PFOS (Slotkin et al., 2008). Cells exposed to a $250 \mu \mathrm{M}$ PFOS solution showed a decrease in DNA synthesis by approximately $10 \%$. When the cells were exposed to a $250 \mu \mathrm{M}$ PFOSA solution, DNA synthesis decreased by almost $80 \%$. The authors attributed the difference in neurotoxicity in part to the difference in the lipophilicities of PFOS and PFOSA: PFOSA has a higher lipophilicity than PFOS (a free sulfonic acid) and, as a result, is more readily available to cross the BBB and elicit neurotoxic effects. This indicates that the low PFOS:PFOSA correlation (25:1) found in the present polar bear 
brains can at least be partially attributed to the higher permeability of PFOSA relative to PFOS across the BBB.

\subsubsection{PFCA and PFSA Patterns and Concentrations among Brain Regions}

Among brain regions, lipid-normalized $\Sigma$-PFCA concentrations accounted for $66 \%$ of $\Sigma$-PFAA concentrations, with the remaining $34 \%$ attributable to $\Sigma$-PFSAs, namely PFOS. PFOS was the dominant PFAA $(347.10 \pm 23.19 \mathrm{ng} / \mathrm{g} \mathrm{lw})$, accounting for $93 \%$ of the $\Sigma$-PFSA concentrations (Table 3.5). PFOS levels accounted for $31 \%$ of $\Sigma$-PFAA concentrations, followed by PFTriA (27\%), PFUA (14\%), and PFPA (9\%). As further discussed below, the PFCAs present at the highest concentrations in the brain are longer chains $\left(C_{11}-C_{15}\right)$ compared to the shorter chains $\left(C_{9}-C_{11}\right)$ that have been previously seen in East Greenland polar bear liver samples (Smithwick et al., 2005b; Dietz et al., 2008). These differences may indicate differences in PFAA-protein associations between the brain and the liver. 
Table 3.5 Arithmetic mean lipid contents and lipid-corrected concentrations (ng/g lipid \pm SE), including concentration ranges, of all detected perfluorinated compounds in all brain regions.

\begin{tabular}{|c|c|c|c|c|c|c|c|c|c|c|}
\hline $\begin{array}{c}\text { Brain } \\
\text { Compartment }\end{array}$ & & $\begin{array}{c}\text { Pons/ } \\
\text { Medulla } \\
(n=14)\end{array}$ & $\begin{array}{l}\text { Cerebellum } \\
(n=15)\end{array}$ & $\begin{array}{l}\text { Frontal } \\
\text { Cortex } \\
(n=16)\end{array}$ & $\begin{array}{c}\text { Occipital } \\
\text { Cortex } \\
(n=17)\end{array}$ & $\begin{array}{c}\text { Temporal } \\
\text { Cortex }(n=15)\end{array}$ & $\begin{array}{c}\text { Striatum } \\
(n=11)\end{array}$ & $\begin{array}{c}\text { Thalamus } \\
(n=8)\end{array}$ & $\begin{array}{l}\text { Hypothalamus } \\
\qquad(n=4)\end{array}$ & $\begin{array}{l}\text { Whole Brain, } \\
\text { Average } \\
(n=115)\end{array}$ \\
\hline $\begin{array}{c}\text { Lipid Content } \\
(\% \pm \mathrm{SE})^{\mathrm{a}} \\
\end{array}$ & & $18.48 \pm 0.95$ & $9.49 \pm 1.03$ & $8.38 \pm 0.64$ & $10.54 \pm 0.57$ & $9.17 \pm 0.69$ & $11.44 \pm 0.89$ & $12.65 \pm 0.63$ & $15.55 \pm 0.15$ & $11.20 \pm .0 .39$ \\
\hline \multirow{2}{*}{ PFOA } & Mean: & $1.47 \pm 0.57$ & $2.98 \pm 0.78$ & $3.33 \pm 0.96$ & $2.00 \pm 0.57$ & $3.07 \pm 0.83$ & $2.00 \pm 1.20$ & $6.88 \pm 6.18$ & n.d. & $2.71 \pm 0.50$ \\
\hline & Range: & n.d. -8.41 & n.d. -11.70 & n.d. -13.98 & n.d. -7.85 & n.d. -13.11 & n.d. -13.89 & n.d. -50.12 & n.d. & n.d. -50.12 \\
\hline \multirow{2}{*}{ PFNA } & Mean: & $13.81 \pm 2.75$ & $26.49 \pm 4.62$ & $21.13 \pm 3.27$ & $17.40 \pm 3.02$ & $24.08 \pm 7.13$ & $12.02 \pm 1.93$ & $20.04 \pm 11.39$ & $10.30 \pm 1.76$ & $18.85 \pm 1.61$ \\
\hline & Range: & $6.90-46.23$ & $6.42-65.24$ & $9.08-62.91$ & $6.31-58.54$ & $4.83-121.11$ & $2.86-21.47$ & $1.68-99.07$ & $5.09-12.77$ & $1.68-121.11$ \\
\hline \multirow{2}{*}{ PFDA } & Mean: & $16.60 \pm 2.41$ & $24.37 \pm 4.36$ & $21.97 \pm 2.96$ & $19.21 \pm 2.42$ & $19.79 \pm 2.68$ & $17.72 \pm 2.97$ & $26.85 \pm 9.38$ & $18.77 \pm 3.20$ & $20.39 \pm 1.28$ \\
\hline & Range: & $6.01-36.54$ & $7.01-68.22$ & $5.23-50.24$ & $4.69-36.40$ & 8.77 - 43.32 & $9.26-42.99$ & $7.26-89.69$ & $10.24-25.61$ & $4.69 * 89.69$ \\
\hline \multirow{2}{*}{ PFUA } & Mean: & $139.80 \pm 13.21$ & $160.48 \pm 18.45$ & $166.97 \pm 19.10$ & $149.79 \pm 17.01$ & $147.04 \pm 15.53$ & $148.98 \pm 21.63$ & $153.80 \pm 21.21$ & $151.10 \pm 28.78$ & $151.67 \pm 6.68$ \\
\hline & Range: & $77.24-268.84$ & $66.39-292.26$ & $65.01+320.39$ & $62.06 \cdot 315.19$ & $87.31-256.90$ & $70.23-314.96$ & $56.49-240.07$ & $71.00-207.89$ & $43.06 \cdot 504.71$ \\
\hline \multirow{2}{*}{ PFDoA } & Mean: & $62.00+4.86$ & $68.41 \pm 6.95$ & $73.01 \pm 6.88$ & $68.49 \pm 9.47$ & $64.95 \pm 5.42$ & $68.35 \pm 8.88$ & $75.67 \pm 8.76$ & $69.20 \pm 11.48$ & $68.00 \pm 2.89$ \\
\hline & Range: & $35.64-87.69$ & $25.78-124.46$ & $24.77-122.97$ & $24.77-174.69$ & $37.20-101.38$ & $30.76-130.83$ & $31.76-106.67$ & $34.90-82.35$ & $17.84-219.74$ \\
\hline \multirow{2}{*}{ PFTriA } & Mean: & $262.20 \pm 18.54$ & $288.96 \pm 31.44$ & $319.95 \pm 37.81$ & $300.50 \pm 46.27$ & $263.56 \pm 24.31$ & $302.53 \pm 44.68$ & $341.87 \pm 38.34$ & $313.38 \pm 65.75$ & $295.74 * 14.25$ \\
\hline & Range: & $165.00-390.90$ & $116.43-535.94$ & $106.96-623.10$ & $109.18-806.63$ & $135.85-463.02$ & $104.29-629.10$ & $175.83-529.68$ & $136.40-463.02$ & $100.34-1143.37$ \\
\hline \multirow{2}{*}{ PFTeA } & Mean: & $57.52 \pm 4.86$ & $71.67 \pm 5.39$ & $75.71 \pm 7.06$ & $74.70 \pm 11.74$ & $67.49 \pm 5.48$ & $67.04 \pm 8.86$ & $83.45 \pm 15.09$ & $52.49 \pm 8.98$ & $70.04 \pm 3.05$ \\
\hline & Range: & $34.20-104.79$ & $40.14-113.47$ & $40.11-140.46$ & $30.84-229.35$ & $38.52-121.74$ & $25.99 \cdot 103.42$ & $45.81-178.93$ & $29.96-70.33$ & $25.99-229.35$ \\
\hline \multirow{2}{*}{ PFPA } & Mean: & $74.91 \pm 6.04$ & $101.12 \pm 8.88$ & $109.63 \pm 13.75$ & $115.58 \pm 21.88$ & $105.27 \pm 15.08$ & $96.64 \pm 16.07$ & $92.07 \pm 18.54$ & $65.76 \pm 14.80$ & $100.99 \pm 5.76$ \\
\hline & Range: & $37.08-110.76$ & $54.63-153.88$ & $57.29-237.34$ & $42.71-438.07$ & $52.35-277.13$ & $20.65-159.41$ & $15.92-153.55$ & $42.64-107.92$ & $15.92-438.07$ \\
\hline \multirow{2}{*}{ ¿-PFCA } & Mean: & $629.04 \pm 45.02$ & $745.71 \pm 71.93$ & $793.20 \pm 80.53$ & $749.01 \pm 105.84$ & $696.68 \pm 62.84$ & $719.54 \pm 97.10$ & $808.33 \pm 100.49$ & $682.80 \pm 124.55$ & $730.35 \pm 31.94$ \\
\hline & Range: & $395.76-964.54$ & $318.07-1347.90$ & $318.65-1419.57$ & $310.92-2033.03$ & $390.69-1129.30$ & $289.52-1395.63$ & $405.69-1230.44$ & $330.80-903.64$ & $252.43-2515.83$ \\
\hline \multirow{2}{*}{ PFHxS } & Mean: & $7.66 \pm 1.48$ & $22.81 \pm 4.65$ & $18.40 \pm 3.22$ & $13.78 \pm 1.97$ & $16.97 \pm 3.16$ & $8.14 \pm 3.14$ & $10.59 \pm 6.01$ & $8.31 \pm 0.91$ & $14.17 \pm 1.20$ \\
\hline & Range: & $1.39-22.08$ & $3.56-55.43$ & 2.54 - 48.59 & $3.14-31.91$ & $5.18-52.19$ & n.d. -36.39 & n.d. -51.43 & $5.80-9.84$ & n.d. -55.43 \\
\hline \multirow{2}{*}{ PFOS } & Mean: & $259.39 \pm .36 .63$ & $446.52 \pm 91.88$ & $411.16 \pm 62.61$ & $320.31 \pm 40.86$ & $347.92 \pm 54.10$ & $305.05 \pm 69.60$ & $310.59 \pm 59.09$ & $379.00 \pm 77.10$ & $347.10 \pm 23.19$ \\
\hline & Range: & $93.21-573.52$ & $114.55-1180.07$ & $117.50-1090.21$ & $86.55-725.49$ & $112.53-884.04$ & $81.71 \cdot 930.15$ & $113.05-636.88$ & $188.63-564.90$ & $75.93-1583.06$ \\
\hline \multirow{2}{*}{ PFDS } & Mean: & $7.86 \pm 2.02$ & $14.28 \pm 3.93$ & $14.09 \pm 3.22$ & $11.76 \pm 2.55$ & $13.30 \pm 3.84$ & $14.99 \pm 5.34$ & $19.79 \pm 12.74$ & $4.12 \pm 1.49$ & $12.86 \pm 1.44$ \\
\hline & Range: & $0.88-27.57$ & n.d. -49.17 & n.d. -40.42 & n.d. -29.51 & n.d. -46.57 & n.d. -52.95 & n.d. -107.75 & n.d. -6.75 & n.d. -107.75 \\
\hline \multirow{2}{*}{ E-PFSA } & Mean: & $275.08 \pm 37.52$ & $488.58 \pm 95.06$ & $445.63 \pm 63.51$ & $347.19 \pm 41.86$ & $383.53 \pm 58.19$ & $328.46 \pm 69.85$ & $341.20 \pm 65.28$ & $391.61 \pm 77.36$ & $376.06 \pm 24.07$ \\
\hline & Range: & $106.00-585.26$ & $120.50-1249.78$ & $136.75-1122.22$ & $92.75-745.79$ & $120.18-916.62$ & $91.61-949.06$ & $115.90-645.59$ & $197.65-574.86$ & $78.81-1650.43$ \\
\hline \multirow{2}{*}{ PFOSA } & Mean: & $8.34 \pm 2.04$ & $17.38 \pm 3.56$ & $15.78 \pm 3.24$ & $12.69 \pm 2.38$ & $13.14 \pm 3.55$ & $10.82 \pm 3.31$ & $14.21 \pm 4.62$ & $13.32 \pm 3.76$ & $13.63 \pm 1.28$ \\
\hline & Range: & $0.52-22.99$ & n.d. -49.16 & n.d. -44.67 & n.d. -40.40 & n.d. -47.47 & n.d. -38.35 & n.d. -37.35 & $7.44-24.32$ & n.d. -98.52 \\
\hline
\end{tabular}

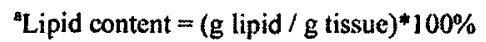


For the mean concentrations of longer chain PFCAs (Figure 3.4a), after lipidnormalization there were no significant differences among the eight brain regions ( $>0.05$ ) (Figure 3.4b). Brain compartments with higher extractable lipid content (and thus a more non-polar chemical environment) may provide a suitable location for the accumulation of long-chain PFCAs (containing a long hydrophobic tail). Lipids make up approximately $50 \%$ of the brain's dry weight, making it the second-most lipid-rich tissue in the body following adipose tissue (Mitchell et al., 2011a). Although it is believed that the brain is able to synthesize a few nonessential fatty acids, the majority of fatty acids needed for the brain's normal activity must cross the BBB. It is important to note that longer-chain PFCAs resemble saturated fatty acids, which are constantly being shuttled across the BBB to replenish lipids in the brain (Mitchell et al., 2011a, 2011b).

It has been hypothesized that although small- and medium-chain length fatty acids are capable of passive diffusion across the BBB, longer-chain length fatty acids require a mechanistic mode of transport to cross the BBB. While this mode of transport has not been fully elucidated, it appears that non-specific fatty acid transport proteins and nonspecific fatty acid binding proteins on the BBB membrane play a role (Mitchell et al., $2011 \mathrm{a}, 2011 \mathrm{~b})$. Here, we hypothesize that long-chain PFCAs $\left(\mathrm{C}_{11}-\mathrm{C}_{14}\right)$, bound to albumin in the blood stream, undergo a similar transport mechanism as saturated fatty acids at the BBB membrane, thus explaining the correlational relationship between longchain PFCA concentrations and extractable lipid content. 

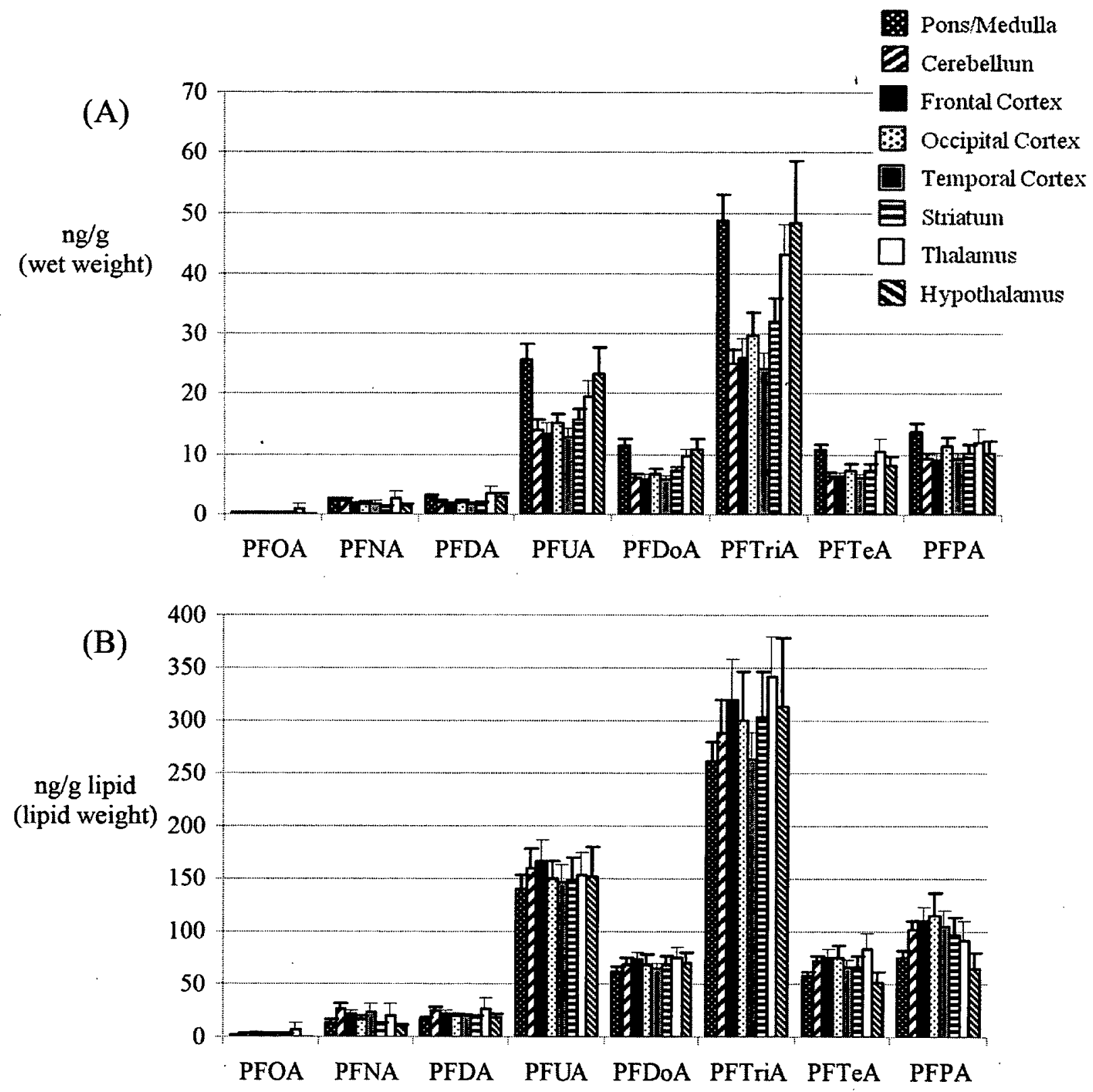

Figure 3.4 Concentrations of perfluoroalkyl carboxylates (PFCAs) throughout the eight brain regions of East Greenland polar bears, with (A) wet weight concentrations and (B) lipid-weight concentrations. Error bars represent standard error. Before lipid-correction, statistically significant differences can be seen between compartments, especially for perfluoroundecanoic acid (PFUA) and perfluorotridecanoic acid (PFTriA). These differences become statistically insignificant once corrected for lipid content in the tissues indicating PFCA brain distribution occurs in a lipid-related fashion. For a full list of abbreviations, please see Table 2.3. 


\subsubsection{Estimate of Measured PFC Burden in the Entire Brain}

In order to compare with other studies, we were able to calculate a reasonable estimate of the measured PFC burden in the whole polar bear brain based on the eight brain regions under study. The whole brain mass was recorded for 16 of the 19 bears used in this study (Table 2.1), with an average weight of $392 \mathrm{~g}$. Kamiya and Pirlot (1988) analysed the brain anatomy of the sun bear (Ursus malayanus) and reported the distribution of brain compartments on a percent mass basis. Based on the compartments analysed in this study, concentrations could be directly estimated for approximately $89 \%$ of the total brain weight. For the remaining $11 \%$ of the brain which was not analyzed in this study, the average concentrations throughout the whole brain were used to extrapolate burdens.

The overall burden of PFCs in the polar bear brain was estimated to be $46 \mu \mathrm{g}$ (Table 3.6). This is similar to the burden found in harbour seal (Phoca vitulina) brain (28 $\mu \mathrm{g})$, and higher than the burden found in herring gull (Larus argentatus) brain $(0.16 \mu \mathrm{g})$ (Ahrens et al., 2009; Gebbink and Letcher, 2012). The largest PFC burden was found in the neocortex $(24.1 \mu \mathrm{g})$ due to its large mass $(59.47 \%$ of the total brain mass), followed by the cerebellum $(6.5 \mu \mathrm{g})$, and the diencephalon (3.2 $\mu \mathrm{g})$. Ahrens et al. (2009) estimated that the PFC burden in the brain represented approximately $1 \%$ of the overall PFC body burden in harbour seals. Although further research is needed, it is thus possible that total body burden of PFCs in polar bears could be on the order of milligrams. 
Table 3.6 Estimated PFC burden for the entire polar bear brain. Estimations are based on the polar bear brain masses recorded (Table 2.1), and using brain anatomy data as described by Kamiya and Pirlot (1988).

\begin{tabular}{|c|c|c|c|c|c|c|c|}
\hline Brain Region & $\begin{array}{l}\text { Compartment } \\
\text { Analyzed }^{\mathrm{a}}\end{array}$ & $\begin{array}{l}\text { Percentile mass } \\
\text { composition of } \\
\text { the brain }(\%)^{b}\end{array}$ & $\begin{array}{c}\Sigma \text {-PFCAs } \\
(\mu g)\end{array}$ & $\begin{array}{c}\text { D-PFSAs } \\
(\mu \mathrm{g})\end{array}$ & $\begin{array}{c}\text { PFOS } \\
(\mu g)\end{array}$ & $\begin{array}{l}\text { PFOSA } \\
\quad(\mu g)\end{array}$ & $\begin{array}{c}\text { E-PFCs } \\
(\mu g)^{c}\end{array}$ \\
\hline Neocortex & $\begin{array}{l}\text { Frontal Cortex } \\
\text { Occipital Cortex } \\
\text { Temporal Cortex } \\
\end{array}$ & 59.47 & 15.7 & 8.1 & 8.5 & 0.3 & 24.1 \\
\hline Cerebellum & Cerebellum & 15.44 & 4 & 2.4 & 2.2 & 0.1 & 6.5 \\
\hline Diencephalon & $\begin{array}{c}\text { Thalamus } \\
\text { Hypothalamus }\end{array}$ & 5.23 & 2.1 & 1 & 0.9 & 0 & 3.2 \\
\hline Rhinencephalon & N/A & 5.1 & 1.5 & 0.8 & 0.7 & 0 & 2.3 \\
\hline Medulla Oblongata & Pons/Medulla & 4.44 & 2 & 0.9 & 0.8 & 0 & 2.9 \\
\hline Striatum & Striatum & 4.21 & 1.3 & 0.6 & 0.5 & 0 & 1.9 \\
\hline Mesencephalon & N/A & 3.22 & 1 & 0.5 & 0.4 & 0 & 1.5 \\
\hline Hippocampus & N/A & 1.96 & 0.6 & 0.3 & 0.3 & 0 & 0.9 \\
\hline Olfactory bulb & $\mathrm{N} / \mathrm{A}$ & 0.62 & 0.2 & 0.1 & 0.1 & 0 & 0.3 \\
\hline \multirow[t]{2}{*}{ Septum } & N/A & 0.31 & 0.1 & 0 & 0 & 0 & 0.1 \\
\hline & Whole Brain & 100 & 30 & 15 & 14 & 0.5 & 46 \\
\hline
\end{tabular}

"N/A = Brain region was not analyzed in this study. Burden estimates are based on the average of the compartments analyzed.

'Kamiya \& Pirlot (1988)

${ }^{2} \Sigma$-PFCs $=\Sigma$-PFCAs $+\Sigma$-PFSAs + PFOSA 


\subsubsection{Comparison of PFCAs and PFSAs in the Brains of Other Studied Mammals}

To compare the present brain PFCA and PFSA concentrations in polar bear with data reported elsewhere in tissues of other mammals, comparison on a wet weight basis is required. The dominant PFSA among all brain compartments was PFOS, representing from $91 \%$ (thalamus) to $97 \%$ (hypothalamus) of the $\Sigma$-PFSA concentrations. The mean PFOS levels found in the brain regions of the present polar bears ranged from $31.91 \pm$ 5.91 to $58.77 \pm 11.84 \mathrm{ng} / \mathrm{g}$ ww (Table 3.1 ). These brain levels were comparable to recent studies on the brain of harbour porpoises (24 ng/g ww) off the coast of Ukraine [20], and the brain of harbour seals from the German Bight ( $99 \mathrm{ng} / \mathrm{g} \mathrm{ww}$ ) (Ahrens et al., 2009). PFOS concentrations in the brains of avian species (glaucous gulls, pelicans) have been found to be lower ( $<5 \mathrm{ng} / \mathrm{g}$ ww, and $3.5 \mathrm{ng} / \mathrm{g}$ ww, respectively) than the current polar bear brain samples (Verreault et al., 2005; Olivero-Verbel et al., 2006). This data is summarized in Figure 3.5. The overall dominance of PFOS in the brains in the present study $(35.17 \pm 1.97 \mathrm{ng} / \mathrm{g} \mathrm{ww})$ is consistent with other reports for East Greenland polar bear liver studies. However, the PFOS concentrations in the brain are roughly 100 -fold lower than previously reported liver concentrations $(3,000$ to $4,000 \mathrm{ng} / \mathrm{g} \mathrm{ww})$ for bears collected in the same geographical location and/or the same year (2006) (Bossi et al., 2005; Smithwick et al., 2005a, 2005b; Dietz et al., 2008). 
Figure 3.5 Recently reported mean brain PFOS concentrations among mammalian and avian species (ng/g ww).

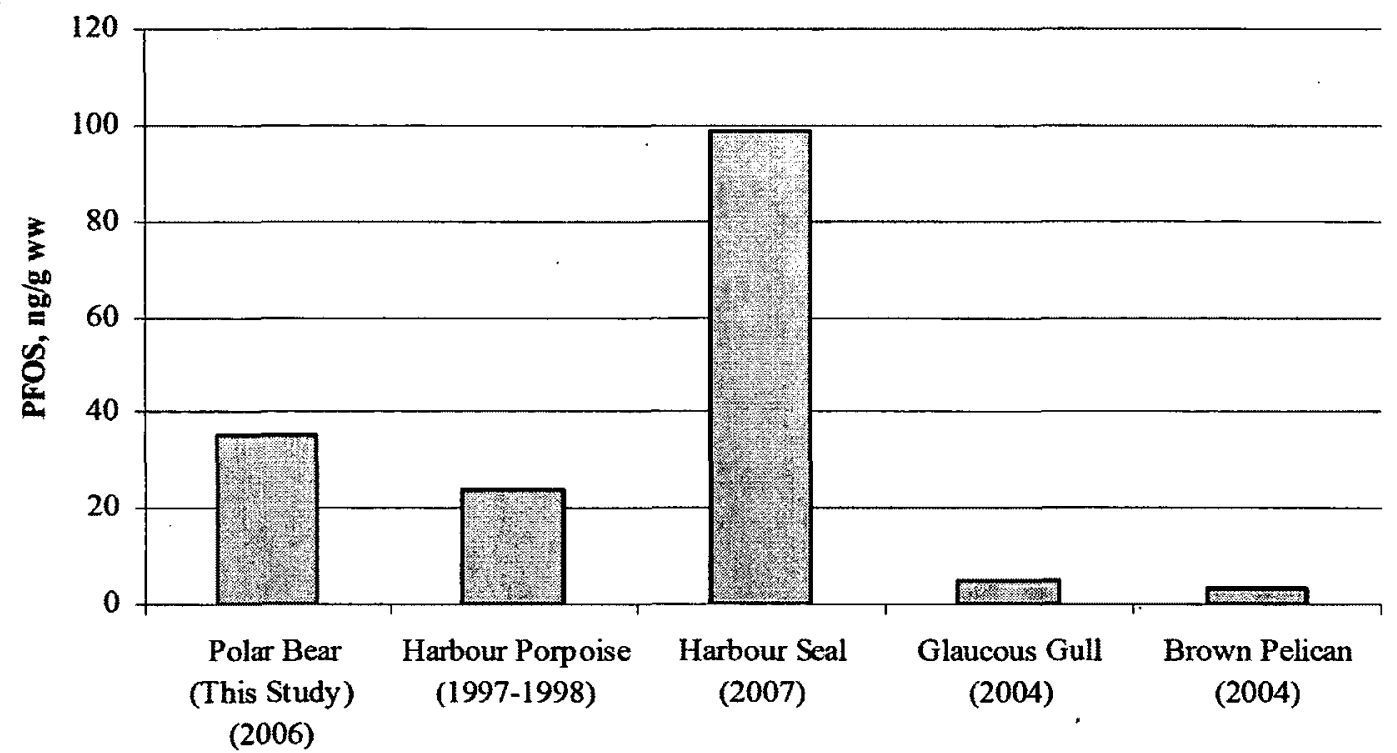

Within all compartments, the major PFCAs were PFTriA $\left(\mathrm{C}_{13}\right)(31.38 \pm 1.47 \mathrm{ng} / \mathrm{g}$ ww), PFUA $\left(C_{11}\right)(16.02 \pm 0.72 \mathrm{ng} / \mathrm{g} w w)$, and PFPA $\left(C_{15}\right)(10.41 \pm 0.48 \mathrm{ng} / \mathrm{g} w w)$. The major PFCA $\left(\mathrm{C}_{13}\right)$ in the brain is a longer chain than what has been reported for polar bear liver, where the major PFCA was PFNA ( $\left.\mathrm{C}_{9}\right)$ (Smithwick et al., 2005a, 2005b). This is a more pronounced shift than what was found in harbour seals (Ahrens et al., 2009), where there was a slight shift from $\mathrm{C}_{9}$ being dominant in liver, to $\mathrm{C}_{10}$ being dominant in brain. The shift towards longer chain-length PFCAs in the brain may be an indication of different pharmacokinetics in the brain due to the transport across the BBB.

This is the first study to show a PFCA (PFTriA) remotely approaching levels of PFOS in any tissue of any wildlife. PFOS has always been the dominant PFAA in East Greenland polar bear liver, with the next most abundant PFAA (PFNA) typically in the 
range of 10 to 20 times lower (Smithwick et al., 2005a, 2005b; Dietz et al., 2008). However, the dominance of PFOS relative to PFTriA is statistically negligible $(p>0.26)$ in the whole brain (PFOS $35.17 \pm 1.97 \mathrm{ng} / \mathrm{g}$ ww vs. PFTriA $31.38 \pm 1.47 \mathrm{ng} / \mathrm{g} \mathrm{ww}$ ), as well as in each of the eight individually analyzed brain regions. This leads to the suggestion that PFCAs may cross the BBB more efficiently than PFSAs, thus explaining PFOS's extreme dominance over PFCAs in the liver, and yet their similar levels in the brain. This hypothesis is supported by the study of Ahrens et al., (2009) who also observed a similar trend in harbour seals. In that study, long-chain PFCAs were proportionally more present in the brain than PFOS, when compared to their levels in the liver: PFCA $\left(\mathrm{C}_{11}-\mathrm{C}_{14}\right)$ levels in the brain were $28 \%$ of those found in the liver, whereas PFOS levels in the brain were only $10 \%$ of those found in the liver. It appears that PFCAs enter the brain more easily than PFOS, which suggests that transport processes across the BBB have a preference for longer-chain PFCAs relative to the liver. This is consistent with the strong correlation that was found between long-chain PFCAs and extractable lipid content, previously discussed.

Odd-chain length PFCAs were present at higher concentrations across all brain regions compared to even-chain length PFCAs of comparable chain length (i.e., PFUA > PFDA, PFTriA > PFDoA, PFPA > PFTeA). This trend has previously been observed in the brain of red-throated divers (Gavia stellata) from the Baltic Sea (Rubarth et al., 2011), as well as in the liver of polar bears and other Arctic species (Smithwick et al., 2005b; Butt et al., 2010). This odd-even relationship seems to be indicative of PFCA sources in the Arctic. It is known that FTOHs, although manufactured solely in even chain-lengths, yield both even and odd chain-length PFCAs upon degradation (Smithwick et al., 2005b). For example, 10:2 FTOH yields both PFDA and PFUA, and 8:2 FTOH yields both PFOA 
and PFNA. The odd-even relationship seen in the brain, and previously in Arctic liver samples, may indicate that PFC exposure in Arctic biota is in part due to volatile FTOHs that are transported to the Arctic and are subsequently degraded to give odd and even chain-length PFCAs.

\subsection{Conclusions}

This study showed that brain tissue with high lipid content may be more susceptible to PFAA exposure, raising concern as to the potential toxicity effects of PFAAs in the brain. This is the first study to compare PFAA levels within different brain compartments in wildlife. Correlations between PFAA concentrations and extractable lipid content were found for PFOS and long-chain PFCAs $\left(C_{10}-C_{15}\right)$. Recent studies on PFAAs in rodents have found that neonatal exposure to PFOS or PFOA can cause disruption to the central nervous system, resulting in abnormal development of motor neurons and significant changes in gene expression, including genes responsible for calcium signalling pathways, peroxisome proliferator-activated receptor (PPAR) signalling, cell communication, and the cell cycle (Wang et al., 2010; Vongphachan et al., 2011). Other symptoms included deranged spontaneous behaviour, hyperactivity that worsened with age, changes in exploratory behaviour, and reduced muscle strength in males (Johansson et al., 2008; Onishchenko et al., 2011). Future work will include analyzing PFAA distribution in other polar bear tissues, in order to examine accumulation pattern differences among tissues, and to estimate tissue burdens (Chapter 4). 


\section{References}

Ahrens, L., Siebert, U., Ebinghaus, R., 2009. Total body burden and tissue distribution of polyfluorinated compounds in harbor seals (Phoca vitulina) from the German Bight. Marine Pollution Bulletin 58, 520-525.

Austin, M.E., Kasturi, B.S., Barber, M., Kannan, K., MohanKumar, P.S., MohanKumar, S.M.J., 2003. Neuroendocrine effects of perfluorooctane sulfonate in rats. Environmental Health Perspectives 111, 1485-1489.

Benskin, J.P., De Silva, A.O., Martin, L.J., Arsenault, G., Mccrindle, R., Riddell, N., Mabury, S.A., Martin, J.W., 2009. Disposition of perfluorinated acid isomers in Sprague-Dawley rats; Part 1: Single dose. Environmental Toxicology and Chemistry $28,542-554$.

Bossi, R., Riget, F.F., Dietz, R., Sonne, C., Fauser, P., Dam, M., Vorkamp, K., 2005. Preliminary screening of perfluorooctane sulfonate (PFOS) and other fluorochemicals in fish, birds and marine mammals from Greenland and the Faroe Islands. Environmental Pollution 136, 323-329.

Butt, C.M., Berger, U., Bossi, R., Tomy, G.T., 2010. Levels and trends of poly- and perfluorinated compounds in the arctic environment. Science of the Total Environment 408, 2936-2965.

Cassone, C.G., Vongphachan, V., Chiu, S.Z., Williams, K.L., Letcher, R.J., Pelletier, E., Crump, D., Kennedy, S.W., 2012. In ovo effects of perfluorohexane sulfonate and perfluorohexanoate on toxicity, development, mRNA expression and thyroid hormone levels in chicken embryos. Toxicological Sciences (in review).

De Silva, A.O., Benskin, J.P., Martin, L.J., Arsenault, G., Mccrindle, R., Riddell, N., Martin, J.W., Mabury, S.A., 2009. Disposition of perfluorinated acid isomers in Sprague-Dawley rats; Part 2: Subchronic dose. Environmental Toxicology and Chemistry 28, 555-567.

Dietz, R., Bossi, R., Riget, F.F., Sonne, C., Born, E.W., 2008. Increasing perfluoroalkyl contaminants in east Greenland polar bears (Ursus maritimus): A new toxic threat to the Arctic bears. Environmental Science \& Technology 42, 2701-2707.

Gebbink, W.A., Sonne, C., Dietz, R., Kirkegaard, M., Born, E.W., Muir, D.C.G., Letcher, R.J., 2008. Target tissue selectivity and burdens of diverse classes of brominated and chlorinated contaminants in polar bears (Ursus maritimus) from East Greenland. Environmental Science \& Technology 42, 752-759.

Gebbink, W.A., Letcher, R.J., Burgess, N.M., Champoux, L., Elliott, J.E., Hebert, C.E., Martin, P., Wayland, M., Weseloh, D.V.C., Wilson, L., 2011. Perfluoroalkyl carboxylates and sulfonates and precursors in relation to dietary source tracers in the 
eggs of four species of gulls (Larids) from breeding sites spanning Atlantic to Pacific Canada. Environment International 37, 1175-1182.

Gebbink, W.A., Letcher, R.J., 2012. Comparative tissue and body compartment accumulation and maternal transfer to eggs of perfluoroalkyl sulfonates and carboxylates in Great Lakes herring gulls. Environmental Pollution 162, 40-47.

Houde, M., Martin, J.W., Letcher, R.J., Solomon, K.R., Muir, D.C.G., 2006a. Biological monitoring of perfluoroalkyl substances: A review. Environmental Science \& Technology 40, 3463-3473.

Houde, M., Balmer, B.C., Brandsma, S., Wells, R.S., Rowles, T.K., Solomon, K.R., Muir, D.C.G., 2006b. Perfluoroalkyl compounds in relation to life-history and reproductive parameters in bottlenose dolphins (Tursiops truncatus) from Sarasota Bay, Florida, USA. Environmental Toxicology and Chemistry 25, 2405-2412.

Houde, M., De Silva, A.O., Muir, D.C.G., Letcher, R.J., 2011. Monitoring of perfluorinated compounds in aquatic biota: An updated review PFCs in aquatic biota. Environmental Science \& Technology 45, 7962-7973.

Johansson, N., Fredriksson, A., Eriksson, P., 2008. Neonatal exposure to perfluorooctane sulfonate (PFOS) and perfluorooctanoic acid (PFOA) causes neurobehavioural defects in adult mice. Neurotoxicology 29, 160-169.

Jones, P.D., Hu, W.Y., De Coen, W., Newsted, J.L., Giesy, J.P., 2003. Binding of perfluorinated fatty acids to serum proteins. Environmental Toxicology and Chemistry 22, 2639-2649.

Kamiya, T., Pirlot, P., 1988. The brain of the Malayan bear (Helarctos-Malayanus). Zeitschrift fur Zoologische Systematik und Evolutionsforschung 26, 225-235.

Kannan, K., Yun, S.H., Evans, T.J., 2005. Chlorinated, brominated, and perfluorinated contaminants in livers of polar bears from Alaska. Environmental Science \& Technology 39, 9057-9063.

Kannan, K., Newsted, J., Halbrook, R.S., Giesy, J.P., 2002. Perfluorooctanesulfonate and related fluorinated hydrocarbons in mink and river otters from the United States. Environmental Science \& Technology 36, 2566-2571.

Letcher, R.J., Bustnes, J.O., Dietz, R., Jenssen, B.M., Jorgensen, E.H., Sonne, C., Verreault, J., Vijayan, M.M., Gabrielsen, G.W., 2010. Exposure and effects assessment of persistent organohalogen contaminants in arctic wildlife and fish. Science of the Total Environment 408, 2995-3043.

Luebker, D.J., Hansen, K.J., Bass, N.M., Butenhoff, J.L., Seacat, A.M., 2002. Interactions of flurochemicals with rat liver fatty acid-binding protein. Toxicology 176, 175-185. 
Martin, J.W., Asher, B.J., Beesoon, S., Benskin, J.P., Ross, M.S., 2010. PFOS or PreFOS? Are perfluorooctane sulfonate precursors (PreFOS) important determinants of human and environmental perfluorooctane sulfonate (PFOS) exposure? Journal of Environmental Monitoring 12, 1979-2004.

McKinney, M.A., Letcher, R.J., Aars, J., Born, E.W., Branigan, M., Dietz, R., Evans, T.J., Gabrielsen, G.W., Peacock, E., Sonne, C., 2011. Flame retardants and legacy contaminants in polar bears from Alaska, Canada, East Greenland and Svalbard, 2005-2008. Environment International 37, 365-374.

Mitchell, R.W., Hatch, G.M., 2011a. Fatty acid transport into the brain: Of fatty acid fables and lipid tails. Prostaglandins, Leukotrienes and Essential Fatty Acids 85, 293-302.

Mitchell, R.W., On, N.H., Del Bigio, M.R., Miller, D.W., Hatch, G.M., 2011b. Fatty acid transport protein expression in human brain and potential role in fatty acid transport across human brain microvessel endothelial cells. Journal of Neurochemistry 117, 735-746.

Olivero-Verbel, J., Tao, L., Johnston-Restrepo, B., Guette-Fernandez, J., Baldiris-Avila, R., O'byrne-Hoyos, I., Kannan, K., 2006. Perfluorooctanesulfonate and related fluorochemicals in biological samples from the north coast of Colombia. Environmental Pollution 142, 367-372.

Onishchenko, N., Fischer, C., Ibrahim, W.N.W., Negri, S., Spulber, S., Cottica, D., Ceccatelli, S., 2011. Prenatal exposure to PFOS or PFOA alters motor function in mice in a sex-related manner. Neurotoxicity Research 19, 452-461.

Rubarth, J., Dreyer, A., Guse, N., Einax, J.W., Ebinghaus, R., 2011. Perfluorinated compounds in red-throated divers from the German Baltic Sea: New findings from their distribution in 10 different tissues. Environmental Chemistry 8, 419-428.

Siegel, G.J., Agranoff, B.W., Albers, R.W., Fisher, S.K., Uhler, M.D., 1999. Basic Neurochemistry: Molecular, Cellular and Medical Aspects. $6^{\text {th }}$ edition. LippencottRaven. Philadelphia, PA, USA.

Slotkin, T.A., MacKillop, E.A., Melnick, R.L., Thayer, K.A., Seidler, F.J., 2008. Developmental neurotoxicity of perfluorinated chemicals modeled in vitro. Environmental Health Perspectives 116, 716-722.

Smithwick, M., Mabury, S.A., Solomon, K.R., Sonne, C., Martin, J.W., Born, E.W., Dietz, R., Derocher, A.E., Letcher, R.J., Evans, T.J., Gabrielsen, G.W., Nagy, J., Stirling, I., Taylor, M.K., Muir, D.C.G., 2005a. Circumpolar study of perfluoroalkyl contaminants in polar bears (Ursus maritimus). Environmental Science \& Technology 39, 5517-5523. 
Smithwick, M., Muir, D.C.G., Mabury, S.A., Solomon, K.R., Martin, J.W., Sonne, C., Born, E.W., Letcher, R.J., Dietz, R., 2005b. Perfluoroalkyl contaminants in liver tissue from East Greenland polar bears (Ursus maritimus). Environmental Toxicology and Chemistry 24, 981-986.

Smithwick, M., Norstrom, R.J., Mabury, S.A., Solomon, K., Evans, T.J., Stirling, I., Taylor, M.K., Muir, D.C.G., 2006. Temporal trends of perfluoroalkyl contaminants in polar bears (Ursus maritimus) from two locations in the North American Arctic, 1972-2002. Environmental Science \& Technology 40, 1139-1143.

Van de Vijver, K.I., Hoff, P., Das, K., Brasseur, S., Van Dongen, W., Esmans, E., Reijnders, P., Blust, R., De Coen, W., 2005. Tissue distribution of perfluorinated chemicals in harbor seals (Phoca vitulina) from the Dutch Wadden Sea. Environmental Science \& Technology 39, 6978-6984.

Van de Vijver, K.I., Hoslbeek, L., Das, K., Blust, R., Joiris, C., De Coen, W., 2007. Occurrence of perfluorooctane sulfonate and other perfluorinated alkylated substances in harbor porpoises from the Black Sea. Environmental Science \& Technology 41, 315-320.

Verreault, J., Houde, M., Gabrielsen, G.W., Berger, U., Haukas, M., Letcher, R.J., Muir, D.C.G., 2005. Perfluorinated alkyl substances in plasma, liver, brain, and eggs of glaucous gulls (Larus hyperboreus) from the Norwegian Arctic. Environmental Science \& Technology 39, 7439-7445.

Vongphachan, V., Cassone, C.G., Wu, D.M., Chiu, S.Z., Crump, D., Kennedy, S.W., 2011. Effects of perfluoroalkyl compounds on mRNA expression levels of thyroid hormone-responsive genes in primary cultures of avian neuronal cells. Toxicological Sciences 120, 392-402.

Wang, F.Q., Liu, W., Jin, Y.H., Dai, J.Y., Yu, W.G., Liu, X.H., Liu, L., 2010. Transcriptional effects of prenatal and neonatal exposure to PFOS in developing rat brain. Environmental Science \& Technology 44, 1847-1853. 


\section{CHAPTER 4 \\ Tissue Distribution and Tissue Burden Estimates of Perfluoroalkyl Acids in East Greenland Polar Bears}

\subsection{Introduction}

Numerous studies have examined the distribution of PFAAs, specifically PFSAs and PFCAs, in wildlife worldwide, including remote regions such as the Arctic (Bossi et al., 2005a, 2005b; Smithwick et al., 2005a, 2005b, 2006; Verreault et al., 2005; Dietz et al., 2008; Powley et al., 2008; Kelly et al., 2009; Butt et al., 2010; Letcher et al., 2010; Sturm and Ahrens, 2010; Houde et al., 2011). It has been found that PFSAs $\left(>C_{6}\right)$, and PFCAs $\left(>\mathrm{C}_{8}\right)$ bioaccumulate and biomagnify in aquatic food webs (Martin et al., 2003; Houde et al., 2011). As a result, apex predators have typically been shown to be the most exposed to PFAAs.

Due to the amphiphilic nature of PFCAs and PFSAs, it is difficult to predict their fate in the body based solely on modelling studies. While the transport and distribution mechanisms of PFCAs, PFSAs, and their precursors throughout the body have not been fully elucidated, laboratory exposure studies have shown that PFCAs (ex: PFHxA, PFOA) and PFSAs (ex: PFHxS, PFOS) tend to accumulate in protein rich tissues, such as the liver, blood, and yolk sac (Ahrens et al., 2009; Cassone et al., 2012). Due to their large concentrations in the liver and blood, it is suspected that PFCAs and PFSAs are retained in the body via enterohepatic recirculation. Previous studies have shown that PFCAs and PFSAs are capable of binding to serum albumin, thus indicating a potential transport pathway throughout the body.

In Chapter 3 , it was shown that long-chain PFCAs $\left(C_{10}-C_{15}\right)$ are strongly correlated with extractable lipid content in the brain, but so far only non-significant 
correlative relationships have been reported between e.g. PFOS concentrations and lipid content in liver or plasma samples (Kannan et al., 2002, 2005; Houde et al., 2006a).

The majority of PFCA and PFSA (and precursor) studies have focused on hepatic concentrations, while a few (including human studies) have examined their concentrations in the blood (Kannan et al., 2002; Smithwick et al., 2005a, 2005b; Wilhelm et al., 2009; Pan et al., 2010). In the last few years, however, studies have emerged examining multiple tissues in the body. These studies are highly useful in determining the total PFCA and PFSA body burden in a population, as well as gaining insight into the distribution pathways in the body. Ahrens et al. (2009) examined the PFCA and PFSA distribution in 10 tissues from harbour seals from the German Bight. PFOS was found to be present in the highest concentrations, with a concentration of $1,017 \mathrm{ng} / \mathrm{g}$ wet weight (ww) in the liver. Other tissue distribution studies have been performed on harbour porpoises, ringed seals, bearded seals, red-throated divers, glaucous gulls, herring gulls, and brown pelicans (Van de Vijver et al., 2005, 2007; Verreault et al., 2005; Olivero-Verbel et al., 2006; Powley et al., 2008; Rubarth et al., 2011; Gebbink and Letcher., 2012).

East Greenland polar bears are a great candidate for tissue distribution studies. Hepatic PFOS concentrations have been reported as high as $6,340 \mathrm{ng} / \mathrm{g}$ ww, and are consistently reported above $1,000 \mathrm{ng} / \mathrm{g}$ ww. Furthermore, quantifiable PFCA and PFSA concentrations such as PFOS, PFDA, and PFTriA in the livers of polar bears from East Greenland, have been reported to be increasing exponentially from 2000 to 2006 (Dietz et al., 2008). Although past studies have documented hepatic PFCA and PFSA concentrations, after extensive literature searches very little data is available regarding examination of other tissues in the body. 
In this chapter, the tissue distribution and patterns of PFCAs and PFSAs and select precursors are examined in the liver, blood, muscle, adipose, and brain of East Greenland polar bears $(n=20)$. Potential confounding factors, such as age, gender, and tissue lipid content are examined. As the liver is considered to be the major repository of PFAAs, it is hypothesized that the concentration of PFCAs and PFSAs in the liver will far exceed all other tissues.

\subsection{Results and Discussion}

A complete list of levels for all detected compounds can be found in Table 4.1. In all tissues analyzed, PFCAs $\left(\mathrm{C}_{8}-\mathrm{C}_{15}\right)$, PFOS, and PFOSA were found above the method limit of quantification (MLOQ). Other PFCs were found in some tissues, but not all. For example, PFHxS was found above the MLOQ in all tissues except the brain (i.e.: liver, blood, muscle, and adipose).

For all tissues, PFBS, 6:2 FTOH, 8:2 FTOH, and 10:2 FTOH were consistently found in less than $50 \%$ of the samples, and were therefore not included in any statistical analysis of the overall data. All compounds not consistently found in tissue samples can be found in Table 4.2, where their concentration ranges are stated. 
Table 4.1 Arithmetic mean concentrations (ng/g ww) and ranges for all detected compounds. All compounds reported were found above the method limit of quantification (MLOQ) in at least $50 \%$ of the samples for a given tissue. For compounds which were not detected (n.d.) in $\geq 50 \%$ of the samples, their ranges are given in Table 4.2 .

\begin{tabular}{|c|c|c|c|c|c|c|}
\hline Tissue & & Liver $(n=19)$ & Blood $(n=19)$ & Brain $(n=115)$ & Muscle $(n=20)$ & Adipose $(\mathrm{n}=\mathbf{2 0})$ \\
\hline $\begin{array}{l}\text { Lipid Content } \\
(\% \pm \text { SE })\end{array}$ & & $6.04 \pm 0.61$ & $1.36 \pm 0.13$ & $11.20 \pm 0.39$ & $1.61 \pm 0.46$ & $63.79 \pm 1.43$ \\
\hline \multicolumn{7}{|c|}{ PERFLUOROALKYL CARBOXYLATES (PFCAs) } \\
\hline \multirow{2}{*}{ PFHXA } & Mean: & $18.51 \pm 0.55$ & \multirow{2}{*}{ n.d. } & \multirow{2}{*}{ n.d. } & $0.27 \pm 0.05$ & \multirow{2}{*}{ n.d. } \\
\hline & Range: & $14.42-24.70$ & & & n.d. -0.80 & \\
\hline \multirow{2}{*}{ PFHрA } & Mean: & $8.39 \pm 1.36$ & $0.50 \pm 0.06$ & \multirow{2}{*}{ n.d. } & $0.19 \pm 0.02$ & \multirow{2}{*}{ n.d. } \\
\hline & Range: & n.d. -14.80 & $0.13 \cdot 1.00$ & & n.d. -0.42 & \\
\hline \multirow{2}{*}{ PFOA } & Mean: & $39.24 \pm 3.36$ & $3.53 \pm 0.31$ & $0.27 \pm 0.06$ & $0.42 \pm 0.05$ & $0.42 \pm 0.10$ \\
\hline & Range: & $19.86-86.69$ & $1.54=6.10$ & n.d. -6.34 & n.d. -0.75 & n.d. -1.82 \\
\hline \multirow{2}{*}{ PFNA } & Mean: & $496.8 \pm 43.5$ & $17.79 \pm 1.58$ & $1.87 \pm 0.14$ & $1.99 \pm 0.18$ & $1.57 \pm 0.23$ \\
\hline & Range: & $159.8-887.3$ & $7.14 \cdot 37.47$ & $0.23-12.53$ & $1.20-4.57$ & $0.37-4.69$ \\
\hline \multirow{2}{*}{ PFDA } & Mean: & $183.8 \pm 17.0$ & $7.05 \pm 0.79$ & $2.12 \pm 0.13$ & $1.00 \pm 0.10$ & $0.74 \pm 0.14$ \\
\hline & Range: & $56.44-328.6$ & $3.32-16.55$ & $0.42-11.35$ & $0.46-2.48$ & n.d. -2.69 \\
\hline \multirow{2}{*}{ PFUA } & Mean: & $275.6 \pm 24.3$ & $21.83 \pm 2.60$ & $16.02 \pm 0.72$ & $3.67 \pm 0.37$ & $3.07 \pm 0.45$ \\
\hline & Range: & $80.10-497.8$ & $10.16 \cdot 56.07$ & $5.27-49.11$ & $1.80 \cdot 8.71$ & $1.01-9.35$ \\
\hline \multirow{2}{*}{ PFDoA } & Mean: & $41.46 \pm 3.29$ & $5.16 \pm 0.57$ & $7.21 \pm 0.33$ & $0.98 \pm 0.08$ & $0.84 \pm 0.13$ \\
\hline & Range: & $18.45-67.71$ & $2.82-11.72$ & $2.62-20.73$ & $0.51-1.79$ & n.d. -2.46 \\
\hline \multirow{2}{*}{ PFTriA } & Mean: & $82.13 \pm 7.24$ & $14.34 \pm 1.52$ & $31.38 \pm 1.47$ & $2.96 \pm 0.23$ & $3.05 \pm 0.34$ \\
\hline & Range: & $28.92-143.8$ & $7.19-27.27$ & $10.70-80.07$ & $1.45-4.64$ & $1.11-6.48$ \\
\hline \multirow{2}{*}{ PFTeA } & Mean: & $17.96 \pm 0.68$ & $2.66 \pm 0.14$ & $7.45 \pm 0.34$ & $1.56 \pm 0.22$ & $1.32 \pm 0.15$ \\
\hline & Range: & $12.23-25.70$ & $1.97-3.81$ & $2.39-22.63$ & $0.30-3.12$ & $0.38-2.57$ \\
\hline \multirow{2}{*}{ PFPA } & Mean: & $0.81 \pm 0.08$ & $1.35 \pm 0.13$ & $10.41 \pm 0.48$ & $0.65 \pm 0.07$ & $0.57 \pm 0.07$ \\
\hline & Range: & $0.22-1.46$ & $0.45-2.45$ & $2.01-31.15$ & $0.20-1.20$ & $0.22-1.17$ \\
\hline \multirow{2}{*}{ E-PFCA } & Mean: & $1164 \pm 92$ & $74.26 \pm 6.93$ & $76.96 \pm 3.25$ & $13.69 \pm 0.94$ & $11.70 \pm 1.37$ \\
\hline & Range: & $436.4-2055$ & $37.11-158.6$ & $30.78-186.2$ & $7.29-24.22$ & $4.43-28.83$ \\
\hline \multicolumn{7}{|c|}{ PERFLUOROALKYL SULFONATES (PFSAS) } \\
\hline \multirow{2}{*}{ PFHxS } & Mean: & $30.93 \pm 2.14$ & $17.97 \pm 1.07$ & $1.37 \pm 0.10$ & $1.87 \pm 0.11$ & $1.55 \pm 0.20$ \\
\hline & Range: & $17.58-46.48$ & $9.60-29.66$ & n.d. -6.51 & $1.25-3.13$ & $0.28-3.72$ \\
\hline \multirow{2}{*}{ PFOS } & Mean: & $3271 \pm 292.4$ & $127.9 \pm 16.82$ & $35.17 \pm 1.97$ & $15.90 \pm 1.69$ & $15.41 \pm 1.90$ \\
\hline & Range: & $938.6-5526$ & $44.31-288.2$ & $7.94-100.3$ & $6.66-39.57$ & $4.41-41.72$ \\
\hline \multirow{2}{*}{ PFDS } & Mean: & \multirow{2}{*}{ n.d. } & $1.28 \pm 0.22$ & $1.30 \pm 0.15$ & $1.40 \pm 0.04$ & \multirow{2}{*}{ n.d. } \\
\hline & Range: & & n.d. -2.15 & n.d. -13.63 & $1.11 \cdot 1.73$ & \\
\hline SEFSA & Mean: & $3308 \pm 295$ & $147.4 \pm 17.7$ & $38.03 \pm 2.02$ & $19.38 \pm 1.81$ & $18.00 \pm 2.13$ \\
\hline GTPSA & Range: & $962.0-5568$ & $54.00-113.0$ & $8.27-105.6$ & $10.03-44.02$ & $5.34-48.91$ \\
\hline & & PERF & OROALKYL SU & FONAMIDES (PI & As) & \\
\hline DEost & Mean: & $151.4 \pm 31.64$ & $3.50 \pm 0.99$ & $1.33 \pm 0.10$ & $1.56 \pm 0.13$ & $0.69 \pm 0.10$ \\
\hline FFUSA & Range: & $32.91-557.7$ & n.d. -16.89 & n.d. -5.50 & n.d. -2.03 & a.d. -1.48 \\
\hline & & LUOROTELON & R UNSATURAT & CARBOXYLIC & DS (FTUCAs) & \\
\hline 6.2 FTUICA & Mean: & $0.98 \pm 0.22$ & nd & nd & $0.016 \pm 0.003$ & nd \\
\hline $0.2110 \mathrm{CA}$ & Range: & n.d. -2.55 & 11.u. & 10.0. & n.d. -0.040 & ה.u. \\
\hline 8.2 FTUCA & Mean: & $1.13 \pm 0.12$ & nd & ind & nd & nd $\quad$ - \\
\hline $0: 2$ FIUCA & Range: & n.d. -1.53 & 11.0. & 0.0. & H.d. & 11.0. \\
\hline 10.2 MTUCA & Mean: & $n d \quad-2$ & nd & $n d$ & $0.082 \pm 0.018$ & $n d \quad$ a \\
\hline TO:2 FIUCA & Range: & 11.L. & 11.u. & 110.0. & a.d. -0.177 & H.u. \\
\hline$\Sigma$-PFCs & & $4626 \pm 393$ & $224.9 \pm 24.0$ & $115.9 \pm 5.0$ & $34.53 \pm 2.69$ & $30.14 \pm 3.48$ \\
\hline
\end{tabular}


Table 4.2 Concentration ranges for all non-detected compounds. Compounds were considered not detected if more than $50 \%$ of samples for a given tissue were below the method limit of quantification (MLOQ).

\begin{tabular}{|c|c|c|c|c|c|c|}
\hline Tissue & & $\begin{array}{c}\text { Liver } \\
(\mathrm{n}=19)\end{array}$ & $\begin{array}{c}\text { Blood } \\
(n=19)\end{array}$ & $\underset{(n=115)}{\text { Brain }}$ & $\begin{array}{c}\text { Muscle } \\
(n=20)\end{array}$ & $\begin{array}{c}\text { Adipose } \\
(\mathbf{n}=\mathbf{2 0})\end{array}$ \\
\hline \multirow{2}{*}{ PFBS } & Range: & n.d. & n.d. -3.15 & n.d. -3.14 & n.d. -3.42 & n.d. -2.07 \\
\hline & $\%>M^{\prime} O Q^{\mathrm{a}}$ & 0 & 11 & 6 & 5 & 5 \\
\hline \multirow{2}{*}{ PFDS } & Range: & n.d. -21.78 & \multirow{2}{*}{ N/A } & \multirow{2}{*}{ N/A } & \multirow{2}{*}{ N/A } & n.d. -3.44 \\
\hline & $\%>M_{L O Q}$ & 32 & & & & 30 \\
\hline \multirow{2}{*}{ PFHxA } & Range: & \multirow{2}{*}{ N/A } & n.d. -0.46 & n.d. -1.28 & \multirow{2}{*}{ N/A } & n.d. -0.20 \\
\hline & $\%>M_{L O Q}^{\mathrm{a}}$ & & 5 & 6 & & 10 \\
\hline \multirow{2}{*}{ PFHpA } & Range: & \multirow{2}{*}{ N/A } & \multirow{2}{*}{ N/A } & n.d. -6.66 & \multirow{2}{*}{$\mathrm{N} / \mathrm{A}$} & n.d. -1.11 \\
\hline & $\%>M^{\prime} O Q^{a}:$ & & & 32 & & 10 \\
\hline \multirow{2}{*}{ 6:2 FTOH } & Range: & n.d. & n.d. -1.29 & n.d. -3.25 & n.d. & n.d. \\
\hline & $\%>M^{\prime} O Q^{a}:$ & 0 & 11 & 1 & 0 & 0 \\
\hline \multirow{2}{*}{ 8:2 FTOH } & Range: & n.d. & n.d. & n.d. -28.39 & n.d. & n.d. -4.88 \\
\hline & $\%>M L O Q^{a}:$ & 0 & 0 & 9 & 0 & 10 \\
\hline \multirow{2}{*}{ 10:2 FTOH } & Range: & n.d. & n.d. & n.d. -3.23 & n.d. -2.95 & n.d. \\
\hline & $\%>M^{2} Q^{\mathrm{B}}$ & 0 & 0 & 3 & 5 & 0 \\
\hline \multirow{2}{*}{ 6:2 FTUCA } & Range: & \multirow{2}{*}{ N/A } & n.d. -0.24 & n.d. -0.71 & \multirow{2}{*}{ N/A } & n.d. -0.33 \\
\hline & $\%>M L O Q^{\mathrm{a}}$ & & 26 & 7 & & 15 \\
\hline \multirow{2}{*}{ 8:2 FTUCA } & Range: & \multirow{2}{*}{ N/A } & n.d. -0.37 & n.d. -1.35 & n.d. -0.04 & n.d. -0.23 \\
\hline & $\%>\mathrm{MLOQ}^{\mathrm{a}}$ & & 42 & 16 & 45 & 40 \\
\hline \multirow{2}{*}{ 10:2 FTUCA } & Range: & n.d. -2.04 & n.d. & n.d. -0.80 & \multirow{2}{*}{ N/A } & n.d. -0.40 \\
\hline & $\%>M_{L O Q}{ }^{\mathrm{a}}$ & 21 & 0 & 12 & & 20 \\
\hline \multirow{2}{*}{ N-Me-FOSA } & Range: & n.d. & n.d. -5.32 & n.d. -9.44 & n.d. -2.53 & n.d. -4.11 \\
\hline & $\%>M^{\prime} O Q^{a}:$ & 0 & 5 & 5 & 25 & 10 \\
\hline
\end{tabular}

a $>$ MLOQ: The percentage of samples above the method limit of quantification

n.d. $=$ not detected

N/A : More than $50 \%$ of the samples were above the limit of quantification, and can be found in Table 4.1 


\subsubsection{Relationship between PFAA Concentrations and Extractable Lipid Content}

The lipid content was determined gravimetrically for every sample analyzed. As previously described in Chapter 3, strong and significant correlations between lipid content and long-chain PFCAs $\left(\mathrm{C}_{10}-\mathrm{C}_{15}\right)$ were found in the brain $(\mathrm{p} \leq 0.0015)$. The liver also showed statistically significant correlations for PFOS, as well as PFNA, and PFDA concentrations with lipid content $(\mathrm{p} \leq 0.032)$. However, blood, muscle, and adipose tissue showed weak and non-significant $(p>0.05)$ correlations with lipid content. Figure 4.1 illustrates a selection of these lipid correlations. For a full list of p- and r-values, please see Table 4.3.

Correlations between PFC concentrations and extractable lipid content were not previously observed in studies on liver (polar bear, mink) or plasma (bottlenose dolphin) (Kannan et al., 2002, 2005; Houde et al., 2006a). Long-chain PFCAs greatly resemble saturated fatty acids. It is possible that the lipid correlations seen in the brain and liver are a result of PFCAs mimicking fatty acids. A hypothesis presented in Chapter 3 suggested that perhaps long-chain PFCAs associate with lipid-binding proteins that are permeable to the $\mathrm{BBB}$; when the lipid-binding proteins cross the BBB to replenish fatty acids in the brain, the long-chain PFCAs are transported into the brain. Additionally, the liver has many lipid-related functions, including the synthesis of triglycerides and lipoproteins (Harvey and Ferrier, 2010). It is possible that due to their resemblance to fatty acids, the liver provides a suitable chemical environment for PFSAs and PFCAs, thus potentially explaining the correlative relationships. Overall, the present correlative relationships between long-chain PFCAs and lipid content warrants further investigation.

The existence of correlations between PFSA and PFCA concentrations and lipid content in the present polar bears may be significant due to the nature of the statistical 
analysis employed in this study. Based on the data, it appears that lipid is a confounding factor for some tissues, but not others. However, the majority of samples in this study showed no correlation with extractable lipid content. As a result, it was concluded that extractable lipid content was not a significant confounding factor. Therefore, all analysis of concentration data was done on a wet weight basis (ww) as opposed to a lipid weight basis (lw).
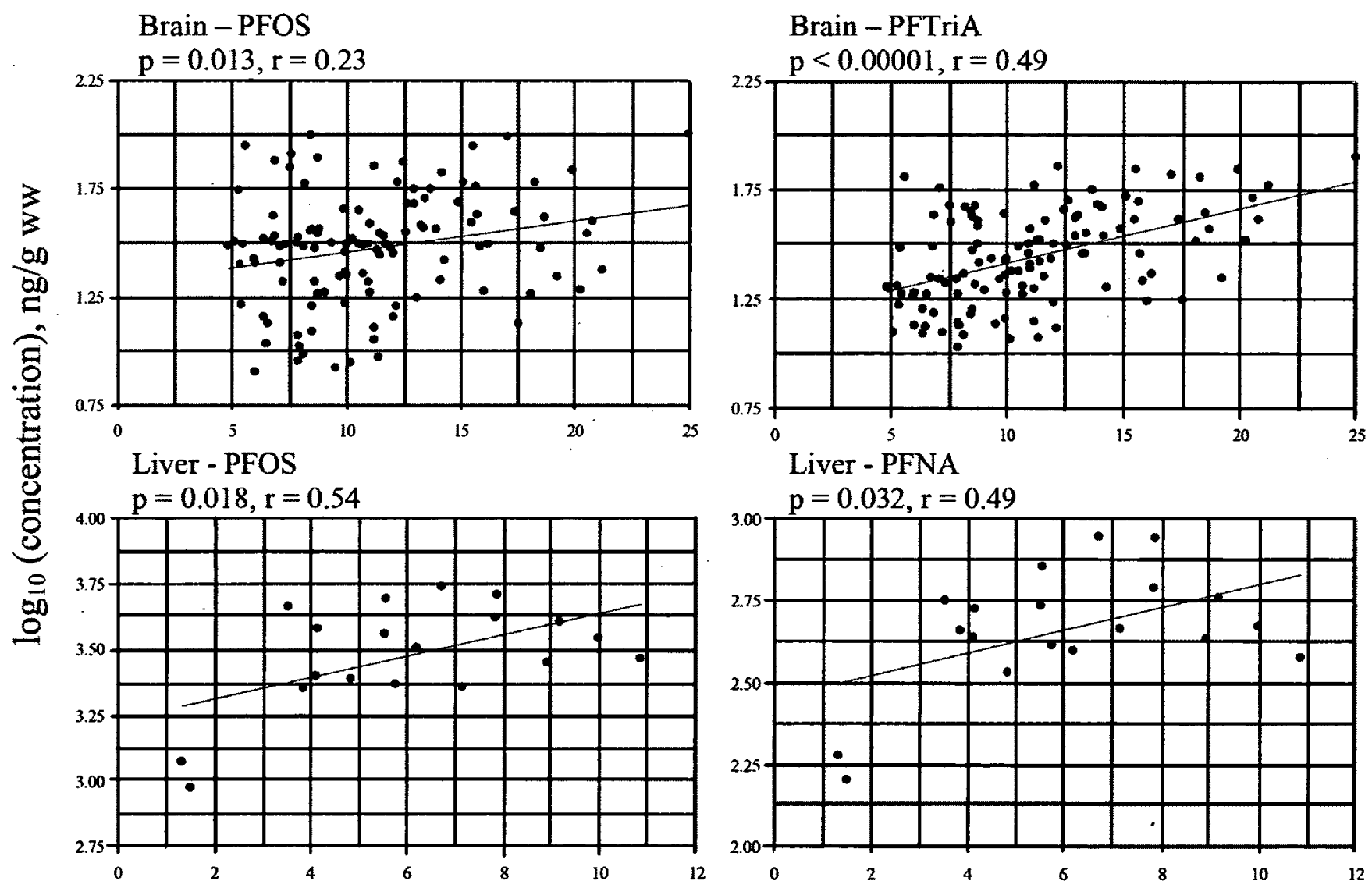

Lipid content (\%), (g lipid/g tissue) x 100\%

Figure 4.1 Correlations between extractable lipid content and PFAA concentrations in both the brain (top), and liver (bottom). 
Table 4.3 All Pearson's coefficients (r-values) and significance levels ( $p$-values) for all significant correlations found between extractable lipid content and PFCA and PFSA concentrations. Correlations were considered strong when $r \geq 0.50$, and significant when $p$ $\leq 0.05$.

\begin{tabular}{clcc}
\hline Tissue & Compound & $\begin{array}{c}\text { Pearson } \\
\text { Coefficient, } \mathbf{r}\end{array}$ & $\begin{array}{c}\text { Significance } \\
\text { Level, } \mathbf{p}\end{array}$ \\
\hline \multirow{6}{*}{ Brain } & PFOS & 0.23 & 0.013 \\
& PFDA & 0.29 & 0.0015 \\
& PFUA & 0.48 & $<0.00001$ \\
& PFDoA & 0.48 & $<0.00001$ \\
& PFTriA & 0.49 & $<0.00001$ \\
& PFTeA & 0.51 & $<0.00001$ \\
& PFPA & 0.35 & 0.0001 \\
\hline \multirow{3}{*}{ Liver } & PFOS & 0.54 & 0.018 \\
& PFNA & 0.49 & 0.032 \\
& PFDA & 0.49 & 0.032 \\
\hline
\end{tabular}

\subsubsection{Gender Differences}

The samples used in this study came from 14 males and 6 females, from Scoresby Sound, East Greenland. Gender differences were analyzed by one-way ANOVA, followed by a Tukey HSD test, with $\alpha$ set to 0.05 . Differences between males and females were not found for any PFC under study in adipose and muscle samples. In the brain, gender differences were observed for PFDoA, PFTriA, and PFOSA, such that wet weight concentrations were statistically higher in males. In the blood, gender differences existed for PFHpA (higher in males), and for PFNA (higher in females). In the liver, PFHxS was found to be higher in females. All other compounds showed no gender differences for any tissue studied. A complete list of gender differences can be seen in Table 4.4. The majority of samples showed no large differences between accumulation profiles in males and females, similar to what was found by Smithwick et al. (2005b). 
Other large groups of persistent organic pollutants (POPs) include the lipophilic polychlorinated biphenyls (PCBs) and chlordanes (CHLs). These lipophilic compounds accumulate in lipid-rich tissue such as adipose, and have been found to leave the body through gestation and lactation in females. As a result, gender differences are often seen for PCB and CHL concentrations. However, the relative lack of gender differences observed for PFCs in these polar bears indicates that gestation and lactation are not major depuration pathways for females.

Table 4.4 Gender differences for applicable PFCA, PFSA and PFOSA accumulation in East Greenland polar bears.

\begin{tabular}{cccc}
\hline Tissue & Compound & $\begin{array}{c}\text { Significance } \\
\text { Level, } \mathbf{p}\end{array}$ & $\begin{array}{c}\text { Gender with the } \\
\text { higher concentration }\end{array}$ \\
\hline \multirow{3}{*}{ Brain } & PFDoA & 0.0024 & Males \\
& PFTriA & 0.0032 & Males \\
& PFOSA & 0.0219 & Males \\
\hline Liver & PFHxS & 0.0228 & Females \\
\hline \multirow{2}{*}{ Blood } & PFHpA & 0.0051 & Males \\
& PFNA & 0.0305 & Females \\
\hline
\end{tabular}

Due to the limited number of gender differences observed, it was decided that any small gender differences, like those described above, were not substantial. Therefore, further analysis of the data considered the present cohort of bears as one group. 


\subsubsection{Age Correlations}

Of the 20 East Greenland polar bears used for this study, ages ranged from 3 to 19 years of age. The age of the bears was determined by counting the annual growth layer in the cementum of the $I_{3}$ tooth after decalcification, thin layer sectioning $(14 \mu \mathrm{m})$, and staining with toluidine blue (Dietz et al., 2004). Both the brain and muscle showed highly significant $(\mathrm{p} \leq 0.015)$ and strong correlations $(\mathrm{r} \geq 0.50)$ between $\Sigma$-PFCA concentrations and age (Figure 4.2). Correlations between $\Sigma$-PFSA concentrations and age were observed for the brain, muscle, and blood (Figure 4.2), and were similarly highly significant ( $\mathrm{p} \leq$ $0.011)$ and strong $(r \geq 0.50)$. These findings are similar to other polar bear studies in the past decade (Smithwick et al., 2005a, 2005b), where age trends for PFOS were shown in polar bear liver samples.

Smithwick et al. (2005a, 2005b) found that PFOS accumulated in the liver of juvenile polar bears $(<6$ years) at a different rate than adult polar bears $(\geq 6$ years). They showed a sharp increase in PFOS concentrations in juvenile bears, and then a much slower increase in adult bears. The apparent difference between juvenile and adult bears suggests that polar bears are perhaps very inefficient at clearing PFOS from the body at a young age, but that around the age of sexual maturity (around 4 years for females, and 6 years for males) (Rosing-Asvid et al., 2002), there seems to be a shift in their depuration pathways, leading them to clear PFOS more efficiently. It should be noted that significant age trends were not seen for liver samples in this study. The discrepancy between this study and those performed by Smithwick et al. (2005a, 2005b) is most likely attributed to non-evenly distributed age ranges, and small sample sizes (Table 2.1).

The exact half-lives of PFCAs and PFSAs in polar bears are not known, although half-lives in other animals have been reported to vary wildly. For example, PFOS has 
been shown to have half-lives ranging from $30-103$ days in male rats, to 21 weeks in bottlenose dolphins, 5.4 years in humans, and 5.6 years in harbor seals (Houde et al., 2006b; Genuis et al., 2010; Martin et al., 2010; Lindstrom et al., 2011). The known halflives for PFCAs and PFSAs are generally longer in larger mammals compared to smaller mammals. Therefore, it could be hypothesised that the half-life of PFCAs and PFSAs in polar bears is relatively long, due to their large size. However, polar bears undergo large fluctuations in mass and dietary consumption every year. During the hibernating winter months, polar bears undergo extreme fasting and adipose tissue deposits may be reduced as low as $10 \%$ of body mass (Polischuk et al., 2002). Following hibernation, polar bears gorge on prey to quickly regain lost mass. Therefore, modelling the half-life and bioenergetics associated with accumulation and depuration of POPs is not straightforward. Regardless, the fact that over their lifetimes the concentrations of PFCAs and PFSAs increase in the body indicates that polar bears accumulate PFCAs and PFSAs faster than depuration pathways clear them out. 

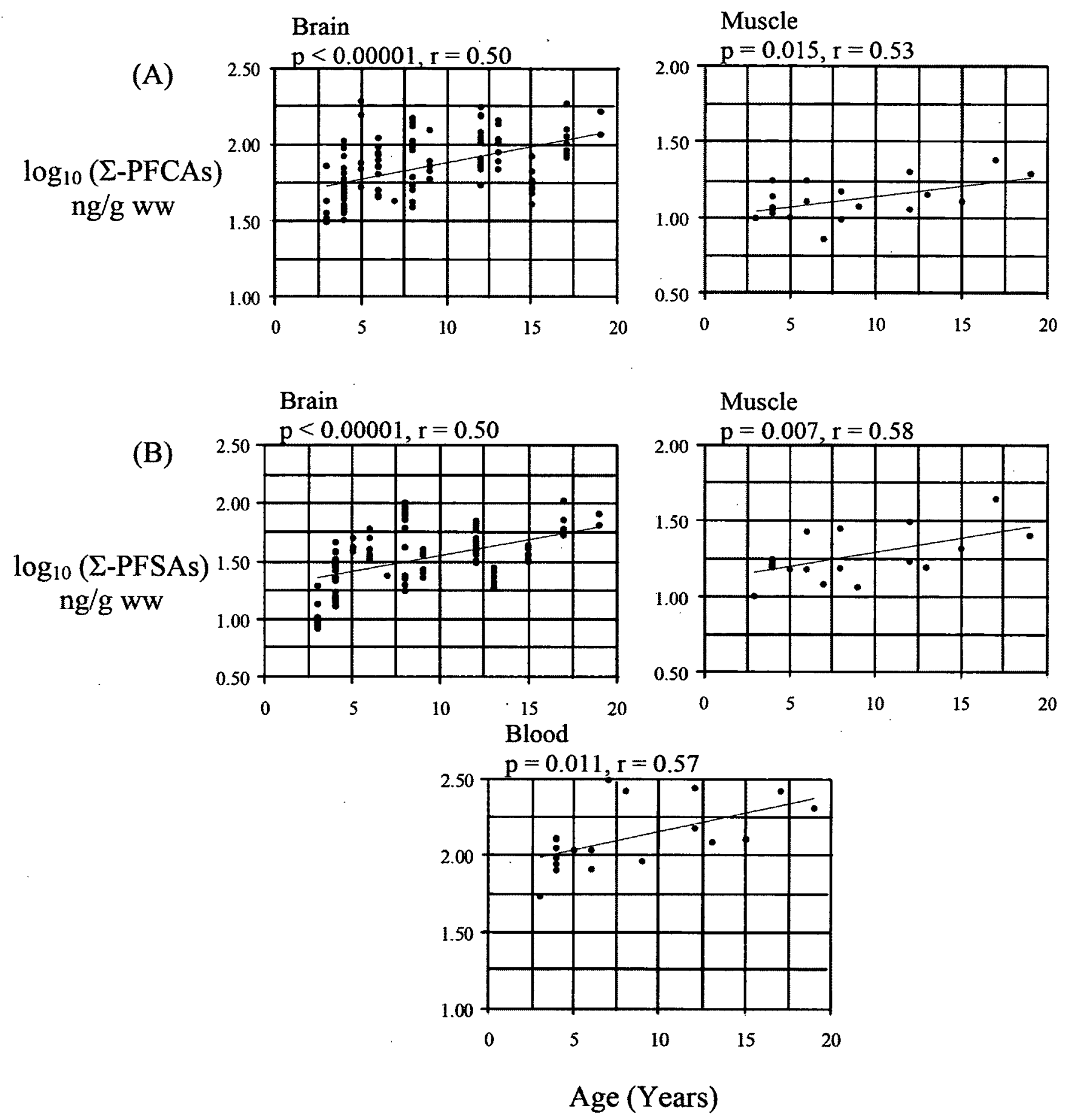

Figure 4.2 Correlations between age and (A) $\Sigma$-PFCA concentrations (ng/g wet weight), and (B) $\Sigma$-PFSA concentrations (ng/g wet weight) in East Greenland polar bears. 


\subsubsection{Distribution of PFCAs}

There was a large difference in terms of absolute PFCA concentrations between tissues. For example, the liver had an overall $\Sigma$-PFCA concentration of 1,164 ng/g ww, whereas in the other extreme, the adipose had an overall $\Sigma$-PFCA concentration of 11.70 $\mathrm{ng} / \mathrm{g}$ ww (Table 4.1). This indicates that there are up to two orders of magnitude difference separating the PFCA concentrations in different tissues. $\Sigma$-PFCA concentrations decreased in the following order: liver $(1,164 \mathrm{ng} / \mathrm{g} \mathrm{ww})>$ brain $(79.96 \mathrm{ng} / \mathrm{g}$ ww) $>$ whole blood $(74.26 \mathrm{ng} / \mathrm{g} \mathrm{ww})>$ muscle $(13.69 \mathrm{ng} / \mathrm{g} \mathrm{ww})>$ adipose $(11.70 \mathrm{ng} / \mathrm{g} \mathrm{ww})$ (Figure 4.3).

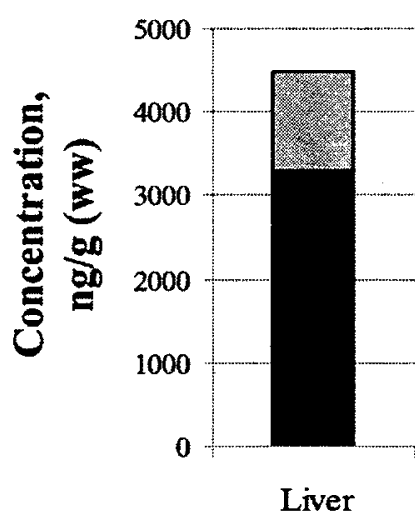

Liver

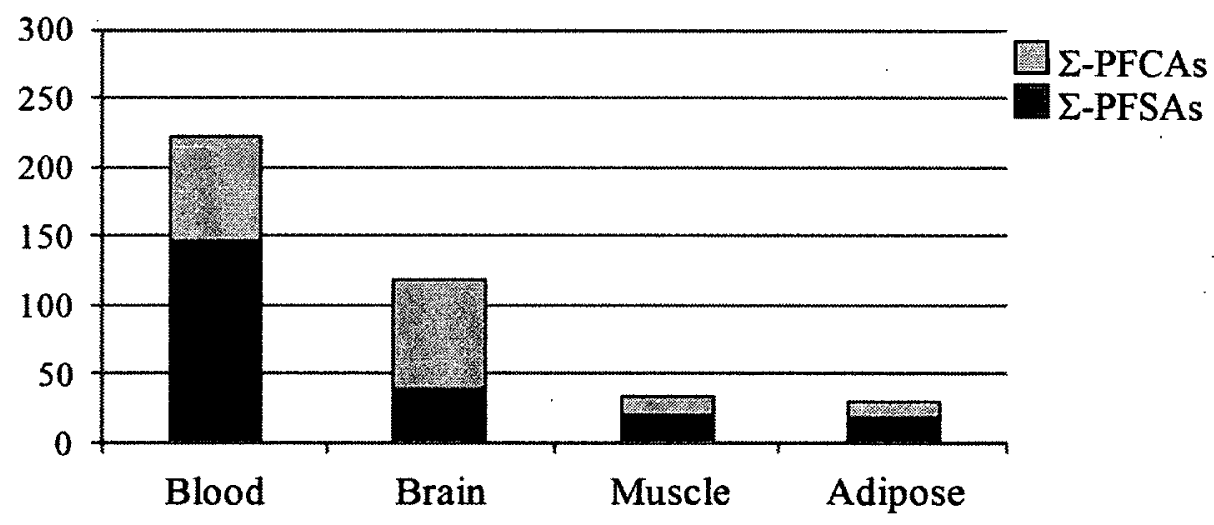

Tissue

Figure 4.3 Arithmetic mean concentrations (ng/g ww) of $\Sigma$-PFCAs and $\Sigma$-PFSAs in the liver, blood, brain, muscle, and adipose tissue from 20 East Greenland polar bears. The vast majority of the $\Sigma$-PFSA concentrations are due to PFOS, accounting for between $87 \%$ (blood) and 99\% (liver) of $\Sigma$-PFSA concentrations.

Large tissue differences were seen in the proportional make-up of the PFCA concentrations. For instance, as seen in Figure 4.4, PFNA accounted for $42.6 \%$ of the 
overall PFCA burden in liver samples, whereas it only accounted for $2.4 \%$ of the overall PFCA burden in brain samples. Similarly, although in reverse, PFPA accounted for $13.1 \%$ of the overall PFCA burden in brain samples, whereas it only accounted for $0.07 \%$ of the overall PFCA burden in liver samples. As a result, the dominant PFCA varied from tissue to tissue, such that short/medium chain lengths were proportionally higher in the liver and medium/long-chain lengths were proportionally higher in the brain. This trend followed a sliding scale where the highest proportion of short-chain PFCAs was found in the liver, followed by whole blood, muscle, adipose, and finally the brain (Figure 4.4).

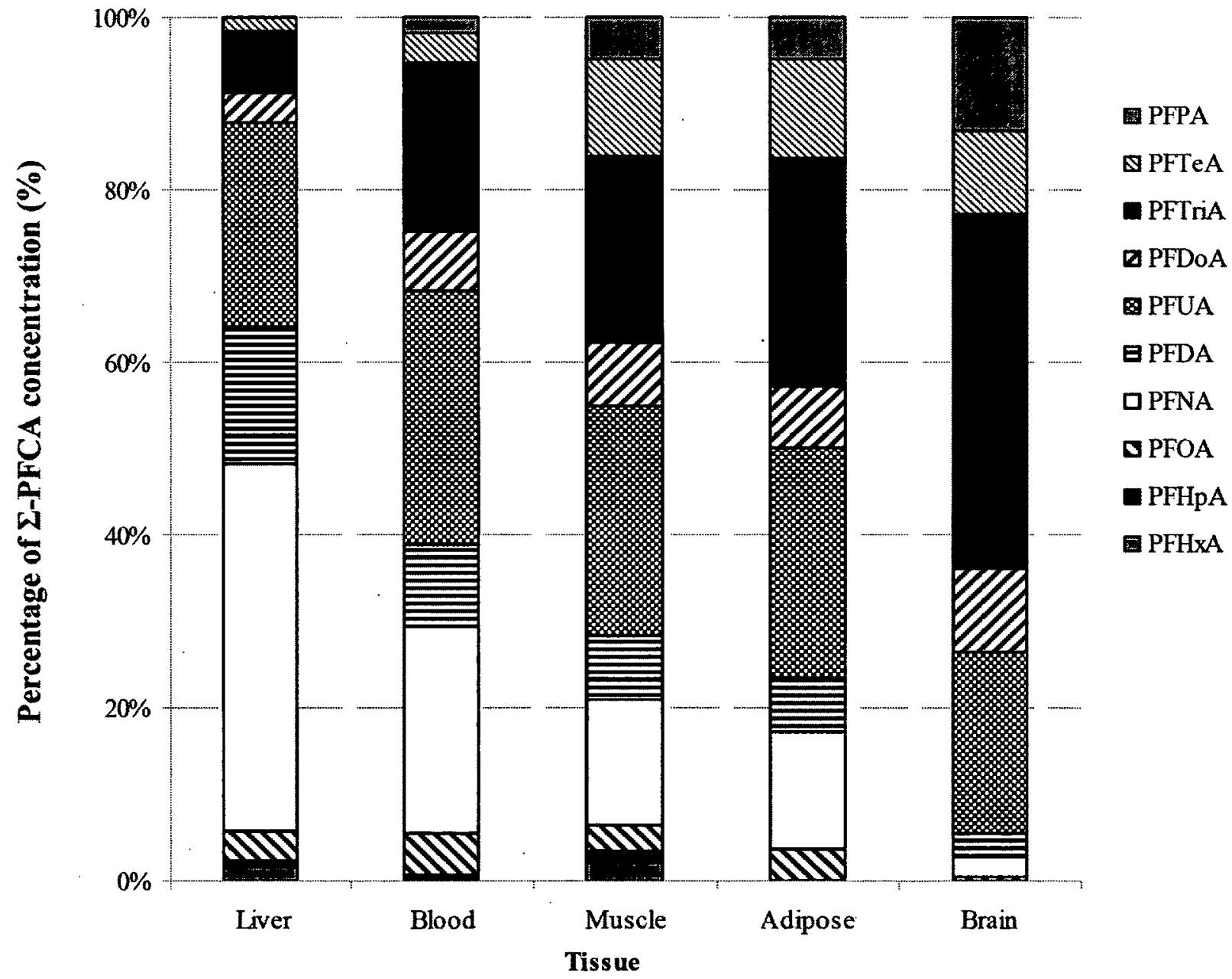

Figure 4.4 Percent compositions of $\Sigma$-PFCA concentrations from 20 East Greenland polar bears. 
As a result, the dominant PFCA varied as a function of tissue. The dominant PFCA was PFNA in the liver, PFUA and PFNA in the blood, PFUA and PFTriA in muscle and adipose, and PFTriA in the brain. This pattern indicates that PFCAs are regionally distributed in the body partially based on their chain length.

Jing et al., (2009) were recently able to experimentally determine the octanol-water partitioning coefficient $\left(\log K_{\mathrm{OW}}\right)$ of PFCAs. There was a clear relationship between the chain length of the PFCA and its lipophilic behaviour: longer chain lengths possessed higher $\log K_{\text {Ow }}$ values, indicating that they have an increased solubility in non-polar environments. Based on the percentage $\Sigma$-PFCA distribution shown in Figure 4.4, and the experimentally obtained $\log K_{\text {Ow }}$ values obtained by Jing et al. (2009), a PFCA-normalized $\log K_{\text {ow }}$ value was obtained for each tissue (Figure 4.5). An example calculation of how these normalized $\log K_{\mathrm{OW}}$ values were obtained can be seen in Appendix 2. Figure 4.5 reinforces the trend seen in Figure 4.4. The liver accumulates PFCAs with lower lipophilicities, whereas the brain accumulates PFCAs with higher lipophilicities. It is interesting to note that this relationship is not related to the lipid content found in the tissues, since the normalized $\log K_{\mathrm{OW}}$ values do not follow the same trend as lipid contents. This favorably supports the hypothesis that tissue differences may be attributed to localized proteins that preferably bind to one chain length over another, and therefore direct the PFCA in question to a specific region of the body. 


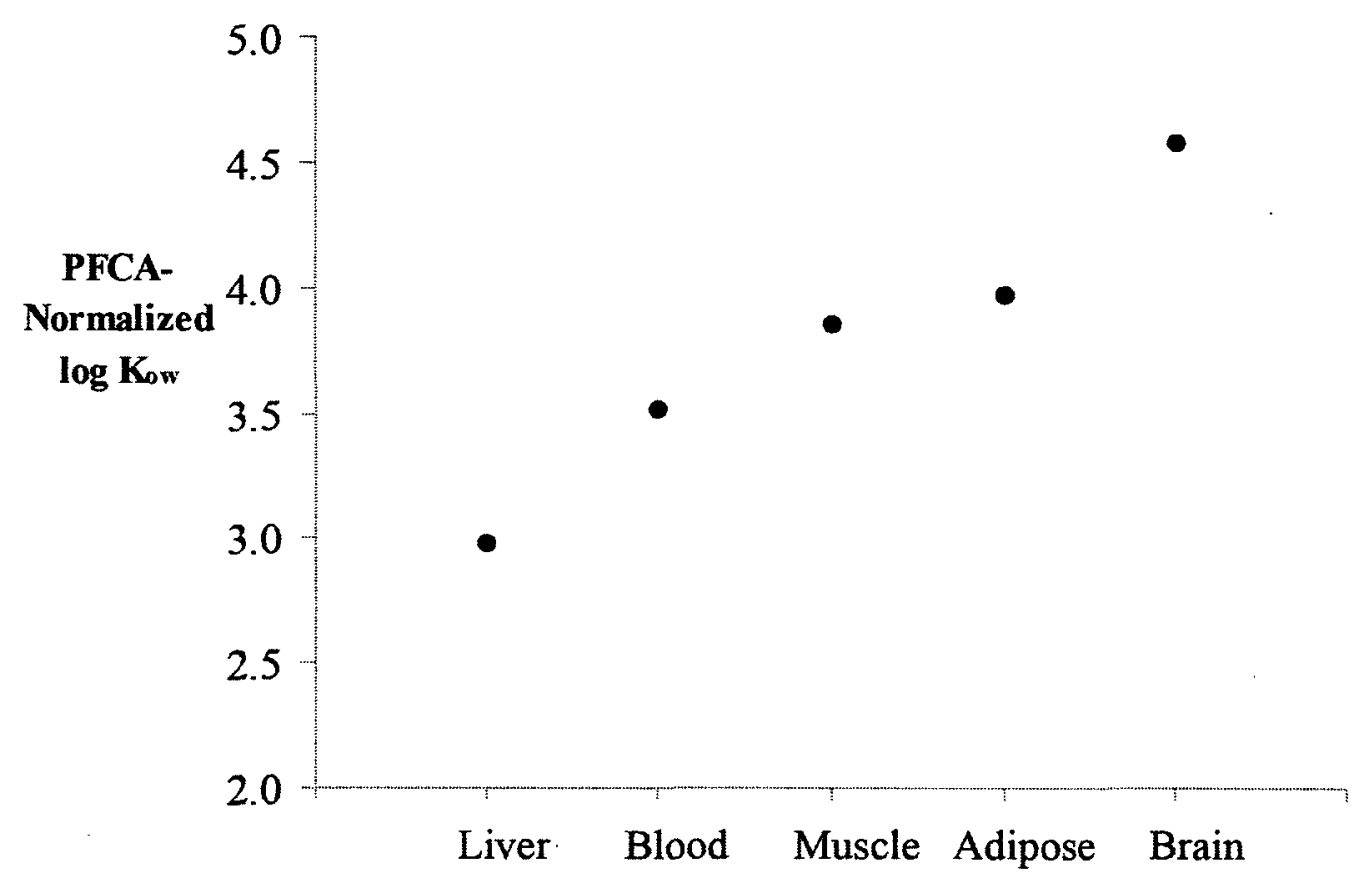

Figure 4.5 PFCA-normalized $\log K_{\text {OW }}$ values for all tissues analyzed. All $\log K_{\text {OW }}$ values were calculated from the percentage $\Sigma$-PFCA composition in each tissue, and individual $\log K_{\text {Ow }}$ values obtained by Jing et al., (2009). An example normalized $\log K_{\text {OW }}$ calculation can be seen in Appendix 2.

It is interesting to note that most of the few tissue distribution studies done to date show inconsistent trends relating to the dominant PFCA by tissue. Recently, Gebbink and Letcher (2012) found similar trends as reported here in herring gulls from the Great Lakes, such that the dominant PFCAs were PFNA and PFDA in the liver, PFTriA in the brain, and PFUA in the muscle and adipose. Rubarth et al. (2011) found the dominant PFCA in redthroated divers from the German Baltic Sea to be principally PFUA, with the exception of the brain (PFTriA). Ahrens, Siebert and Ebinghaus (2009) reported on the whole body burden of PFCs in harbor seals from the German Bight and found that the dominant PFCA for all tissues studied was exclusively either PFNA or PFDA. Verreault et al. (2005) found 
the dominant PFCA to vary by tissue in Norwegian Arctic glaucous gulls, such that PFUA was dominant in plasma, and PFTriA was dominant in the liver. The reason for these large inter-species differences remains unclear, but may in part be due to differences in diet, excretion pathways, and geographical location.

By far, the liver contained the highest concentrations of short/medium-chain length PFCAs (ie: $\mathrm{C}_{6}-\mathrm{C}_{12}$ ), with concentrations at least 5.5 times higher than any other tissue. However, the long-chain length PFCAs (ie: $\mathrm{C}_{13}-\mathrm{C}_{15}$ ), are drastically reduced in the liver compared to other tissues, to the point where the concentration of PFPA is 13 times higher in the brain $(10.56 \mathrm{ng} / \mathrm{g} \mathrm{ww}$ in the brain vs. $0.81 \mathrm{ng} / \mathrm{g}$ ww in the liver). The reason for these large accumulation differences between short- and long-chain PFCAs is not fully elucidated, but as mentioned above, is likely related to protein binding. Since many proteins are to some extent tissue-specific, it is possible that different length PFCAs are distributed protein-specifically and thus tissue-specifically. For example, chylomicrons and very low density lipoproteins (VLDLs) are formed in the liver to transport fatty acids from the intestines to the liver, and the liver to adipose, respectively. Newsted et al. (2007) showed that PFOS associated with VLDLs in the yolk of quails and mallards. It is possible that long-chain PFCAs, greatly resembling saturated fatty acids, are transported from the liver to adipose, thus explaining their low levels in the liver, and high levels in adipose.

\subsubsection{Distribution of PFSAs}

Similar to what was found for the distribution of PFCAs, there were large differences in PFSA concentrations between tissues. For example, the average PFOS concentration in the liver was $3,271 \mathrm{ng} / \mathrm{g}$ ww, whereas the next largest PFOS concentration was in the blood at $127.9 \mathrm{ng} / \mathrm{g} \mathrm{ww}$, an almost 26 -fold difference. $\Sigma$-PFSA concentrations 
decreased in the following order: liver $(3,308 \mathrm{ng} / \mathrm{g} \mathrm{ww})>$ blood $(147.4 \mathrm{ng} / \mathrm{g} \mathrm{ww})>$ brain $(38.03 \mathrm{ng} / \mathrm{g} \mathrm{ww})>$ muscle $(19.38 \mathrm{ng} / \mathrm{g} \mathrm{ww}) \approx$ adipose $(18.00 \mathrm{ng} / \mathrm{g} \mathrm{ww})$ (Figure 4.3).

For all tissues, PFOS was by far the most dominant PFSA, accounting for between $87 \%$ (blood) and $99 \%$ (liver) of all PFSAs detected. This extreme dominance of PFOS has been seen in other arctic wildlife studies, and has been accounted for by its large bioconcentration factor, estimated between 1100 and 5400 (Martin et al., 2003). The hyper-dominance of PFOS in the liver compared to other tissues seems to indicate that either (1) the liver is more exposed to PFOS than other tissues, (2) the liver has a larger PFOS bioconcentration factor than other tissues, or (3) the metabolism of PFOS precursor compounds (ex: PFOSA) is much higher in the liver than other tissues.

The high concentrations of PFOS in the liver are a cause for concern. Polar bear liver has some of the highest PFOS concentrations seen to date (Letcher et al., 2010; Houde et al., 2011). Limited data is available on the No Observable Adverse Effect Level (NOAEL), or Lowest Observable Adverse Effect Level (LOAEL) in wildlife, although NOAELs for hepatic PFOS concentrations ranged from 358 to $370 \mu \mathrm{g} / \mathrm{g}$ ww in SpragueDawley rats, and 59 to $70 \mu \mathrm{g} / \mathrm{g}$ ww in cynomolgus monkeys (Seacat et al., 2002, 2003). Although current hepatic PFC concentrations in polar bears have not yet approached these values, Dietz et al. (2008) showed that levels of e.g. PFOS in polar bears have been quickly increasing from $1996-2006$, despite the recent voluntary phase-out of $\mathrm{C}_{8}$-PFOSF chemistry by the $3 \mathrm{M}$ Company in 2002 . Up to that time, the $3 \mathrm{M}$ Company were reported to have been producing up to $80 \%$ of the world's PFOS supply (Martin et al., 2010).

Most toxicity studies have focused on the effects of PFOS, particularly in the liver and the brain. In the liver, PFOS and PFOA have been shown to be both peroxisome proliferators, and tumour promoters (Berthiaume and Wallace, 2002; Lindstrom et al., 
2011). Yu et al. (2011) also recently showed that hepatic exposure to PFOS increased the expression of both the organic anionic transporter protein (OATP2), as well as the multidrug resistance-associated protein (MRP2) in rats. Increased expression of OATP2 and MRP2 may lead to increased thyroid hormone metabolism, ultimately leading to structural brain damage, developmental delay and various neurological effects. In the brain, prenatal PFOS exposure in rats lead to the upregulation of glial fibrillary acidic protein (GFAP) and S100 calcium binding protein B (S-100ß) (Zeng et al., 2011). These proteins act to promote brain development and maintain a homeostatic environment at low concentrations. However, at high concentrations, S-100 $\beta$ can lead to neuroinflammation and neuronal dysfunction (Zeng et al., 2011). These studies suggest that exposure to PFCs will result in various toxicity effects, depending on the tissue exposed.

\subsubsection{Distribution of Precursor Compounds}

Of all the precursor compounds studied, the only compound to be consistently found above the MLOQ was PFOSA. PFOSA was by far the most present in the liver (151.4 ng/g ww), over 40 times higher than the next most contaminated tissue, blood ( 3.5 ng/g ww). The PFOSA levels found in all tissues generally mimicked PFOS patterns; tissues with high levels of PFOS also had high levels of PFOSA, and vice versa, as has

previously been shown elsewhere (Kannan et al., 2002; Gebbink et al., 2009). The correlation between PFOS and PFOSA concentrations is further discussed in section 4.2.7.

The fluorotelomer alcohols analyzed (6:2, 8:2, and 10:2 FTOHs) were not found in the majority of samples for any tissue studied. The percentage of samples above the method limit of quantification (MLOQ) ranged from $0-11 \%$ for the $6: 2 \mathrm{FTOH}, 0-10 \%$ for the 8:2 FTOH, and 0-5\% for the 10:2 FTOH (Table 4.2). 
The fluorotelomer unsaturated acids $(6: 2,8: 2$, and 10:2 FTUCAs) were found in the majority of liver and muscle samples, although at very low levels. The liver contained both 6:2 FTUCA ( $53 \%$ of samples above the MLOQ) and 8:2 FTUCA ( $84 \%$ of samples above the LOD), whereas muscle contained both 6:2 FTUCA ( $55 \%$ of samples above the MLOQ) and 10:2 FTUCA ( $55 \%$ of samples above the MLOQ).

Unfortunately, direct comparisons to polar bear prey are difficult due to a lack of data. Polar bears consume ringed seal blubber as their main dietary staple. Although studies have examined PFC concentrations in ringed seal liver, there are no studies to our knowledge that have examined PFC concentrations in East Greenland ringed seal blubber. In the liver of ringed seals from East Greenland collected in 2003, PFOSA concentrations have been found to be relatively low (1.2 ng/g ww) (Bossi et al., 2005b). Since it is known that the liver contains much higher concentrations of PFCs compared to the blubber (adipose), it can be assumed that ringed seal blubber contains very low PFOSA concentrations.

\subsubsection{Relationship between PFOS and PFOSA Concentrations}

PFOS is the major PFC in the environment. It has been found worldwide, in mammals, birds, and fish and is most often the PFC found at highest concentrations. It can be emitted into the environment directly from sources, as well as from less stable compounds, such as PFOSA, that can degrade to give PFOS (Martin et al., 2010).

To determine the relationship between PFOS and PFOSA, only samples that had both PFOS and PFOSA concentrations above the MLOQ were analyzed, accounting for $81 \%$ of all samples. The brain $(r=0.70)$, blood $(r=0.60)$, adipose $(r=0.55)$, liver $(r=$ $0.53)$, and muscle $(r=0.51)$ all showed strong statistical correlations $(p \leq 0.038)$ between 
PFOS and PFOSA concentrations. Ratios of PFOS to PFOSA ranged from $9.2 \pm 0.8$ (muscle) to $36.4 \pm 6.7$ (liver) (Table 4.5). Although the reason for the ratio differences between tissues remains unclear, these findings indicate perhaps one of the following: (1) tissues such as the liver and blood preferentially accumulate PFOS more strongly than other tissues; (2) the liver and blood may have more difficulty eliminating PFOS compared to other tissues; (3) the liver may proportionally convert more PFOSA to PFOS compared to other tissues. Studies have shown that PFOSA is converted to PFOS in liver microsomes (Tomy et al., 2004; Xu et al., 2004; Benskin et al., 2009). Specifically, Benskin et al. (2009) showed that two enzymes from the cytochrome P450 family, CYP2C9 and CYP2C19, were majorly responsible for PFOSA metabolism in human liver microsomes. These CYPs are mostly present in the liver, for the purpose of oxidizing xenobiotic compounds. Although they have been detected in tissues other than the liver, CYP2C9 and CYP2C19 have not been detected in the blood, and have been detected in very small quantities in the brain (Nishimura et al., 2003; Furukawa et al., 2004). Consequently, the majority of their activity (and thus PFOSA metabolism) occurs in the liver.

Table 4.5 Arithmetic mean ratio ( \pm SE) between PFOS and PFOSA concentrations in East Greenland polar bears.

\begin{tabular}{cccc}
\hline Tissue & $\begin{array}{c}\text { PFOS to PFOSA } \\
\text { Ratio } \pm \text { SE }\end{array}$ & $\begin{array}{c}\text { Pearson } \\
\text { coefficient, } \mathbf{r}\end{array}$ & $\begin{array}{c}\text { Significance } \\
\text { Level, } \mathbf{p}\end{array}$ \\
\hline Muscle $(\mathrm{n}=18)$ & $9.2 \pm 0.8$ & 0.51 & 0.029 \\
Adipose $(\mathrm{n}=15)$ & $17.8 \pm 1.7$ & 0.55 & 0.033 \\
Brain $(\mathrm{n}=100)$ & $25 \pm 1.0$ & 0.72 & $<0.0001$ \\
Blood $(\mathrm{n}=12)$ & $28.9 \pm 3.5$ & 0.60 & 0.038 \\
Liver $(\mathrm{n}=19)$ & $36.4 \pm 6.7$ & 0.53 & 0.023 \\
\hline
\end{tabular}


The PFOS to PFOSA ratio in the liver $(36.4 \pm 6.7)$ is much lower than previous East Greenland polar bear studies. Smithwick et al. (2005a) and Dietz et al. (2008) both showed PFOS to PFOSA ratios on the order of 200:1 to 250:1. However, as mentioned in section 2.4.4, these studies quantified the concentration of PFOSA by firstly using ${ }^{13} \mathrm{C}-\mathrm{N}$ Me-FOSA as an internal standard, and secondly by using ESI as an ionization mode. To our knowledge there has not been a study analyzing PFOSA in polar bear liver using both the new ${ }^{13} \mathrm{C}$-labelled PFOSA internal standard, as well as the new ionization technique, APPI. Therefore comparisons between this data and previous data are difficult. This data indicates that previous PFOSA quantification using ${ }^{13} \mathrm{C}-\mathrm{N}-\mathrm{Me}-\mathrm{FOSA}$ as an internal standard may have been underestimated, and that comparisons between PFOSA data generated prior to 2010 should perhaps not be directly compared to PFOSA data generated post 2010.

\subsubsection{Correlations between Tissues}

Tissue distribution studies, although extremely useful, are also time consuming, and require the complete dissection and harvesting of animal specimens. It would be extremely useful to deduce predictive relationships between tissue accumulation patterns, such that with the analysis of a few tissues (ex: blood), an overall body burden estimate could be calculated. This would also be extremely useful for human PFAA exposure studies, where invasive procedures are not possible.

Correlations between the concentrations of PFSAs and PFCAs among tissues were examined for the five tissues studied, and a complete list of all statistically significant correlations can be found in Table 4.6. PFOS concentrations were significantly correlated among all tissues $(0.48 \leq \mathrm{r} \leq 0.87)$, with the exclusion of the liver. A correlation of $\Sigma$ - 
PFSA concentrations did exist between the liver and the brain $(r=0.47)$, although it did not exist for an individual PFSA.

PFCAs were correlated between compartments according to their chain lengths. Muscle and blood $(r \geq 0.47)$ were statistically correlated for the shorter chain PFCAs $\left(C_{7}\right.$ and $\left.\mathrm{C}_{8}\right)$. Muscle and brain $(\mathrm{r} \geq 0.55)$ were correlated for the medium chain length PFCAs $\left(\mathrm{C}_{10}-\mathrm{C}_{13}\right)$, and muscle and adipose $(\mathrm{r} \geq 0.61)$ were correlated for the medium and longer chain PFCAs $\left(\mathrm{C}_{9}, \mathrm{C}_{11}, \mathrm{C}_{13}-\mathrm{C}_{15}\right)$.

Correlations between the liver and other tissues were clearly defined by chain length. The liver was correlated with the blood $(r \geq 0.51)$ for PFOA and PFNA. The liver was correlated with the brain $(r \geq 0.50)$ for PFUA and PFDoA, and the liver was correlated with muscle ( $\mathrm{r} \geq 0.49)$ for PFDoA, PFTriA, and PFPA. 
Table 4.6 PFC concentration correlations among tissues. All values shown are the Pearson correlation coefficients ( $r$-values) for all statistically significant correlations $(p \leq 0.05)$. The symbol - denotes a non-statistically significant correlation.

\begin{tabular}{|c|c|c|c|c|c|c|c|c|c|c|}
\hline Compound & $\begin{array}{l}\text { Liver vs. } \\
\text { Blood }\end{array}$ & $\begin{array}{c}\text { Liver vs. } \\
\text { Brain }\end{array}$ & $\begin{array}{l}\text { Liver vs. } \\
\text { Muscle }\end{array}$ & $\begin{array}{l}\text { Liver vs. } \\
\text { Adipose }\end{array}$ & $\begin{array}{c}\text { Muscle vs. } \\
\text { Blood }\end{array}$ & $\begin{array}{c}\text { Muscle vs. } \\
\text { Brain }\end{array}$ & $\begin{array}{c}\text { Muscle vs. } \\
\text { Adipose }\end{array}$ & $\begin{array}{l}\text { Blood vs. } \\
\text { Brain }\end{array}$ & $\begin{array}{l}\text { Blood vs. } \\
\text { Adipose }\end{array}$ & $\begin{array}{c}\text { Adipose vs. } \\
\text { Brain }\end{array}$ \\
\hline PFOS & - & - & - & - & 0.66 & 0.76 & 0.87 & 0.63 & 0.48 & 0.68 \\
\hline$\sum$-PFSAs & - & 0.47 & - & $=$ & 0.62 & 0.74 & 0.83 & 0.63 & - & 0.73 \\
\hline PFHpA & - & - & - & - & 0.59 & - & - & - & - & $=$ \\
\hline PFOA & 0.57 & - & - & - & 0.47 & $=$ & - & 0.56 & - & - \\
\hline PFNA & 0.51 & - & - & - & - & - & 0.61 & - & - & - \\
\hline PFDA & - & - & - & - & - & 0.55 & - & - & - & - \\
\hline PFUA & - & 0.52 & - & - & - & 0.77 & 0.8 & - & - & 0.7 \\
\hline PFDoA & - & 0.5 & 0.49 & - & - & 0.67 & - & - & - & - \\
\hline PFTriA & - & - & 0.6 & - & - & 0.63 & 0.65 & 0.53 & - & - \\
\hline PFTEA & - & - & - & - & - & - & 0.77 & - & - & 0.56 \\
\hline PFPA & 0.56 & - & 0.67 & - & 0.59 & - & 0.7 & - & - & - \\
\hline$\Sigma$-PFCAs & - & - & - & - & - & 0.6 & 0.58 & - & - & 0.65 \\
\hline PFOSA & - & 0.49 & - & 0.51 & - & - & - & - & - & - \\
\hline
\end{tabular}


Although correlations of PFCA and PFSA concentrations between tissues do exist, the pattern is not well enough defined to be able to use predictive equations to estimate concentrations in a tissue based on their concentrations in another tissue. This is especially true for blood samples, which saw very few correlations.

\subsubsection{Estimated PFC Tissue Burdens}

The total PFC tissue burdens were estimated for all tissues analyzed, with the exception of the muscle (Table 4.7). Estimates were based on tissue mass correlations from numerous sources (Herschel, 1972; Prothero, 1980, 1982; Armstrong, 1983; Polischuk et al., 2002). The total body mass of the polar bears in this study was not recorded. However, the total brain mass was recorded for 16 of the 20 bears. Herschel (1972) correlated the polar bear brain size with its total body mass, such that the brain represented $0.192 \%$ of the total body mass (Equation 1). Using this data, the total body masses for 16 of the 20 bears were estimated. Subsequently, the liver and blood masses were estimated based on Prothero $(1980,1982)$ (Equations 2,3$)$ such that liver weight $(\mathrm{kg})=0.087$ (total body mass, kg) ${ }^{0.87}$ (Prothero, 1982). The blood masses were similarly estimated such that blood mass $(\mathrm{kg})=0.086$ (total body mass, $\mathrm{kg})^{0.99}$ (Prothero, 1980). The mass of adipose tissue was based on Polischuk et al. (2002), who demonstrated that adipose levels in polar bears drop to approximately $25 \%$ of total body mass after seasonal fasting (Equation 4 ). This estimate was deemed appropriate for this study as all bears were collected between January and March, towards the end of their fasting season. The total burden of PFCs in muscle tissue was not calculated. To my knowledge, there has not been a study to correlate total skeletal muscle mass with overall polar bear body length or body mass. As a result, no reasonable 
skeletal muscle mass could be estimated. All tissue mass estimates can be seen in Appendix 3 .

(1) Mass Brain $(\mathrm{kg})=$ Total Body Mass $(\mathrm{kg}) \times 0.192 \%$

(2) Mass Liver $(\mathrm{kg})=0.087$ (Total Body Mass, $\mathrm{kg})^{0.087}$

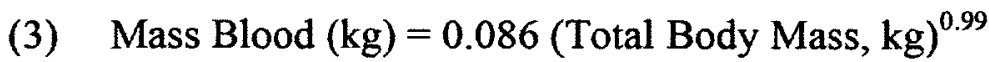

(4) Mass Adipose (kg) = Total Body Mass (kg) $\times 25 \%$

As can be seen in Table 4.6, the liver contained the highest burden of PFCs $(42,402$ $\mu \mathrm{g} \pm 4,910 \mu \mathrm{g})$, followed by blood $(3,784 \mu \mathrm{g} \pm 510 \mu \mathrm{g})$, adipose $(1,683 \mu \mathrm{g} \pm 287 \mu \mathrm{g})$, and finally brain $(49.26 \mu \mathrm{g} \pm 2.61 \mu \mathrm{g})$. It is interesting to note that the estimated PFC burden in the liver far surpassed all other tissues, even though the average mass of the liver was less $(8.87 \mathrm{~kg})$ than the blood $(16.7 \mathrm{~kg})$ or adipose $(51.1 \mathrm{~kg})$.

The data indicates that the liver is the best tissue to use for monitoring purposes in the polar bear, as it best reflects the overall concentration in the whole animal. Not only does the liver contain the highest $\Sigma$-PFC concentration $(4,646 \mathrm{ng} / \mathrm{g}$ ww \pm 393$)$, it also contains the highest tissue burden of all tissues analyzed in this study $(42.4 \mathrm{mg} \pm 4.9 \mathrm{mg})$. 
Table 4.7 Total tissue burden ( $\mu \mathrm{g} \pm \mathrm{SE}$ ) estimates of perfluorinated compounds in the liver, blood, adipose, and brain of East Greenland polar bears. Average tissue masses were estimated based on Equations $1-4$ (see Appendix 3 for a complete table of estimated masses).

\begin{tabular}{|c|c|c|c|c|}
\hline Average Mass & $\begin{array}{c}\text { Liver } \\
8.87 \mathrm{~kg} \\
\end{array}$ & $\begin{array}{c}\text { Blood } \\
16.6 \mathrm{~kg} \\
\end{array}$ & $\begin{array}{c}\text { Adipose } \\
51.0 \mathrm{~kg} \\
\end{array}$ & $\begin{array}{c}\text { Brain } \\
0.39 \mathrm{~kg}\end{array}$ \\
\hline PFHxS & $284.9 \pm 23.04$ & $302.0 \pm 28.7$ & $82.34 \pm 13.93$ & $0.54 \pm 0.04$ \\
\hline PFOS & $30,108 \pm 3541$ & $2,181 \pm 360$ & $855.6 \pm 154.6$ & $15.06 \pm 1.02$ \\
\hline PFDS & $70.75 \pm 24.97$ & $22.78 \pm 4.54$ & $64.35 \pm 21.20$ & $0.52 \pm 0.07$ \\
\hline$\Sigma$-PFSA & $30,464 \pm 3,574$ & $2,509 \pm 386$ & $1,008 \pm 174$ & $16.20 \pm 1.05$ \\
\hline PFHxA & $166.0 \pm 11.9$ & n.d. & n.d. & n.d. \\
\hline PFHpA & $89.27 \pm 13.22$ & $8.51 \pm 1.28$ & n.d. & n.d. \\
\hline PFOA & $355.2 \pm 43.9$ & $60.18 \pm 6.47$ & $23.57 \pm 6.74$ & $0.11 \pm 0.03$ \\
\hline PFNA & $4,542 \pm 526$ & $294.1 \pm 28.3$ & $90.20 \pm 17.51$ & $0.77 \pm 0.06$ \\
\hline PFDA & $1,713 \pm 213$ & $115.0 \pm 14.3$ & $44.39 \pm 10.75$ & $0.89 \pm 0.06$ \\
\hline PFUA & $2,250 \pm 319$ & $351.1 \pm 45.1$ & $173.7 \pm 35.6$ & $6.81 \pm 0.37$ \\
\hline PFDoA & $382.1 \pm 47.1$ & $84.47 \pm 11.14$ & $47.70 \pm 9.87$ & $3.04 \pm 0.16$ \\
\hline PFTriA & $752.2 \pm 101.1$ & $239.7 \pm 33.8$ & $163.6 \pm 27.2$ & $13.44 \pm 0.76$ \\
\hline PFTeA & $161.8 \pm 12.8$ & $44.32 \pm 3.77$ & $68.60 \pm 10.04$ & $3.13 \pm 0.17$ \\
\hline PFPA & $7.29 \pm 0.90$ & $22.95 \pm 2.98$ & $29.45 \pm 5.09$ & $4.39 \pm 0.24$ \\
\hline$\Sigma$-PFCA & $10,719 \pm 1213^{\circ}$ & $1,221 \pm 134$ & $649.1 \pm 110.8$ & $32.66 \pm 1.68$ \\
\hline PFOSA & $1,385 \pm 395$ & $58.93 \pm 22.57$ & $39.77 \pm 6.51$ & $0.57 \pm 0.05$ \\
\hline E-PFCs & $42,402 \pm 4,910$ & $3,784 \pm 510$ & $1,683 \pm 287$ & $49.26 \pm 2.61$ \\
\hline
\end{tabular}

Gebbink et al. (2008) estimated tissue burdens of various organohalogen compounds such as polychlorinated biphenyls (PCBs), chlordanes (CHLs), and polybrominated diphenyl ethers (PBDEs), in polar bears from East Greenland. Most organohalogen compounds are lipophilic, and as such accumulate in fatty tissue such as adipose, over less fatty tissues. As a result, they found the total burdens of $\Sigma$-PCBs and $\Sigma$ CHLs in polar bear adipose tissue to be $840 \mathrm{mg}$ and $134 \mathrm{mg}$, respectively (Gebbink et al., 
2008). These burdens far surpass the $\Sigma$-PFC burden in adipose tissue found in this study (1.7 mg). However, the liver, blood and brain burdens of $\Sigma$-PCBs $(25 \mathrm{mg}, 1.5 \mathrm{mg}, 18 \mu \mathrm{g}$, respectively) and $\Sigma$-CHLs ( $30 \mathrm{mg}, 0.2 \mathrm{mg}, 1.5 \mu \mathrm{g}$, respectively) are very comparable to the $\Sigma$-PFC burdens found in this study (42 mg, $3.8 \mathrm{mg}, 49 \mu \mathrm{g}$, respectively), indicating that these tissues are exposed to similar levels of PFCs, PCBs, and CHLs.

\subsection{Conclusions}

The findings in this chapter have confirmed that the PFAA distribution profile is different among tissues, such that shorter chain PFCAs are found in the liver and blood, and longer chain PFCAs are found in the brain, and adipose (Figure 4.5). The overall PFAA distribution was such that the liver had the highest concentration, followed by blood $>$ brain $>$ muscle $\approx$ adipose. Despite the 2000 phase-out of $\mathrm{C}_{8}$-based chemistry by the $3 \mathrm{M}$ Co., concentrations of PFOS and PFOSA are still extremely high in East Greenland polar bear liver $(3,271 \mathrm{ng} / \mathrm{g} \mathrm{ww}$, and $151.4 \mathrm{ng} / \mathrm{g}$ ww, respectively), and have been shown to still be increasing (Smithwick et al., 2006; Dietz et al., 2008). It is important to note that the exact NOAEL in polar bears is not known, but that current hepatic PFC concentrations are approaching the NOAEL found in cynomolgus monkeys (Seacat et al., 2002). It continues that East Greenland polar bears have some of the highest PFC concentrations known and efforts should be made in examining their toxicological effects. 


\section{References}

Ahrens, L., Siebert, U., Ebinghaus, R., 2009. Total body burden and tissue distribution of perfluorinated compounds in harbor seals (Phoca vitulina) from the German Bight. Marine Pollution Bulletin 58, 520-525.

Armstrong, E., 1983. Relative brain size and metabolism in mammals. Science 220, 1302-1304.

Benskin, J.P., Holt, A., Martin, J.W., 2009. Isomer-specific biotransformation rates of a perfluorooctane sulfonate (PFOS)-precursor by cytochrome P450 isozymes and human liver microsomes. Environmental Science \& Technology 43, 8566-8572.

Berthiaume, J., Wallace, K.B., 2002. Perfluorooctanoate, perfluorooctanesulfonate, and N-ethyl perfluorooctanesulfonamido ethanol: Peroxisome proliferation and mitochondrial biogenesis. Toxicology Letters 129, 23-32.

Bossi, R., Riget, F.F., Dietz, R., 2005a. Temporal and spatial trends of perfluorinated compounds in ringed seal (Phoca hispida) from Greenland. Environmental Science \& Technology 39, 7416-7422.

Bossi, R., Riget, F.F., Dietz, R., Sonne, C., Fauser, P., Dam, M., Vorkamp, K., Preliminary screening of perfluorooctane sulfonate (PFOS) and other fluorochemicals in fish, birds and marine mammals from Greenland and the Faroe Islands. Environmental Pollution 136, 323329.

Butt, C.M., Berger, U., Bossi, R., Tomy, G.T., 2010. Levels and trends of poly- and perfluorinated compounds in the Arctic environment. Science of the Total Environment 408, 2936-2965.

Cassone, C.G., Vongphachan, V., Chiu, S.Z., Williams, K.L., Letcher, R.J., Pelletier, E., Crump, D., Kennedy, S., 2012. In ovo effects of perfluorohexane sulfonate and perfluorohexanoate on toxicity, development, mRNA expression and thyroid hormone levels in chicken embryos. Toxicological Sciences. In Review.

Dietz, R., Riget, F.F., Sonne, C., Letcher, R.J., Born, E.W., Muir, D.C.G., 2004. Seasonal and temporal trends in polychlorinated biphenyls and organochlorine pesticides in East Greenland polar bears (Ursus maritimus), 1990-2001. Science of the Total Environment $331,107-124$.

Dietz, R., Bossi, R., Riget, F.F., Sonne, C., Born, E.W., 2008. Increasing perfluoroalkyl contaminants in East Greenland polar bears (Ursus maritimus): A new toxic threat to the Arctic bears. Environmental Science \& Technology 42, 2701-2707.

Furukawa, M., Nishimura, M., Ogino, D., Chiba, R., Ikai, I., Ueda, N., Naito, S., Kuribayashi, S., Moustafa, M.A., Uchita, T., Sawada, H., Kamataki, T., Funae, Y., Fukumoto, M., 
Cytochrome P450 gene expression levels in peripheral blood mononuclear cells in comparison with the liver. Cancer Science 95, 520-529.

Gebbink, W.A., Sonne, C., Dietz, R., Kirkegaard, M., Born, E.W., Muir, D.C.G., Letcher, R.J., 2008. Target tissue selectivity and burdens of diverse classes of brominated and chlorinated contaminants in polar bears (Ursus maritimus) from East Greenland. Environmental Science \& Technology 42, 752-759.

Gebbink, W.A., Hebert, C.E., Letcher, R.J., 2009. Perfluorinated carboxylates and sulfonates and precursor compounds in herring gull eggs from colonies spanning the Laurentian Great Lakes of North America. Environmental Science \& Technology 43, 7443-7449.

Gebbink, W.A., Letcher, R.J., 2012. Comparative tissue and body compartment accumulation and maternal transfer to eggs of perfluoroalkyl sulfonates and carboxylates in Great Lakes herring gulls. Environmental Pollution 162, 40-47.

Genuis, S.J., Birkholz, D., Ralitsch, M., Thibault, N., 2010. Human detoxification of perfluorinated compounds. Public Health 124, 367-375.

Harvey, R.A., Ferrier, D.R., 2010. Biochemistry, $5^{\text {th }}$ Edition. Lippincott Williams \& Wilkins. Philadelphia, Pennsylvania USA.

Herschel, J., 1972. Scaled ratio of body-weight to brain weight as a comparative index for relative importance of brain size in mammals of widely varying body mass. Psychological Reports 31, 84-86.

Houde, M., Balmer, B.C., Brandsma, S., Wells, R.S., Rowles, T.K., Solomon, K.R., Muir, D.C.G., 2006a. Perfluoroalkyl compounds in relation to life-history and reproductive parameters in bottlenose dolphins (Tursiops truncatus) from Sarasota Bay, Florida, USA. Environmental Toxicology and Chemistry 25, 2405-2412.

Houde, M., Martin, J.W., Letcher, R.J., Solomon, K.R., Muir, D.C.G., 2006a. Biological monitoring of perfluoroalkyl substances: A review. Environmental Science \& Technology 40, 3463-3473.

Houde, M., De Silva, A.O., Muir, D.C.G., Letcher, R.J., 2011. Monitoring of perfluorinated compounds in aquatic biota : An updated review of PFCs in aquatic biota. Environmental Science \& Technology 45, 7962-7973.

Jing, P., Rodgers, P.J., Amemiya, S., 2009. High lipophilicity of perfluoroalkyl carboxylate and sulfonate: Implications for their membrane permeability. Journal of the American Chemical Society $131,2290-2296$.

Kannan, K., Newsted, J., Halbrook, R.S., Giesy, J.P. 2002. Perfluorooctanesulfonate and related fluorinated hydrocarbons in mink and river otters from the United States. Environmental Science \& Technology 36, 2566-2571. 
Kannan, K., Yun S.H., Evans, T.J., 2005. Chlorinated, brominated, and perfluorinated contaminants in livers of polar bears from Alaska. Environmental Science \& Technology $39,9057-9063$.

Kelly, B.C., Ikonomou, M.G., Blair, J.D., Surridge, B., Hoover, D., Grace, R., Gobas, F.A.P.C., 2009. Perfluoroalkyl contaminants in the Arctic marine food web: Trophic magnification and wildlife exposure. Environmental Science \& Technology 43, 4037-4043.

Letcher, R.J., Bustnes, J.O., Dietz, R., Jenssen, B. M., Jorgensen, E.H., Sonne, C., Verreault, J., Vijayan, M.M., Gabrielsen, G.W., 2010. Exposure and effects assessment of persistent organohalogen contaminants in arctic wildlife and fish. Science of the Total Environment 408, 2995-3043.

Lindstrom, A.B., Strynar, M.J., Libelo, E.L., 2011. Perfluorinated compounds: Past, present, and future. Environmental Science \& Technology 45, 7954-7961.

Martin, J.W., Mabury, S.A., Solomon, K.R., Muir, D.C.G., 2003. Bioconcentration and tissue distribution of perfluorinated acids in rainbow trout (Oncorhynchus mykiss). Environmental Toxicology and Chemistry 22, 196-204.

Martin, J.W., Asher, B.J., Beesoon, S., Benskin, J.P., Ross, M.S., 2010. PFOS or PreFOS? Are perfluorooctane sulfonate precursors (PreFOS) important determinants of human and environmental perfluorooctane sulfonate (PFOS) exposure? Journal of Environmental Monitoring 12, 1979-2004.

Newsted, J.L., Coady, K.K., Beach, S.A., Butenhoff, J.L., Gallagher, S., Giesy, J.P., 2007. Effects of perfluorooctane sulfonate on mallard and northern bobwhite quail exposed chronically via the diet. Environmental Toxicology and Pharmacology 23, 1-9.

Nishimura, M., Yaguti, H., Yoshitsugu, H., Naito, S., Satoh, T., 2003. Tissue distribution of mRNA expression of human cytochrome $\mathrm{P} 450$ isoforms assessed by high-sensitivity realtime reverse transcription PCR. Yakugaku Zasshi 123, 369-375.

Olivero-Verbel, J., Tao, L., Johnston-Restrepo, B., Guette-Fernandez, J., Baldiris-Avila, R., O'byrne-Hoyos, I., Kannan, K., 2006. Perfluorooctanesulfonate and related fluorochemicals in biological samples from the north coast of Colombia. Environmental Pollution 142, 367-372.

Pan, Y.Y., Shi, Y.L., Wang, J.M., Cai, Y.Q., Wu, Y.N., 2010. Concentrations of perfluorinated compounds in human blood from twelve cities in China. Environmental Toxicology and Chemistry 29, 2695-2701.

Polischuk, S.C., Norstrom, R.J., Ramsay, M.A., 2002. Body burdens and tissue concentrations of organochlorines in polar bears (Ursus maritimus) vary during seasonal fasts. Environmental Pollution 118, 29-39. 
Powley, C.R., George, S.W., Russell, M.H., Hoke, R.A., Buck, R.C., 2008. Perfluorinated chemicals in spatially and temporally integrated food webs in the Western Arctic. Chemosphere 70, 664-672.

Prothero, J.W., 1980. Scaling of blood parameters in mammals. Comparative Biochemistry and Physiology Part A - Physiology 67, 649-657.

Prothero, J.W., 1982. Organ scaling in mammals - the liver. Comparative Biochemistry and Physiology Part A - Physiology 71, 567-577.

Rosing-Asvid, A., Born, E.W., Kingsley, M.C.S., 2002. Age at sexual maturity of males and timing of the mating season of polar bears (Ursus maritimus) in Greenland. Polar Biology $25,878-883$.

Rubarth, J., Dreyer, A., Guse, N., Einax, J.W., Ebinghaus, R., 2011. Perfluorinated compounds in red-throated divers from the German Baltic Sea: New findings from their distribution in 10 different tissues. Environmental Chemistry 8, 419-428.

Seacat, A.M., Thomford, P.J., Hansen, K.J., Olsen, G.W., Case, M.T., Butenhoff, J.L., 2002. Subchronic toxicity studies on perfluorooctanesulfonate potassium salt in cynomolgus monkeys. Toxicological Sciences 68, 249-264.

Seacat, A.M., Thomford, P.J., Hansen, K.J., Clemen, L.A., Eldridge, S.R., Elcombe, C.R., Butenhoff, J.L., 2003. Sub-chronic dietary toxicity of potassium perfluorooctanesulfonate in rats. Toxicology $183,117-131$.

Smithwick, M., Mabury, S.A., Solomon, K.R., Sonne, C., Martin, J.W., Born, E.W., Dietz, R., Derocher, A.E., Letcher, R.J., Evans, T.J., Gabrielsen, G.W., Nagy, J., Stirling, I., Taylor, M.K., 2005a. Circumpolar study of perfluoroalkyl contaminants in polar bears (Ursus maritimus). Environmental Science \& Technology 39, 5517-5523.

Smithwick, M., Muir, D.C.G., Mabury, S.A., Solomon, K.R., Martin, J.W., Sonne, C., Born, E.W., Letcher, R.J., Dietz, R., 2005b. Perfluoroalkyl contaminants in liver tissue from East Greenland polar bears (Ursus maritimus). Environmental Toxicology and Chemistry 24, 981-986.

Smithwick, M., Norstrom, R.J., Mabury, S.A., Solomon, K., Evans, T.J., Stirling, I., Taylor, M.K., Muir, D.C.G., 2006. Temporal trends of perfluoroalkyl contaminants in polar bears (Ursus maritimus) from two locations in the North American Arctic, 1972-2002. Environmental Science \& Technology 40, 1139-1143.

Sturm, R., Ahrens, L., 2010. Trends of polyfluoroalkyl compounds in marine biota and in humans. Environmental Chemistry 7, 457-484. 
Tomy, G.T., Tittlemier, S.A., Palace, V.P., Budakowski, W.R., Braekevelt, E., Brinkworth, L., Friesen, K., 2004. Biotransformation of N-ethyl perfluorooctanesulfonamide by rainbow trout (Onchorhynchus mykiss) liver microsomes. Environmental Science \& Technology 38, 758-762.

Van de Vijver, K.I., Hoff, P., Das, K., Brasseur, S., Van Dongen, W., Esmens, E., Reijnders, P., Blust, R., De Coen, W., 2005. Tissue distribution of perfluorinated chemicals in harbor seals (Phoca vitulina) from the Dutch Wadden Sea. Environmental Science \& Technology $39,6978-6984$.

Van de Vijver, K.I., Holsbeek, L., Das, K., Blust, R., Joiris, C., De Coen, W., 2007. Occurrence of perfluorooctane sulfonate and other perfluorinated alkylated substances in harbor porpoises from the Black Sea. Environmental Science \& Technology 41, 315-320.

Verreault, J., Houde, M., Gabrielsen, G.W., Berger, U., Haukas, M., Letcher, R.J., Muir, D.C.G., 2005. Perfluorinated alkyl substances in plasma, liver, brain, and eggs of glaucous gulls (Larus hyperboreus) from the Norwegian Arctic. Environmental Science \& Technology 39, 7439-7445.

Wilhelm, M., Holzer, J., Dobler, L., Rauchfuss, K., Midasch, O., Kraft, M., Angerer, J., Wiesmuller, G., 2009. Preliminary observations on perfluorinated compounds in plasma samples (1977-2004) of young German adults from an area with perfluorooctanoatecontaminated drinking water. International Journal of Hygiene and Environmental Health $212,142-145$.

Xu, L., Krenitsky, D.M., Seacat, A.M., Butenhoff, J.L., Anders, M.W., Biotransformation of Nethyl-N-(2-hydroxyethyl)perfluorooetanesulfonamide by rat liver microsomes, cytosol, and slices and by expressed rat and human cytochromes P450. Chemical Research in Toxicology 17, 767-775.

Yu, W.G., Liu, W., Liu, L., Jin, Y.H., 2011. Perfluorooctane sulfonate increased hepatic expression of OAPT2 and MRP2 in rats. Archives of Toxicology 85, 613-621.

Zeng, H.C., Zhang, L., Li, Y.Y., Wang, Y.J., Xia, W., Lin, Y., Wei, J., Xu, S.Q., 2011. Inflammation-like glial response in rat brain induced by prenatal PFOS exposure. Neurotoxicology 32, 130-139. 


\section{CHAPTER 5 \\ Conclusions and Future Directions}

\subsection{Conclusions}

This study examined the distribution patterns of perfluoroalkyl sulfonates (PFSAs) and carboxylates (PFCAs) and select precursors in brain regions as well as liver, blood, adipose, and muscle of polar bears from Scoresby Sound, East Greenland. This was the first study to examine the intra-brain distribution of PFCs in any species, and the first to estimate the PFC burden in the brain of polar bears. Furthermore, this was the first study to examine the distribution of bioaccumulative PFCs in polar bear tissue other than liver and blood. A brief overview of the major findings of this study is provided here.

In Chapter 3, eight different regions of the brain were examined to determine the levels and distribution profiles of PFAAs. It was shown that, on a wet weight basis, PFAA accumulation in the brain was region-specific. However, concentrations on a lipid weight basis showed no brain region-specific accumulation. It was also shown that long-chain PFCAs $\left(\mathrm{C}_{10}-\mathrm{C}_{15}\right)$ were strongly and positively correlated with extractable lipid content, indicating that long-chain PFCAs accumulate in the brain in a lipid-related fashion, such that brain regions with high extractable lipid content (ex: pons/medulla) had the highest PFCA concentrations. This finding implies that the brain's exposure to PFCs is not consistent across all brain regions, and consequently, certain regions of the brain (ex: pons/medulla) are more at risk of PFC accumulation than others. These lipid correlations indicate that the toxicokinetics of PFCs varies across the brain as a function of lipid content. Thus, it is possible that brain 
regions with high lipid content may be more susceptible to PFSA and PFCA exposure-related toxicities.

Although PFSA and PFCA concentrations in the brain are low relative to known hepatic concentrations, the brain is sensitive to disturbances/changes in its chemical environment. Laboratory exposure studies performed on rats and mice have repeatedly shown neurotoxicity effects such as altered behaviour and altered gene expression. Consequently, animals with known high exposure to bioaccumulative PFSAs and PFCAs (such as East Greenland polar bears), are perhaps the most likely to present neurotoxicity effects.

It was hypothesized that long-chain PFCAs $\left(\mathrm{C}_{10}-\mathrm{C}_{15}\right)$ are able to cross the bloodbrain barrier (BBB) by mimicking straight-chain fatty acids of similar length. Fatty acids have been shown to cross the BBB by associating with fatty acid transport proteins and fatty acid binding proteins found at the BBB. It was reasoned that due to their similar size and shape to saturated fatty acids, PFCAs may utilize the same mechanistic modes of action to cross the BBB.

The levels and patterns observed in the brain were compared with the levels and patterns observed in the liver, whole blood, muscle, and adipose tissue (Chapter 4). The distribution profiles of PFCAs among all tissues were significantly different. Proportionally, the liver and blood contained more short-chain PFCAs, whereas the brain and adipose contained more long-chain PFCAs. Consequently, the dominant chain length PFCA varied by tissue. These differences in distribution profiles were hypothesized to be due in part to varying pharmacokinetics across the tissues. It was suggested that the distribution differences observed were due to chain length-dependent binding to proteins, and thus the localization of proteins dictated the distribution of PFCAs. For example, chylomicrons and very low density 
lipoproteins (VLDLs) transport triglycerides from the liver to adipose tissue. Due to the resemblance between triglycerides and (long-chain) PFCAs, it was hypothesized that these proteins actively transport long-chain PFCAs from the liver to adipose, thus explaining their relatively high abundance in adipose, and relatively low abundance in liver.

The tissue-specific protein localization patterns may also imply different toxicity concerns for different tissues. For example, PFOS was detected in all tissues analyzed, however it has been shown that its protein interactions vary by tissue. In the liver, PFOS exposure has lead to increased organic anion transporter protein 2 (OATP2) mRNA expression, ultimately leading to increased thyroid hormone metabolism. In the brain, PFOS exposure has lead to the increased expression of glial fibrillary acidic proteins (GFAPs) and S-100 calcium binding protein B (S-100ßs), which can lead to neuroinflammation and neuronal dysfunction.

The relationship between PFOS and PFOSA concentrations was examined for all tissues. Ratios varied between 9.2 in muscle and 36.4 in liver. It was suggested that the ratio differences between tissues could possibly be attributed to a preferential uptake of PFOS in the liver compared to the muscle. However, the main reason for the high PFOS to PFOSA ratio in the liver was attributed to liver-specific PFOSA metabolism. It has been shown that two members of the cytochrome P450 family, CYP2C9 and CYP2C19, are largely responsible for PFOSA to PFOS metabolism in liver microsomes. These proteins are primarily found in the liver, thus potentially explaining why PFOSA metabolism is highest in the liver (also explaining the high PFOS to PFOSA ratio).

The liver was determined to be by far the major repository of PFCs in polar bears, with a total tissue burden approximately 11 times higher than the next largest repository, 
whole blood. As such, the liver is the organ that provides the best estimate of the total body burden of PFCs in polar bears, and should continue to be used for future monitoring exercises.

All samples in this study were taken between January and March, at the tail-end of winter hibernation. As a result, polar bears in this study had all been fasting for many months, and questions arise as to the physiological influences of fasting and hibernation on the pharmacokinetics of PFC distribution in the body. During hibernation, a large portion of the polar bear's fat gets metabolised for energy stores. For lipophilic compounds such as PCBs that accumulate in fat, polar bear hibernation induces the release of $\mathrm{PCBs}$ into the bloodstream such that post-hibernation, PCB concentrations in the blood are higher than concentrations pre-hibernation. However, it was shown in this study that PFC accumulation in fat is minimal. In fact, it is unsure how PFC distribution in the body would change over the year due to the complex bioenergetics of the polar bear. It is possible, for instance, that liver metabolism of PFOSA to PFOS is significantly decreased in the winter hibernation months, due to overall decreased metabolism.

\subsection{Future Directions}

In this study, it was not possible to estimate a whole body burden of PFCs in the polar bear and thus it was not possible to make direct comparisons to previous wildlife studies. Licensing laws and harvesting quotas makes it difficult to obtain certain organ samples and consequently, the number of tissues used in this study was not adequate to make a whole body burden estimate. Data is missing on organs such as the heart, kidneys, spleen, thymus, thyroid, lungs, stomach, intestines, and gall bladder. Without full knowledge of PFC 
concentrations across all organs, it is possible that major PFC repositories are being overlooked, and that certain toxicity related effects are not being considered.

Very little information is available concerning how PFCs cross the blood brain barrier (BBB). By knowing how PFCs cross the BBB, we can better understand what compounds can reach the brain to cause neurotoxicity effects. The correlations of PFCA concentrations and extractable lipid content, as shown in this study, implies that perhaps PFCAs are able to cross the BBB by mimicking fatty acids. Further studies should be done on other species to confirm if these correlations are polar bear-specific, or can be generalized for other species. Additionally, a modelling study should be performed to further investigate how PFCs cross the BBB. Passive diffusion potential should be investigated, as well as interactions between PFAAs and proteins found at the BBB, including fatty acid binding proteins (FABPs), and fatty acid transport proteins (FATPs). Both FABPs and FATPs have been shown to assist long-chain saturated fatty acids actively enter the brain. Furthermore, the potential integration of PFCAs into low density lipoproteins (LDLs) should be examined, as LDLs are capable of crossing the BBB through receptor-mediated transport systems.

Although a few studies examining the interaction of PFOS with various hepatic proteins have been conducted in recent years, little information is available concerning the interaction of proteins with PFCAs and PFSAs of many different chain-lengths. Without understanding how PFCAs and PFSAs interact with proteins in the body, it is very difficult, if not impossible, to accurately determine the pharmacokinetics of these compounds in the body. In particular, studies should focus on the interaction of PFCAs $\left(\mathrm{C}_{6}-\mathrm{C}_{15}\right)$ and PFSAs $\left(\mathrm{C}_{4}-\right.$ $\mathrm{C}_{10}$ ) with lipid-binding proteins, such as serum albumin, chylomicrons, very low density 
lipoproteins, low density lipoproteins, fatty acid binding proteins, and fatty acid transport proteins.

This study examined some of the largest groups of PFCs, namely PFCAs, PFSAs, and PFOSAs. However, other PFC groups were not investigated, including perfluorinated ethylcyclohexane sulfonates (PFECHSs), perfluorinated phosphonic acids (PFPAs) and perfluorinated phosphates (PAPs). PAPs have been shown to degrade to fluorotelomer alcohols, which in turn are metabolized to PFCAs. It is thus possible that some of the PFCA concentrations observed in this study are due to the degradation of PAPs. There is very little information regarding the levels of PFECHSs, PFPAs, and PAPs in the Arctic environment, their levels in Arctic wildlife, and their bioaccumulation potential. Future studies should consider examining the concentrations of PFECHSs, PFPAs, and PAPs in Arctic wildlife, in particular species found at the top of the food web, including polar bears and glaucous gulls.

There is presently very little information available concerning PFSA and PFCA isomer distribution in wildlife. A few studies have examined either PFOS isomer distribution or PFCA isomer distribution $\left(\mathrm{C}_{8}-\mathrm{C}_{13}\right)$ in either the liver, blood, or egg samples. However, a study has yet to examine the distribution of these isomers in multiple tissues of the same species. It has been hypothesized that branched isomers may be different from linear isomers in terms of their accumulation patterns, toxicity effects, and adverse effect levels. As a result, PFSA and PFCA isomer patterns may be tissue-specific. A study is currently underway examining the PFOS isomer distribution in polar bear tissues, as alluded to in Appendix 4. Future studies should consider examining the PFSA and PFCA isomer distribution profiles among multiple tissues of monitored species to confirm tissue-specific isomer accumulation patterns. 


\section{Appendix 1}

Chromatograms of all monitored ion transitions for both HPLC-APPI-MS/MS (above), and HPLC-ESI-MS/MS (below, and continued onto following page).
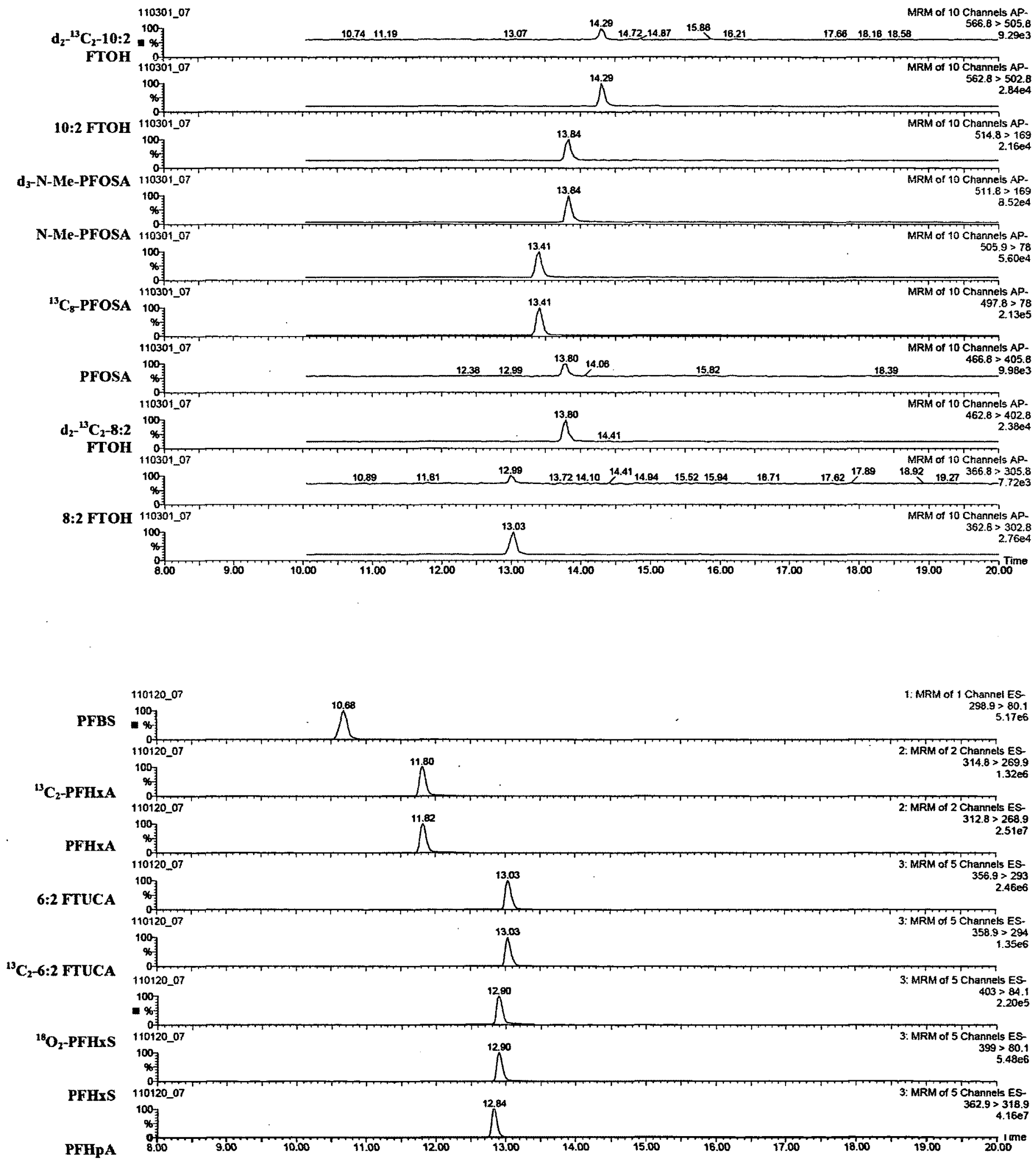


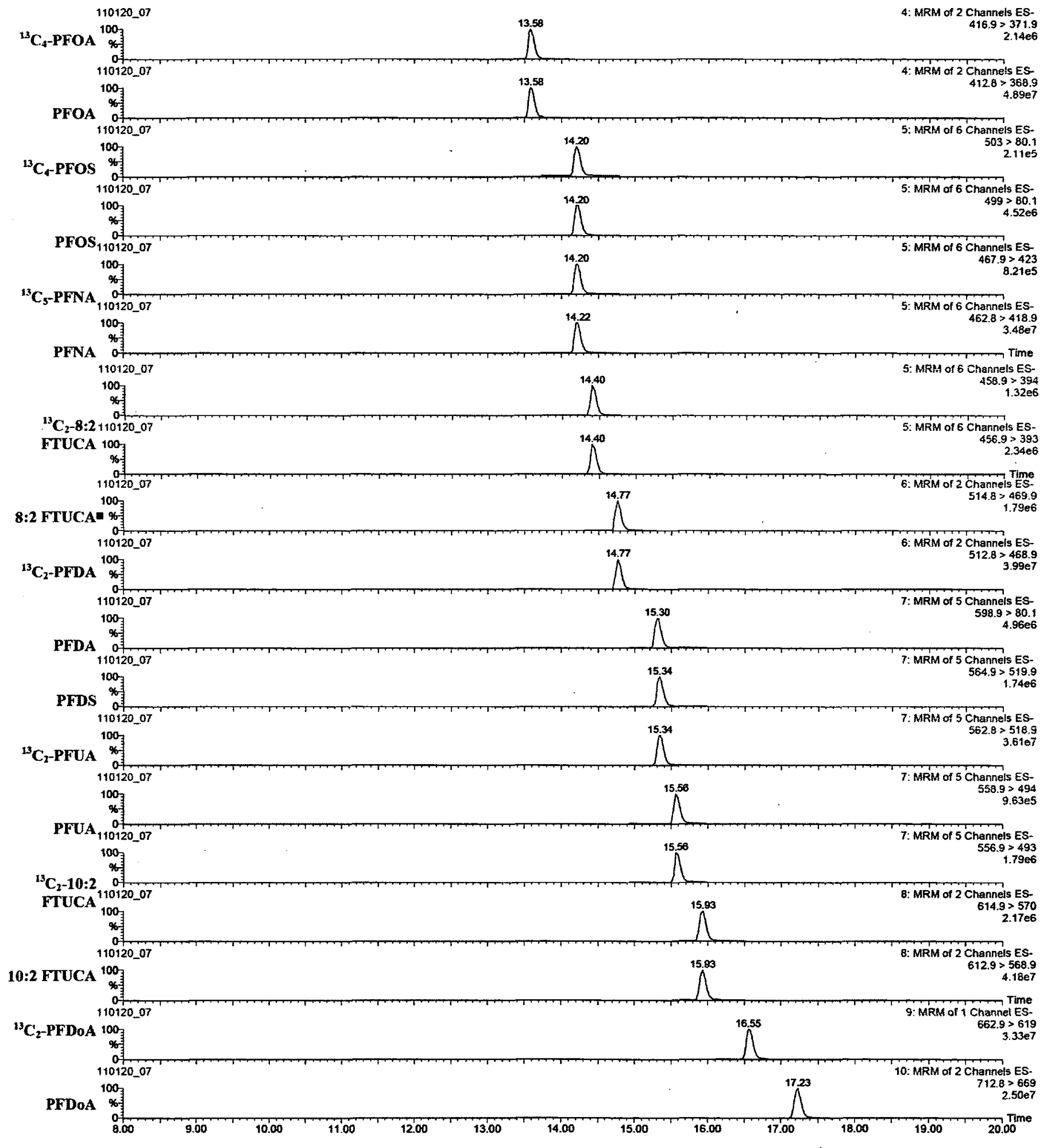




\section{Appendix 2}

Example calculation for the determination of a PFCA-normalized $\log K_{\mathrm{OW}}$ value for the liver. Each PFCA-normalized $\log K_{\text {Ow }}$ value was plotted as a function of tissue in Figure 4.6. All percentage composition concentrations are identical as those described in Figure 4.5.

\begin{tabular}{|c|c|c|}
\hline Compound & $\begin{array}{c}\text { Percentage Composition of } \\
\text { इ-PFCA Concentrations in } \\
\text { the Liver }(\%)\end{array}$ & $\begin{array}{c}\text { Experimentally } \\
\text { Determined } \\
\log K_{\text {ow }}{ }^{a} \\
\end{array}$ \\
\hline PFHxA & 1.589 & 0.54 \\
\hline PFHpA & 0.720 & 1.15 \\
\hline PFOA & 3.370 & 1.76 \\
\hline PFNA & 42.654 & 2.37 \\
\hline PFDA & 15.783 & 2.98 \\
\hline PFUA & 23.660 & 3.59 \\
\hline PFDoA & 3.560 & 4.2 \\
\hline PFTriA & 7.052 & 4.81 \\
\hline PFTeA & 1.542 & 5.42 \\
\hline PFPA & 0.070 & 6.03 \\
\hline
\end{tabular}

${ }^{a}$ Jing et al., (2009)

$$
\begin{aligned}
\log \left(K_{\text {OW }}\right)_{\text {Normalized }} & =\sum_{P F C=P F H x A}^{P F P A}(\% \text { composition })\left(\log \left(K_{\text {OW }}\right)\right)_{P F C} \\
\log \left(K_{\text {OW }}\right)_{\text {Normalized }} & =[(1.589 \%)(0.54)]+[(0.720 \%)(1.15)] \ldots+[(0.070 \%)(6.03)] \\
\log \left(K_{\text {OW }}\right)_{\text {Normalized }} & =2.98
\end{aligned}
$$




\section{Appendix 3}

Tissue mass estimates based on the brain mass that was recorded at time of dissection, and based on Equations 1 to 4 (Section 4.2.10). The brain mass for Bears 8, 9, 17, and 19 were not recorded, and as a result, their tissue masses were not estimated. Errors are standard error (SE).

\begin{tabular}{|c|c|c|c|c|c|}
\hline Bear ID & $\begin{array}{l}\text { Total Body } \\
\text { Mass (kg) }\end{array}$ & $\begin{array}{c}\text { Brain mass } \\
(\mathrm{g})\end{array}$ & $\begin{array}{l}\text { Liver mass } \\
\text { (kg) }\end{array}$ & $\begin{array}{c}\text { Adipose Mass } \\
(\mathrm{kg})\end{array}$ & $\begin{array}{c}\text { Blood Mass } \\
(\text { (kg) }\end{array}$ \\
\hline 1 & 240 & 460 & 10.22 & 59.9 & 19.5 \\
\hline 2 & 190 & 364 & 8.34 & 47.4 & 15.5 \\
\hline 3 & 246 & 473 & 10.48 & 61.6 & 20.1 \\
\hline 4 & 195 & 375 & 8.56 & 48.8 & 15.9 \\
\hline 5 & 252 & 484 & 10.69 & 63.0 & 20.5 \\
\hline 6 & 173 & 333 & 7.72 & 43.4 & 14.2 \\
\hline 7 & 245 & 470 & 10.42 & 61.2 & 19.9 \\
\hline 8 & \multirow{2}{*}{\multicolumn{5}{|c|}{ }} \\
\hline 9 & & & & & \\
\hline 10 & 233 & 448 & 9.99 & 58.3 & 19.0 \\
\hline 11 & 230 & 442 & 9.88 & 57.6 & 18.7 \\
\hline 12 & 223 & 428 & 9.60 & 55.7 & 18.2 \\
\hline 13 & 175 & 336 & 7.78 & 43.8 & 14.3 \\
\hline 14 & 145 & 279 & 6.62 & 36.3 & 11.9 \\
\hline 15 & 241 & 463 & 10.28 & 60.3 & 19.6 \\
\hline 16 & 212 & 407 & 9.19 & 53.0 & 17.3 \\
\hline 17 & - & 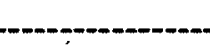 & $--N / A \cdots$ & 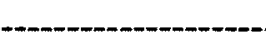 & - \\
\hline 18 & 190 & 365 & 8.36 & 47.5 & 15.5 \\
\hline 19 & $\ldots$ & 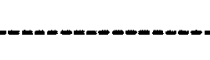 & $--N / A-$ & - & ----- \\
\hline 20 & 76 & 146 & 3.77 & 19.0 & 6.3 \\
\hline Average: & $204 \pm 12$ & $392 \pm 22$ & $8.87 \pm 0.45$ & $51.1 \pm 2.9$ & $16.7 \pm 0.9$ \\
\hline
\end{tabular}




\section{Appendix 4}

PFOS isomer compositions of all tissues analyzed. Isomer compositions are provided on a percentage of $\Sigma$-PFOS basis ( $\% \pm \mathrm{SE}$ ). All isomers were considered not detected (n.d.) if less than $50 \%$ of samples were below the method limit of quantification (MLOQ).

\begin{tabular}{|c|c|c|c|c|c|c|}
\hline & & $\begin{array}{l}\text { Liver } \\
\mathrm{n}=19\end{array}$ & $\begin{array}{l}\text { Blood } \\
\mathrm{n}=19\end{array}$ & $\begin{array}{l}\text { Brain } \\
n=16\end{array}$ & $\begin{array}{c}\text { Muscle } \\
\mathrm{n}=5\end{array}$ & $\begin{array}{c}\text { Adipose } \\
\mathrm{n}=5\end{array}$ \\
\hline n-PFOS & Mean $(\% \pm S E)$ & $92.93 \pm 0.35$ & $85.73 \pm 0.60$ & $97.20 \pm 1.46$ & 100 & $96.91 \pm 3.38$ \\
\hline Linear PFOS & $\begin{array}{c}\text { Range } \\
\%>\text { MLOO }\end{array}$ & $\begin{array}{c}90.61-95.51 \\
100\end{array}$ & $\begin{array}{c}80.88-89.78 \\
100\end{array}$ & $\begin{array}{c}81.99-100 \\
100\end{array}$ & $\begin{array}{l}100 \\
100\end{array}$ & $\begin{array}{c}83.06-100 \\
100\end{array}$ \\
\hline P1MHpS & Mean $(\% \pm S E)$ & $1.18 \pm 0.19$ & $1.78 \pm 0.32$ & n.d. & n.d. & n.d. \\
\hline $\begin{array}{c}\text { Perfluoro-1- } \\
\text { methyl- } \\
\text { heptanesulfonate }\end{array}$ & $\begin{array}{c}\text { Range } \\
\%>\text { MLOQ }\end{array}$ & $\begin{array}{c}\text { n.d. }-2.58 \\
84\end{array}$ & $\begin{array}{c}0.59 \pm 5.53 \\
100\end{array}$ & $\begin{array}{c}\text { n.d. } \\
0\end{array}$ & $\begin{array}{c}\text { n.d. } \\
0\end{array}$ & $\begin{array}{c}\text { n.d. } \\
0\end{array}$ \\
\hline P2MHpS & Mean $(\% \pm S E)$ & $0.58 \pm 0.08$ & $0.33 \pm 0.03$ & n.d. & n.d. & n.d. \\
\hline $\begin{array}{c}\text { Perfluoro-2- } \\
\text { methyl- } \\
\text { heptanesulfonate }\end{array}$ & $\begin{array}{c}\text { Range } \\
\%>\mathrm{MLOQ}\end{array}$ & $\begin{array}{c}0.21-1.45 \\
100\end{array}$ & $\begin{array}{c}\text { n.d. }-0.57 \\
95\end{array}$ & $\begin{array}{c}\text { n.d. } \\
0\end{array}$ & $\begin{array}{c}\text { n.d. } \\
0\end{array}$ & $\begin{array}{c}\text { n.d. }-16.93 \\
20\end{array}$ \\
\hline $\begin{array}{l}\text { P3MHpS } \\
\text { Perfluoro-3- } \\
\text { methyl- } \\
\text { heptanesulfonate }\end{array}$ & $\begin{array}{c}\text { Mean }(\% \pm S E) \\
\text { Range } \\
\%>\text { MLOQ }\end{array}$ & $\begin{array}{c}1.08 \pm 0.10 \\
\text { n.d. }-1.61 \\
95\end{array}$ & $\begin{array}{c}1.09 \pm 0.08 \\
0.65-1.85 \\
100\end{array}$ & $\begin{array}{c}\text { n.d. } \\
\text { n.d. }-12.69 \\
31\end{array}$ & $\begin{array}{c}\text { n.d. } \\
\text { n.d. } \\
0\end{array}$ & $\begin{array}{c}\text { n.d. } \\
\text { n.d. } \\
0\end{array}$ \\
\hline $\begin{array}{l}\text { P4MHpS } \\
\text { Perfluoro-4 } \\
\text { methyl- } \\
\text { heptanesulfonate }\end{array}$ & $\begin{array}{c}\text { Mean }(\% \pm \mathrm{SE}) \\
\text { Range } \\
\%>\text { MLOQ }\end{array}$ & $\begin{array}{c}0.38 \pm 0.04 \\
\text { n.d. }-0.68 \\
89\end{array}$ & $\begin{array}{c}2.41 \pm 0.13 \\
1.70 \pm 3.31 \\
100\end{array}$ & $\begin{array}{c}\text { n.d. } \\
\text { n.d. }-5.32 \\
31\end{array}$ & $\begin{array}{c}\text { n.d. } \\
\text { n.d. } \\
0\end{array}$ & $\begin{array}{c}\text { n.d. } \\
\text { n.d. } \\
0\end{array}$ \\
\hline $\begin{array}{l}\text { P5MHpS } \\
\text { Perfluoro-5- } \\
\text { methyl- } \\
\text { heptanesulfonate }\end{array}$ & $\begin{array}{c}\text { Mean }(\% \pm \mathrm{SE}) \\
\text { Range } \\
\%>\text { MLOQ }\end{array}$ & $\begin{array}{c}1.26 \pm 0.06 \\
0.79-1.62 \\
100\end{array}$ & $\begin{array}{c}5.32 \pm 0.38 \\
2.98-7.67 \\
100\end{array}$ & $\begin{array}{c}\text { n.d. } \\
\text { n.d. } \\
0\end{array}$ & $\begin{array}{c}\text { n.d. } \\
\text { n.d. } \\
0\end{array}$ & $\begin{array}{c}\text { n.d. } \\
\text { n.d. } \\
0\end{array}$ \\
\hline $\begin{array}{c}\text { P6MHpS } \\
\text { Perfluoro-6- } \\
\text { methyl- } \\
\text { heptanesulfonate }\end{array}$ & $\begin{array}{c}\text { Mean }(\% \pm \mathrm{SE}) \\
\text { Range } \\
\%>\text { MLOQ }\end{array}$ & $\begin{array}{c}2.57 \pm 0.07 \\
2.15-3.12 \\
100\end{array}$ & $\begin{array}{c}3.33 \pm 0.14 \\
2.31-4.06 \\
100\end{array}$ & $\begin{array}{c}\text { n.d. } \\
\text { n.d. } \\
0\end{array}$ & $\begin{array}{c}\text { n.d. } \\
\text { n.d. } \\
0\end{array}$ & $\begin{array}{c}\text { n.d. } \\
\text { n.d. } \\
0\end{array}$ \\
\hline $\begin{array}{c}\text { P35DMHXS } \\
\text { Perfluoro-3,5- } \\
\text { dimethyl- } \\
\text { hexanesulfonate }\end{array}$ & $\begin{array}{c}\text { Mean }(\% \pm S E) \\
\quad \text { Range } \\
\%>\text { MLOQ }\end{array}$ & $\begin{array}{c}\text { n.d. } \\
\text { n.d. } \\
0\end{array}$ & $\begin{array}{c}\text { n.d. } \\
\text { n.d. } \\
0\end{array}$ & $\begin{array}{c}\text { n.d. } \\
\text { n.d. } \\
0\end{array}$ & $\begin{array}{c}\text { n.d. } \\
\text { n.d. } \\
0\end{array}$ & $\begin{array}{c}\text { n.d. } \\
\text { n.d. } \\
0\end{array}$ \\
\hline $\begin{array}{c}\text { P44DMHXS } \\
\text { Perfluoro-4,4- } \\
\text { dimethyl- } \\
\text { hexanesulfonate }\end{array}$ & $\begin{array}{c}\text { Mean }(\% \pm S E) \\
\text { Range } \\
\%>\text { MLOQ }\end{array}$ & $\begin{array}{c}\text { n.d. } \\
\text { n.d. }-0.12 \\
11\end{array}$ & $\begin{array}{c}\text { n.d. } \\
\text { n.d. } \\
0\end{array}$ & $\begin{array}{c}\text { n.d. } \\
\text { n.d. } \\
0\end{array}$ & $\begin{array}{c}\text { n.d. } \\
\text { n.d. } \\
0\end{array}$ & $\begin{array}{c}\text { n.d. } \\
\text { n.d. } \\
0\end{array}$ \\
\hline $\begin{array}{c}\text { P45DMHXS } \\
\text { Perfluoro-4,5- } \\
\text { dimethyl- } \\
\text { hexanesulfonate }\end{array}$ & $\begin{array}{c}\text { Mean }(\% \pm S E): \\
\text { Range } \\
\%>\text { MLOQ }\end{array}$ & $\begin{array}{c}\text { n.d. } \\
\text { n.d. } \\
0\end{array}$ & $\begin{array}{c}\text { n.d. } \\
\text { n.d. } \\
0\end{array}$ & $\begin{array}{c}\text { n.d. } \\
\text { n.d. } \\
0\end{array}$ & $\begin{array}{c}\text { n.d. } \\
\text { n.d. } \\
0\end{array}$ & $\begin{array}{c}\text { n.d. } \\
\text { n.d. } \\
0\end{array}$ \\
\hline $\begin{array}{c}\text { P55DMHXS } \\
\text { Perfluoro-5,5- } \\
\text { dimethyl- } \\
\text { hexanesulfonate }\end{array}$ & $\begin{array}{c}\text { Mean }(\% \pm S E) \\
\text { Range } \\
\%>\text { MLOQ }\end{array}$ & $\begin{array}{c}\text { n.d. } \\
\text { n.d. } \\
0\end{array}$ & $\begin{array}{c}\text { n.d. } \\
\text { n.d } \\
0\end{array}$ & $\begin{array}{c}\text { n.d. } \\
\text { n.d. } \\
0\end{array}$ & $\begin{array}{c}\text { n.d. } \\
\text { n.d. } \\
0\end{array}$ & $\begin{array}{c}\text { n.d. } \\
\text { n.d. } \\
0\end{array}$ \\
\hline
\end{tabular}




\section{Appendix 4 (continued)}

PFOS isomer compositions of liver and blood samples analyzed. Isomer compositions are provided on a percentage of $\Sigma$-PFOS basis.

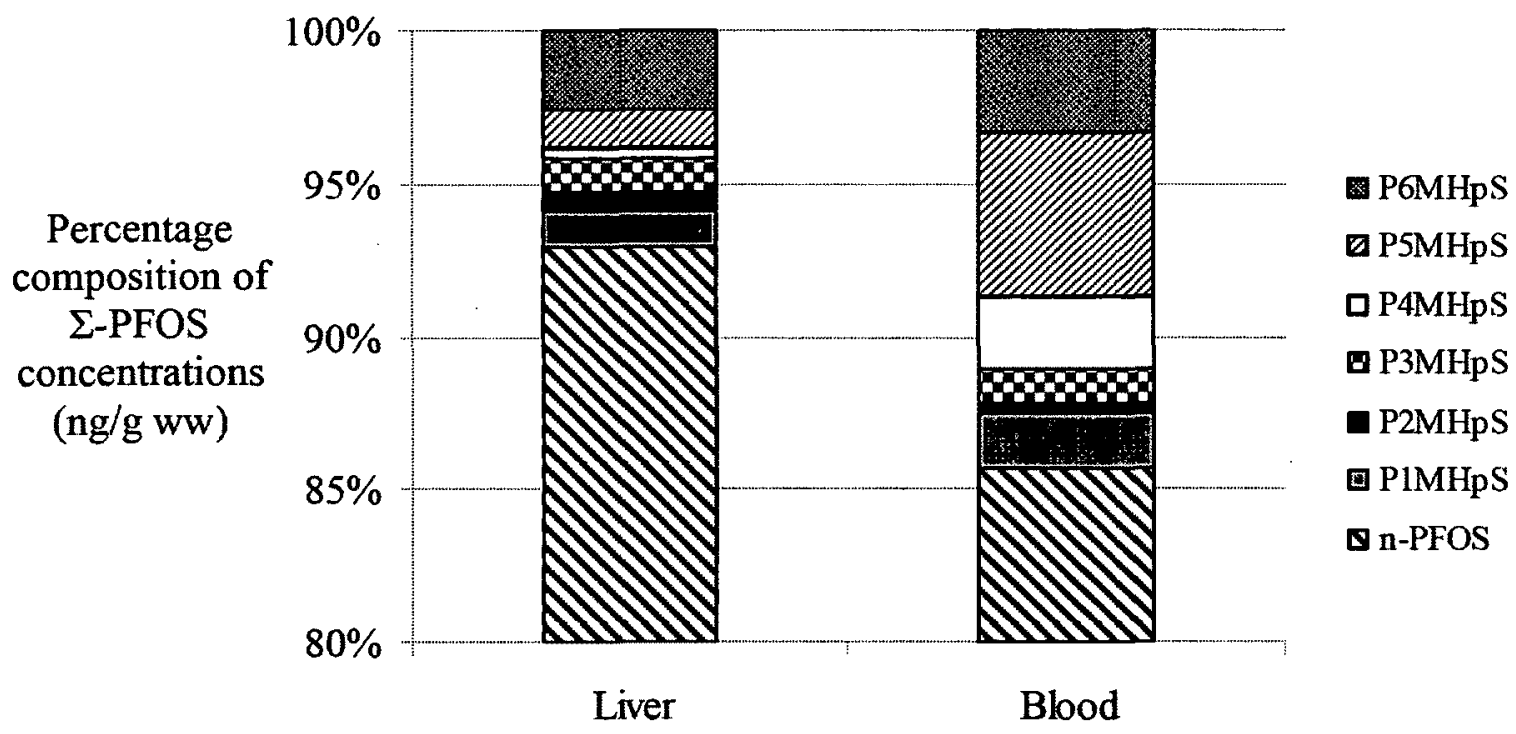

